\title{
Melatonin for sleep problems in individuals with intellectual disabilities: a study into its effectiveness and clinical aspects
}

Citation for published version (APA):

Braam, W. J. (2010). Melatonin for sleep problems in individuals with intellectual disabilities: a study into its effectiveness and clinical aspects. [Doctoral Thesis, Maastricht University]. Uitgeverij Kosmos. https://doi.org/10.26481/dis.20100929wb

Document status and date:

Published: 01/01/2010

DOI:

10.26481/dis.20100929wb

Document Version:

Publisher's PDF, also known as Version of record

Please check the document version of this publication:

- A submitted manuscript is the version of the article upon submission and before peer-review. There can be important differences between the submitted version and the official published version of record.

People interested in the research are advised to contact the author for the final version of the publication, or visit the DOI to the publisher's website.

- The final author version and the galley proof are versions of the publication after peer review.

- The final published version features the final layout of the paper including the volume, issue and page numbers.

Link to publication

\footnotetext{
General rights rights.

- You may freely distribute the URL identifying the publication in the public portal. please follow below link for the End User Agreement:

www.umlib.nl/taverne-license

Take down policy

If you believe that this document breaches copyright please contact us at:

repository@maastrichtuniversity.nl

providing details and we will investigate your claim.
}

Copyright and moral rights for the publications made accessible in the public portal are retained by the authors and/or other copyright owners and it is a condition of accessing publications that users recognise and abide by the legal requirements associated with these

- Users may download and print one copy of any publication from the public portal for the purpose of private study or research.

- You may not further distribute the material or use it for any profit-making activity or commercial gain

If the publication is distributed under the terms of Article $25 \mathrm{fa}$ of the Dutch Copyright Act, indicated by the "Taverne" license above, 


\section{Melatonin for sleep problems in individuals with intellectual disabilities:}

a study into its effectiveness and clinical aspects 
ISBN

Layout Gert Jan Bosgra, Nijmegen

Printed by Uitgeverij Kosmos, Utrecht

copyright W. Braam (2010) 


\title{
Melatonin for sleep problems in individuals with intellectual disabilities: a study into its effectiveness and clinical aspects
}

\author{
Proefschrift
}

ter verkrijging van de graad van doctor aan de Universiteit Maastricht, op gezag van de Rector Magnificus, Prof. mr. G.P.M.F. Mols, volgens het besluit van het College van Decanen, in het openbaar te verdedigen, op woensdag 29 september 2010 om 16.00 uur

door

Wiebe Jan Braam 
Promotor:

Prof. dr. L.M.G. Curfs

\section{Copromotores:}

Dr. M.G. Smits (Hospital Gelderse Vallei, Ede)

Prof. dr. R. Didden (Radboud University Nijmegen)

Assessment Committee:

Prof. dr. J.J. van Os (chair)

Prof. dr. J.P.M. Geraedts

Prof. dr. M.P.F. Berger

Prof. dr. G.A. Kerkhof (Amsterdam University)

Prof. dr. H.M.J. Van Schrojenstein Lantman - De Valk (Radboud University Nijmegen)

Studies described in this study are supported by a research grant by 's Heeren Loo Zorggroep Steunfonds (Amersfoort) and Governor Kremers Center (Maastricht). 


\section{CONTENTS}

$\begin{array}{lll}\text { Chapter } 1 \text { Introduction } & 7\end{array}$

$\begin{array}{lll}\text { Chapter } 2 \text { Exogenous melatonin for sleep problems in } & 19\end{array}$ individuals with intellectual disability: a meta-analysis

Chapter 3 Melatonin treatment in individuals with intellectual disability and chronic insomnia: a randomized placebo-controlled study

Chapter 4 Melatonin for chronic insomnia in Angelman syndrome: a randomized placebo-controlled trial

Chapter 5 Melatonin decreases daytime challenging behaviour in persons with intellectual disability and chronic insomnia

Chapter 6 Loss of response to melatonin treatment is associated with slow melatonin metabolism

Chapter 7 Discussion

Summary

Samenvatting

Dankwoord

Curriculum vitae

Publications 

CHAPTER 1

INTRODUCTION 
CHAPTER 1 


\section{INTRODUCTION}

Intellectual disability is characterized by a total IQ below 70, significant impairments in cognitive and adaptive skills, and onset before 18 years of age (DSM-IV 1999). Intellectual disability is not one specific condition with one specific etiology, but an umbrella diagnosis for over thousand disorders and diseases. Many of these specific disorders or diseases have a specific phenotype, both physical and behavioural. Although individuals with intellectual disability can have the same illnesses as typically developing individuals, several health problems, such as sleep problems, are more prevalent in individuals with intellectual disability than in their peers.

We established an outpatient clinic for the treatment of sleep problems in individuals with intellectual disability, not only because of the treatment of severe sleep problems in the individuals involved, but also to enhance the empirical knowledge regarding the assessment and treatment of sleep problems in this target group. This thesis reflects our clinical and scientific endeavors in this area.

\section{SLEEP PROBLEMS IN INDIVIDUALS WITH INTELLECTUAL DISABILITIES}

Sleep problems are a common complaint in primary care, with prevalence rates ranging from 10\% to 40\% (Simon \& VonKorff 1997; Sateia et al. 2000) in adults and from $30 \%$ to $41 \%$ in children (Lipton et al. 2008). Prevalence rates for individuals with intellectual disability range from $13 \%$ to $88 \%$, depending on study design, participant characteristics and definition of sleep problems. In some syndromes, such as Angelman syndrome, fragile X syndrome, Rett syndrome, Smith Magenis syndrome and tuberous sclerosis, the prevalence rate of sleep problems is exceptionally high (O'Callaghan et al. 1999; Edelman et al. 2007; Young et al. 2007; Pelc et al. 2008; Kronk et al. 2009).

The most common types of sleep problems in individuals with intellectual disability are problems with falling asleep and sleep maintenance (Bartlett $e t$ al. 1985; Quine 1991). Sleep problems, especially insomnia, can have a serious negative influence on daytime functioning of the person with intellectual disability. It can cause somnolence, lethargy, and diminished functioning, as well as irritability, hyperactivity and behavioural problems (Quine 1991; Wiggs \& Stores 1996; Chadwick et al. 2000; Didden et al. 2002). Sleep problems also have adverse consequences for the well-being of the individual's caregivers (see e.g. Didden et al. 2002).

\section{TREATMENT OF SLEEP PROBLEMS}

Treatment of sleep problems in individuals with intellectual disability may take the form of at least three strategies, namely a bedtime routine (good sleep hygiene), 
behavioural strategies, and pharmacological strategies (Lancioni et al. 1999). Professionals should however be careful about prescribing drugs to individuals with intellectual disability, because they often take other medications and the risk of drug interactions is then increased. This interaction may result in daytime sedation, increased risk of sleep related breathing disorder and behavioural problems (Dodge \& Wilson 2001; Doran et al. 2006). In some cases, hypnotics even can lead to paradoxical reactions such as hyperactivity and agitation (Kalachnik et al. 2002). Therefore, effective sleep medication that does not have these adverse side-effects is needed.

\section{MELATONIN}

A number of study trials indicate that melatonin is effective in the treatment of insomnia (McArthur \& Budden 1998; O’Callaghan et al. 1999; Hätönen et al. 1999; Dodge \& Wilson 2001; Niederhofer et al. 2003; Coppola et al. 2004; Garstang \& Wallis 2006; Laakso et al. 2007; Wasdell et al. 2008). Several reviews of these trials emphasized the benefits of melatonin in the treatment of sleep problems in individuals with intellectual disability (Turk 2003; Jan \& Freeman 2004; Phillips \& Appleton 2004; Wassmer \& Whitehouse 2006; Sajith \& Clarke 2007). Despite positive results reported in these studies in individuals with intellectual disability, there still is debate about the efficacy of melatonin in general, given the mixed outcomes of a recent publication of two meta-analyses that included studies performed in individuals without intellectual disability (Brzezinski et al. 2005; Buscemi et al. 2005) and one meta-analysis (Buscemi et al. 2006) in which 6 out of 11 studies were performed in individuals with intellectual disability.

There are several anecdotal reports suggesting that in persons with intellectual disability melatonin treatment may also reduce daytime behavioural problems (Jan et al. 1994; Jan 2000; Ivanenko et al. 2003; Jan \& Freeman 2004; Coppola et al. 2004; Carr et al. 2007).

Melatonin causes few side-effects and it is considered safe on long term in the treatment of chronic insomnia in individuals with intellectual disability (Jan 2000; Ivanenko 2003; Buscemi et al. 2006; Carr et al. 2007). However, there are several case reports suggesting that in a number of individuals melatonin may lose its effectiveness during long term use (McArthur \& Budden 1998; Ishizaki et al.1999; Jan et al. 2000; Andersen et al. 2008). Tolerance to melatonin was suggested as a probable cause of the disappearing effectiveness of exogenous melatonin (Jan et al. 2000).

\section{RESEARCH QUESTIONS AND THESIS OUTLINE}

In this thesis, results are presented of studies on (a) efficacy of melatonin in the treatment of sleep problems in individuals with intellectual disability, 
(b) its effects on daytime challenging behaviours, and (c) a possible cause of disappearing effectiveness of melatonin. These studies aim to provide an answer to the following five main research questions. These are:

1. Is melatonin effective in the treatment of chronic insomnia in persons with intellectual disabilities?

2. Does melatonin reduce sleep problems in persons with intellectual disability?

3. Does melatonin reduce sleep problems in persons with Angelman syndrome?

4. Does melatonin reduce co-existing daytime challenging behaviour?

5. What may be the cause of the loss of response to melatonin in patients after an initial successful treatment?

\section{EXOGENOUS MELATONIN FOR SLEEP PROBLEMS IN INDIVIDUALS WITH INTELLECTUAL DISABILITY: A META-ANALYSIS}

While a number of trials indicate that melatonin is effective in the treatment of insomnia in individuals with intellectual disability (McArthur \& Budden 1998; O'Callaghan et al. 1999; Hätönen et al. 1999; Dodge \& Wilson 2001; Niederhofer et al. 2003; Coppola et al. 2004; Garstang \& Wallis 2006; Laakso et al. 2007; Wasdell et al. 2008), three meta-analyses on melatonin (Brzezinski et al. 2005; Buscemi et al. 2005; Buscemi et al. 2006) in predominantly non-disabled individuals raised doubts on the efficacy of melatonin. At the time of this study, it was unclear whether melatonin was or was not effective for reducing sleep problems in individuals with intellectual disability. Therefore, we investigated the efficacy of melatonin in the management of sleep problems in persons with intellectual disability by performing a meta-analysis of placebo controlled randomized trials with melatonin. Results of this study are presented in chapter 2 of this thesis.

\section{MELATONIN TREATMENT IN INDIVIDUALS WITH INTELLECTUAL DISABILITY AND CHRONIC INSOMNIA: A RANDOMIZED PLACEBO-CONTROLLED STUDY}

Until recently, only few randomized trials with melatonin in persons with intellectual disability have been conducted (Camfield et al. 1996; McArthur \& Budden, 1998; O'Callaghan et al. 1999; Dodge \& Wilson 2001; Niederhofer 2003; Coppola et al. 2004; Garstang \& Wallis, 2006; Laakso et al. 2007; Wasdell et al. 2008). Conclusions drawn in these studies were based on small sample sizes, Dim Light Melatonin Onset (DLMO) was not measured, and the influence of 
exogenous melatonin on the endogenous melatonin rhythm was not studied. Therefore, we conducted a randomized double-blind placebo-controlled trial in a relatively large sample of individuals with intellectual disability $(n=51)$ to investigate the effectiveness of exogenous melatonin in persons with intellectual disability who had chronic insomnia. Next to this, we measured DLMO and assessed the influence of exogenous melatonin on the endogenous melatonin rhythm. The results of this study are presented in chapter 3 of the thesis.

In our three studies, we used a parallel study design, because a cross-over design with intra-individual comparison of melatonin and placebo is inappropriate when evaluating the efficacy of melatonin (see chapter 7). Exogenous melatonin can cause a phase shift advance of the endogenous melatonin rhythm and this effect can last for several days or weeks after treatment has stopped. Therefore, participants who receive melatonin in the first phase of the study may experience a carry-over effect of the melatonin phase into the placebo phase (Kunz et al. 2004; Laakso et al. 2007). By consequence, carry-over effects can result in a smaller difference in outcome between the melatonin and placebo phase of the study, and therefore carry-over effects may be responsible for not finding a significant difference in the dependent variable(s) between melatonin and placebo.

\section{MELATONIN FOR CHRONIC INSOMNIA IN ANGELMAN SYNDROME: A RANDOMIZED PLACEBO-CONTROLLED TRIAL}

Prevalence of sleep problems in Angelman syndrome have been reported up to 90\% (Clayton Smith et al. 1993; Bruni et al. 2004; Didden et al. 2004). Because of this high prevalence, sleep problems are listed as 'associated features' in the clinical diagnostic criteria for Angelman syndrome (Williams et al. 2006).

Sleep problems in children with Angelman syndrome consist of problems with settling, falling asleep, frequent night wakings and difficulty to fall asleep after waking. In many cases, these sleep problems appear resistant to behavioural therapy as well as conventional sleep medication.

A striking finding was reported by Zhdanova et al. (1999) who studied sleep problems in an open-label study in 13 children with Angelman syndrome and chronic insomnia, and who found very low melatonin levels at baseline. A relatively low dose of melatonin (i.e. $0.3 \mathrm{mg}$ ) significantly decreased sleep latency and increased total sleep time in these children. The most important shortcoming of this study was that it lacked a placebo controlled double blind design. Therefore, we examined the efficacy of melatonin on chronic sleep problems in 8 individuals with Angelman syndrome and data were collected within a randomized double-blind placebo-controlled trial. The results of this study are reported in chapter 4 . 


\section{MELATONIN DECREASES DAYTIME CHALLENGING BEHAVIOUR IN PERSONS WITH INTELLECTUAL DISABILITY AND CHRONIC INSOMNIA}

Persons with intellectual disability and sleep problems exhibit more daytime challenging behaviours, irritability and lethargy than persons with intellectual disability who do not have sleep problems (Wiggs \& Stores, 1996; Chadwick et al. 2000; Didden et al. 2002). There are several anecdotal reports suggesting that in persons with intellectual disability and sleep problems, melatonin is not only an effective treatment for sleep problems, it also is associated with a reduction in daytime behavioural problems (Jan et al. 1994; Jan 2000; Ivanenko et al. 2003; Jan \& Freeman, 2004; Coppola et al. 2004; Carr et al. 2007). In these studies, no correlations between a reduction of sleep problems and behavioural problems were given. Furthermore, no attempt was made to explain the reduction in daytime challenging behaviour, or the reduction in challenging behaviour was attributed to the improvement of sleep itself, without further specification.

To investigate the relationship between the effectiveness of melatonin on sleep problems and concordant change in daytime challenging behaviours, we investigated the effects of melatonin on daytime challenging behaviour in a randomized placebo-controlled trial. In this trial, we explored whether there were significant associations between daytime challenging behaviour, chronic insomnia and melatonin circadian rhythm. Results of this study are presented in chapter 5 .

\section{LOSS OF RESPONSE TO MELATONIN TREATMENT IS ASSOCIATED WITH SLOW MELATONIN METABOLISM}

In our study in children with Angelman syndrome, some parents reported the return of night waking after 4 weeks of treatment (see chapter 4). In these patients, salivary melatonin levels after 4 weeks of treatment were extremely high $(>50 \mathrm{pg} / \mathrm{ml})$, when they had been very low at baseline. In these patients sleep improved again substantially after the melatonin dose was lowered to 0.1 mg. We postulated that these patients, although showing the clinical picture of melatonin tolerance, in fact were CYP1A2 poor metabolizers.

Surprisingly, in the medical scientific literature no attention so far has been paid to the phenomenon of the loss of response to melatonin. Only a small number of case reports suggest that melatonin can lose its effectiveness during long term use (McArthur \& Budden1998; Ishizaki et al.1999; Jan et al. 2000; Andersen et al. 2008). In these studies, possible causes of the loss of response to melatonin were not explored. Tolerance to melatonin was suggested as a probable cause (Jan et al. 2000). 
We performed a pilot study on melatonin metabolism in patients in whom the initial effectiveness of melatonin disappeared, in order to test our hypothesis that loss of response to exogenous melatonin is due to 24 hour high melatonin levels, which is caused by slow melatonin metabolism. Results of this study are presented in the $6^{\text {th }}$ chapter of this thesis.

In the $7^{\text {th }}$ chapter of this thesis implications of the results are discussed. A summary completes this thesis.

\section{REFERENCES}

American Psychiatric Association. (1994) Diagnostic and Statistical Manual of Mental Disorders, 4th edn. Washington: DC. American Psychiatric Association.

Andersen I.M., Kaczmarska J., McGrew S.G., \& Malow B.A. (2008) Melatonin for insomnia in children with autism spectrum disorders. Journal of Child Neurology 23, 482-5.

Bartlett L.B., Rooney V., \& Spedding S. (1985). Nocturnal difficulties in a population of mentally handicapped children. British Journal of Mental Subnormality 31, 54-9.

Bruni O., Ferri R., D’Agostino G., Miano S., Roccella M., \& Elia M. (2004) Sleep disturbances in Angelman syndrome: a questionnaire study. Brain Q Development 26, 233-40.

Brzezinski A., Vangel M.G., Wurtman R.J., Norrie G., Zhdanova I., Ben-Shushan A., \& Ford I. (2005) Effects of exogenous melatonin on sleep: a meta-analysis. Sleep Medicine Reviews 9, 41-50.

Buscemi N., Vandermeer B., Hooton N., Pandya R., Tjosvold L., Hartling L., Baker G., Klassen T.P., \& Vohra S. (2005) The efficacy and safety of exogenous melatonin for primary sleep disorders. A meta-analysis. Journal of General Internal Medicine 20, 1151-8.

Buscemi N., Vandermeer B., Hooton N., Pandya R., Tjosvold L., Hartling L., Vohra S., Klassen T.P., \& Baker G. (2006) Efficacy and safety of exogenous melatonin for secondary sleep disorders and sleep disorders accompanying sleep restriction: meta-analysis. British Medical Journal 332, 385-93.

Camfield P., Gordon K., Dooley J., \& Camfield C. (1996) Melatonin appears ineffective in children with intellectual deficits and fragmented sleep: six ' $\mathrm{N}$ of 1 ' trials. Journal of Child Neurology 11, 341-3.

Carr R., Wasdell M.B., Hamilton D., Weiss M.D., Freeman R.D., Tai J., Rietveld W., \& Jan J.E. (2007) Long-term effectiveness of melatonin therapy in children with treatment-resistant circadian rhythm sleep disorders. Journal of Pineal 
Research 43, 351-9.

Chadwick O., Piroth N., Walker J., Bernard S., \& Taylor E. (2000) Factors affecting the risk of behaviour problems in children with severe intellectual disability. Journal of Intellectual Disability Research 44, 108-23.

Clayton-Smith J. (1993) Clinical research on Angelman syndrome in the United Kingdom: observations on 82 affected individuals. American Journal of Medical Genetics 46, 12-5.

Coppola G., Iervolino G., Mastrosimone M., La Torre G., Ruiu F., \& Pascotto A. (2004) Melatonin in wake-sleep disorders in children, adolescents and young adults with mental retardation with or without epilepsy: a double-blind, crossover, placebo-controlled trial. Brain \& Development 26, 373-6.

Didden R., Korzilius H., Van Aperlo B., Van Overloop C., \& De Vries M. (2002) Sleep problems and daytime problem behaviours in children with intellectual disability. Journal of Intellectual Disability Research 46, 537-47.

Didden R., Korzilius H., Smits M.G., \& Curfs L. M. G. (2004) Sleep problems in individuals with Angelman syndrome. American Journal of Mental Retardation 109, 275-84.

Dodge N. N., \& Wilson G. A. (2001) Melatonin for treatment of sleep disorders in children with developmental disabilities. Journal of Child Neurology 16, 581-4.

Doran S., Harvey M., \& Horner R. (2006) Sleep and developmental disabilities: assessment, treatment, and outcome measures. Mental Retardation 44, 13-27.

Edelman E. A., Girirajan S., Finucane B., Patel P. I., Lupski J. R., Smith A. C., \& Elsea S. H. (2007) Gender, genotype, and phenotype differences in SmithMagenis syndrome: a meta-analysis of 105 cases. Clinical Genetics 71, 540-50.

Garstang J., \& Wallis M. (2006) Randomized controlled trial of melatonin for children with autistic spectrum disorders and sleep problems. Child: Care, Health and Development 32, 585-9.

Hätönen T., Kirveskari E., Heiskala H., Sainio K., Laakso M. L., \& Santavuori P. (1999) Melatonin ineffective in neuronal ceroid lipofuscinosis patients with fragmented or normal motor activity rhythms recorded by wrist actigraphy. Molecular Genetics and Metabolism 66, 401-6.

Ishizaki A., Sugama M., \& Takeuchi N. (1999) [Usefulness of melatonin for developmental sleep and emotional/behavior disorders. Studies of melatonin trial on 50 patients with developmental disorders] [Article in Japanese] No To Hattatsu 31, 428-37.

Ivanenko A., McLaughlin Crabtree V., Tauman R., \& Gozal D. (2003) Melatonin in children and adolescents with insomnia: a retrospective study. Clinical Pediatrics 42, 51-8.

Jan M. M. S. (2000) Melatonin for the treatment of handicapped children with severe sleep disorders. Pediatric Neurology 23, 229-32. 
Jan J. E., Espezel H., \& Appleton R. E. (1994) The treatment of sleep disorders with melatonin. Developmental Medicine \& Child Neurology 36, 97-107.

Jan J. E., Hamilton D., Seward N., Fast D. K., Freeman R. D., \& Laudon M. (2000) Clinical trials of controlled-release melatonin in children with sleep-wake cycle disorders. Journal of Pineal Research 29, 34-9.

Jan J.E., \& Freeman R.D. (2004) Melatonin therapy for circadian rhythm sleep disorders in children with multiple disabilities: what have we learned in the last decade? Developmental Medicine a Child Neurology 46, 776-82.

Kalachnik J. E., Hanzel T. E., Sevenich R., \& Harder S. R. (2002) Benzodiazepine behavioral side effects: review and implications for individuals with mental retardation. American Journal of Mental Retardation 107, 376-410.

Kronk R., Dahl R., \& Noll R. (2009) Caregiver reports of sleep problems on a convenience sample of children with Fragile X syndrome. American Journal on Intellectual and Developmental Disabilities 114, 383-92.

Kunz D., Mahlberg R., Müller C., Tilmann A., \& Bes F. (2004) Melatonin in patients with reduced REM sleep duration: two randomized trials. The Journal of Clinical Endocrinology \& Metabolism 89, 128-34.

Laakso M. L., Lindblom N., Leinonen L., \& Kaski M. (2007) Endogenous melatonin predicts efficacy of exogenous melatonin in consolidation of fragmented wristactivity rhythm of adult patients with developmental brain disorders: a doubleblind, placebo-controlled, crossover study. Sleep Medicine 8, 222-39.

Lancioni G. E., O’Reilly M. F., \& Basili G. (1999) Review of strategies for treating sleep problems in persons with severe or profound mental retardation or multiple handicaps. American Journal of Mental Retardation 104, 170-86.

Lipton J., Becker R. E., \& Kothare S. V. (2008) Insomnia in childhood. Current Opinion in Pediatrics 20, 641-9.

McArthur A. J., \& Budden S. S. (1998) Sleep dysfunction in Rett syndrome: a trial of exogenous melatonin treatment. Developmental medicine and child neurology 40, 186-92.

Niederhofer H., Staffen W., Mair A., \& Pittschieler K. (2003) Brief report: Melatonin facilitates sleep in individuals with mental retardation and insomnia. Journal of Autism and Developmental Disorders 33, 469-72.

O'Callaghan F.J., Clarke A.A., Hancock E., Hunt A., \& Osborne J.P. (1999) Use of melatonin to treat sleep disorders in tuberous sclerosis. Developmental Medicine Q Child Neurology 41, 123-6.

Pelc K., Cheron G., Boyd S.G., \& Dan B. (2008) Are there distinctive sleep problems in Angelman syndrome? Sleep Medicine 9, 434-41.

Phillips L., \& Appleton R.E. (2004) Systematic review of melatonin treatment in children with neurodevelopmental disabilities and sleep impairment. Developmental Medicine a Child Neurology 46, 771-5. 
Quine L. (1991) Sleep problems in children with mental handicap. Journal of Mental Deficiency Research 35, 269-90.

Sajith S. G., \& Clarke D. (2007) Melatonin and sleep disorders associated with intellectual disability: a clinical review. Journal of Intellectual Disability Research 51, 2-13.

Sateia M. J., Doghramij K., Hauri P. J., \& Morin C. M. (2000) Evaluation of Chronic Insomnia. Sleep 23, 243-308.

Simon G. E., \& VonKorff M. (1997) Prevalence, Burden, and Treatment of Insomnia in Primary Care. American Journal of Psychiatry 154, 1417-23.

Turk J. (2003) Melatonin supplementation for severe and intractable sleep disturbance in young people with genetically determined developmental disabilities: short review and commentary. Journal of Medical Genetics 11, 79396.

Wasdell M. B., Jan J. E., Bomben M. M., Freeman R. D., Rietveld W. J., Tai J., Hamilton D., \& Weiss M.D. (2008) A randomized, placebo-controlled trial of controlled release melatonin treatment of delayed sleep phase syndrome and impaired sleep maintenance in children with neurodevelopmental disabilities. Journal of Pineal Research 44, 57-64.

Wassmer E., \& Whitehouse W. P. (2006) Melatonin and sleep in children with neurodevelopmental disabilities and sleep disorders. Current Pediatrics 16, 1328.

Wiggs L., \& Stores G. (1996) Severe sleep disturbance and daytime challenging behaviour in children with severe learning disabilities. Journal of Intellectual Disability Research 40, 518-28.

Williams C.A., Beaudet A.L., Clayton-Smith J., Knoll J.H., Kyllerman M., Laan L.A., Magenis R.E., Moncla A., Schinzel A.A., Summers J.A., \& Wagstaff J. (2006) Angelman syndrome 2005: updated consensus for diagnostic criteria. American Journal of Medical Genetics. Part A 140, 413-8.

Young D., Nagarajan L., De Klerk N., Jacoby P., Ellaway C., \& Leonard H. (2007) Sleep problems in Rett syndrome. Brain \& Development 29, 609-16.

Zhdanova I. V., Wurtman R. J., \& Wagstaff J. (1999) Effects of low dose of melatonin on sleep in children with Angelman syndrome. Journal of Pediatric Endocrinology a Metabolism 12, 57-67. 


\section{CHAPTER 2}

\section{EXOGENOUS MELATONIN FOR SLEEP PROBLEMS IN INDIVIDUALS WITH INTELLECTUAL DISABILITY: A META-ANALYSIS}

\section{Published as}

Braam W., Smits M.G., Didden R., Korzilius H., Van Geijlswijk I., Curfs L.M.G. (2009) Exogenous melatonin for sleep problems in individuals with intellectual disability: a meta-analysis. Developmental Medicine Q Child Neurology 51, 340-9. 


\begin{abstract}
Background Recent meta-analyses on melatonin has raised doubts as to whether melatonin is effective in treating sleep problems in people without intellectual disabilities. This is in contrast to results of several trials on melatonin in treating sleep problems in individuals with intellectual disabilities.

Methods To investigate the efficacy of melatonin in treating sleep problems in individuals with intellectual disabilities, we performed a meta-analysis of placebo-controlled randomized trials of melatonin in individuals with intellectual disabilities and sleep problems. Data were selected from articles published on PubMed, Medline, and Embase between January 1990 and July 2008. We examined the influence of melatonin on sleep latency, total sleep time, and number of wakes per night. Quality of trials was assessed using the Downs and Black checklist.

Results Nine studies (including a total of 183 individuals with intellectual disabilities) showed that melatonin treatment decreased sleep latency by a mean of 34 minutes $(\mathrm{p}<0.001)$, increased total sleep time by a mean of 50 minutes $(\mathrm{p}<0.001)$, and significantly decreased the number of wakes per night $(\mathrm{p}<0.05)$.

Conclusions Melatonin decreases sleep latency and number of wakes per night, and increases total sleep time in individuals with intellectual disabilities.
\end{abstract}




\section{INTRODUCTION}

Sleep problems are reported to occur in 13 to $86 \%$ of individuals with intellectual disabilities depending on study design, participant characteristics, and definition of sleep problems (Didden et al. 2002). Such problems are often complex and usually more difficult to treat than in individuals without intellectual disability. When behavioural treatment for the sleep problems (Wiggs \& Stores 1998; Montgomery et al. 2004) is ineffective, sedatives are often prescribed. However, sedatives may induce serious side effects (Doran et al. 2006), such as daytime sedation, increased risk of sleep related breathing problems, and behavioural problems. Where individuals with intellectual disabilities take other medications, the risk of drug interactions is increased. Therefore, melatonin may be an effective and safe treatment option for sleep problems in individuals with intellectual disabilities.

Melatonin, a hormone released by the pineal gland during darkness, is a chronobiotic drug with hypnotic properties (Wirz-Justice \& Armstrong 1996). Melatonin secretion is regulated by an endogenous pacemaker in the suprachiasmatic nucleus of the hypothalamus (biological clock). Information on the light / dark cycle through the retino-hypothalamic tract is needed to synchronize the circadian melatonin rhythm to 24 hours. Many pathophysiological conditions can disturb this complex regulatory system and cause dysfunction of the sleep- wake system (Claustrat et al. 2005).

Biological clock disturbances frequently occur in individuals with intellectual disability and consequently cause sleep-wake disturbances (Jan \& Freeman 2004; Sajith \& Clarke 2007). Low nocturnal melatonin levels have been found, for example, in Angelman syndrome, autism, and Rett syndrome. Recently an abnormal melatonin synthesis in autism spectrum disorders was discovered (Melke et al. 2007).

Several placebo-controlled randomized trials with melatonin in individuals with intellectual disabilities have shown that melatonin improves sleep (McArthur \& Budden 1998; O'Callaghan et al. 1999; Hätönen et al. 1999; Dodge \& Wilson 2001; Niederhofer et al. 2003; Coppola et al. 2004; Garstang \& Wallis 2006; Laakso et al. 2007; Wasdell et al. 2008), i.e. induces a significant reduction of sleep latency and an increase in total sleep time. Several reviews based on these trials, as well as on open studies and case reports, emphasize the benefits of melatonin in the treatment of sleep problems in individuals with intellectual disabilities (Sajith \& Clarke 2007; Wassmer \& Whitehouse 2006; Jan \& Freeman 2004; Phillips \& Appleton 2004; Turk 2003). These results, however, are not in line with results of three meta-analyses of individuals with sleep problems without intellectual disabilities (Brzezinski et al. 2005; Buscemi et al. 2005; Buscemi et al. 2006). Although the meta-analysis by Brzezinski et al. (2005) showed a statistically 
significant improvement of sleep latency, sleep efficiency, and total sleep time, differences between the melatonin and placebo groups were small and seem to be of minor clinical importance.

In the first meta-analysis by Buscemi et al. (2005) on the efficacy of melatonin in the treatment of primary sleep disorders, evidence was found that melatonin is not effective in treating most primary sleep disorders, except for the treatment of delayed sleep phase syndrome. In the second meta-analysis by Buscemi et al. (2006) no evidence for the effectiveness of melatonin in treating secondary sleep disorders was found. These results suggest that melatonin is not effective in individuals without intellectual disability. As stated above, this is in stark contrast to outcomes of controlled trials in individuals with intellectual disability. At present, no quantitative review has been published on the outcomes of placebocontrolled trials on the efficacy of melatonin in individuals with intellectual disabilities. Therefore, we investigated the efficacy of melatonin in the treatment of sleep problems in persons with intellectual disabilities, by performing a metaanalysis of placebo-controlled, randomized trials on melatonin in individuals with sleep problems and intellectual disabilities.

\section{METHOD}

\section{Search strategy}

We performed a computerized search in the electronic databases PubMed, Medline, and Embase for trials on melatonin in individuals with sleep problems and intellectual disabilities, published between January 1990 and July 2008. Search terms used were, 'melatonin' and terms used to describe intellectual disabilities (i.e. 'developmental disability', 'intellectual disability', 'learning disorder', 'mental retardation', and 'neurodevelopmental disability'). In addition, a hand search was undertaken of reference lists of articles identified through this search.

\section{Selection}

All studies in which melatonin was used as an intervention in treating sleep problems in individuals with intellectual disability were initially selected and reviewed. Studies for the meta-analysis were included if (1) they used a randomized double-blind placebo-controlled design, (2) included individuals with any type of a diagnosis of intellectual disabilities, (3) provided quantitative data on at least one of the following primary outcome measures: sleep latency (time between laying down to sleep and the onset of sleep), total sleep time and number of wakes per night, and (4) results were reported in English. Methodological quality of each study was assessed by two independent reviewers using the Downs and Black checklist (Downs \& Black 1998). 


\section{Data extraction}

Outcome variables in this study included, sleep latency, number of wakes per night, and total sleep time. The number of minutes in the time measurements was transformed to decimals. For each study, mean differences and standard deviations (SDs) between baseline and treatment were calculated. For this purpose, we used Elbourne et al.'s method (2002) to compute SDs of the differences, imputing a correlation of 0.5 , as these were not available from the studies.

Meta-analysis with Interactive eXplanations (MIX: version 1.4 [Bax et al. 2006]) was used to perform the calculations. All measures were continuous; as association measure, the mean difference was applied. Following Sutton et al. (2000), the inverse variance method was used to weigh the number of participants in the studies. We used the random effects model; alpha level was 0.05 for each outcome. The numerical output consisted of the empirical value, the mean difference and $95 \%$ confidence interval (CI) of each study together with the $\mathrm{z}$ score and $p$ value and the weight of the studies. As graphical output, standard forest plots were drawn containing mean differences and the $95 \%$ CI of each study, as well as of the pooled analysis.

In order to assess possible publication bias (Begg \& Berlin 1988) we graphically inspected funnel plots, a scatter plot of treatment against the inverse standard error of each study (Light \& Pillemer 1984; Sterne et al. 2001; Bax et al. 2006) and calculated the adjusted rank correlation test (Greenland 1994). To test for statistical heterogeneity between studies, Galbraith plots (Bax et al. 2006) were inspected and the Tau-squared statistic, an estimate of the between study variance, was calculated (DerSimonian-Laird method in Bax et al. 2006). In order to save space, the funnel and Galbraith plots were not added.

\section{RESULTS}

\section{Included studies}

The computerized search strategy initially resulted in 276 references. Figure 1 shows the steps taken throughout the selection process. Screening these articles on selection criteria resulted in eight eligible studies. Reference tracking resulted in four additional studies, all involving individuals with intellectual disability and a specific etiological diagnosis (e.g. Angelman syndrome [Braam et al. 2008-II], autism spectrum disorder [Garstang \& Wallis 2006], ceroid lipofuscinosis [Hätönen 1999], and tuberous sclerosis [O'Callaghan et al. 1999]), and, therefore, not found by general terms describing intellectual disability in the initial computerized search. From these 12 placebo-controlled trials, two studies were excluded because no suitable quantitative data were provided (i.e. Niederhofer et al. 2003; Laakso et al. 2007) and one study was excluded because it was single blind, and lacked 


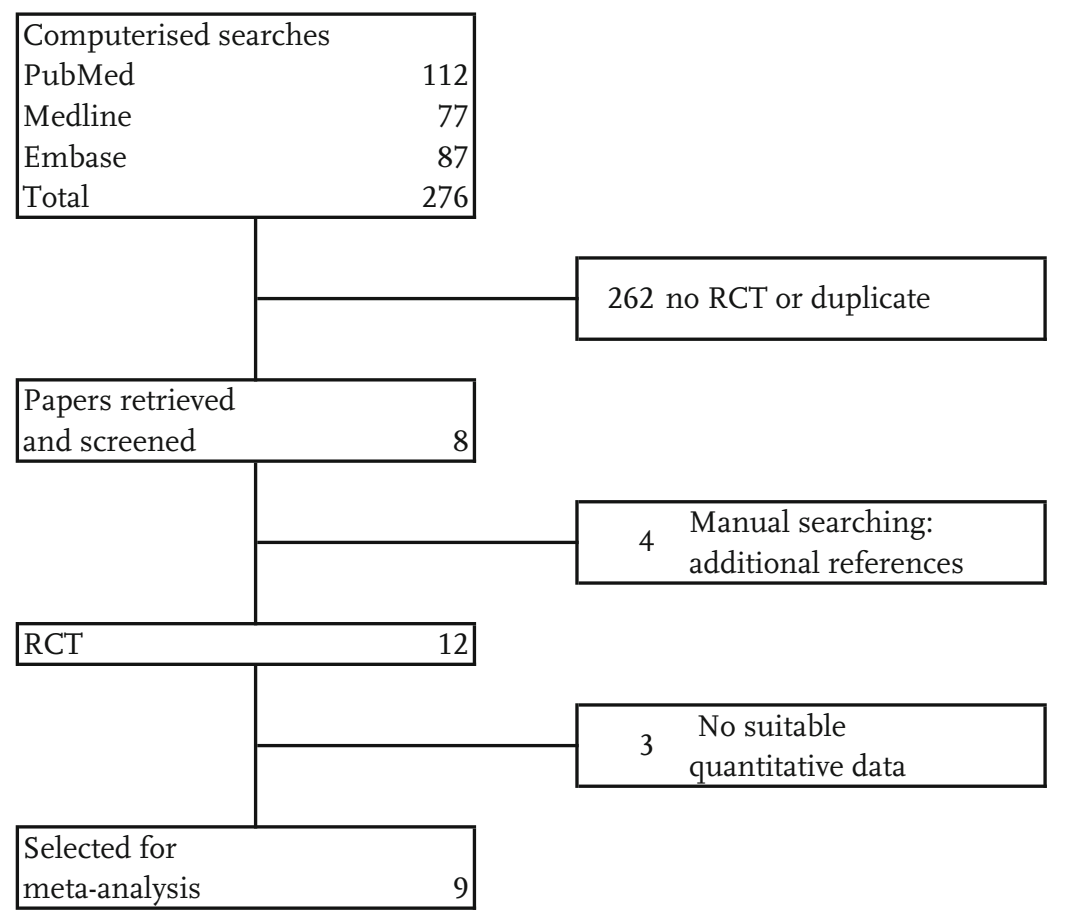

Figure 1: Study retrieval and selection. RCT, randomized controlled trial.

suitable quantitative data (Hätönen et al. 1999). One trial (Garstang \& Wallis 2006) was conducted on a sample of 11 children with autism spectrum disorder in which more than half also had intellectual disability. Therefore, we included nine studies, of which 7 were crossover (i.e. Camfield et al. 1996; McArthur \& Budden 1998; O'Callaghan et al. 1999; Dodge \& Wilson 2001; Coppola et al. 2004; Garstang \& Wallis 2005; Wasdell et al. 2008) and 2 parallel (Braam et al. 2008-I; 2008-II), all double-blind and placebo-controlled studies and involving 183 individuals with sleep problems and intellectual disability, aged between 1 and 78 years. Tables I and II depict their demographic characteristics and study designs. All sleep studies were performed in the participants' home setting. Participants received melatonin or placebo each during 2 weeks (O'Callaghan et al. 1999, Dodge \& Wilson 2001) or 4 weeks (McArthur \& Budden 1998; Coppola et al. 2004; Garstang \& Wallis 2005; Braam et al. 2008-I, 2008-II) separated by a 1 -week washout period. In one study (Wasdell et al. 2008) both study medication periods lasted 10 days, separated by a washout period of 3 to 5 days (to allow for weekends). In one study (Camfield et al. 1996) for each 2 -week interval during the 10 -week trial, participants were randomized to receive placebo or melatonin for 
Table 1: Characteristics of participants of included studies

\begin{tabular}{|c|c|c|c|c|c|c|}
\hline \multirow[b]{2}{*}{ First author } & \multirow[t]{2}{*}{$n$} & \multicolumn{2}{|c|}{ Sex } & \multicolumn{2}{|c|}{ Age (y:mo) } & \multirow[b]{2}{*}{ Diagnosis } \\
\hline & & $\mathrm{M}$ & $\mathrm{F}$ & Mean & Range & \\
\hline Camfield et al. (1996) & 6 & 4 & 2 & $7: 3$ & $3: 0-13: 0$ & Mental disability \\
\hline McArthur \& Budden (1998) & 9 & 0 & 9 & $10: 1$ & $4: 0-17: 0$ & Rett syndrome \\
\hline O'Callaghan et al. (1999) & 7 & 3 & 4 & 11 & $2: 0-28: 0$ & Tuberous sclerosis \\
\hline Dodge \& Wilson (2001) & 20 & NS & NS & $7: 5$ & 1:1 - 12:0 & Developmental disabilities \\
\hline Coppola et al. (2004) & 25 & 16 & 9 & 10:6 & $3: 7-16: 0$ & Mental retardation / learning disability \\
\hline Garstang \& Wallis (2006) & 7 & 6 & 1 & NS & $5: 0-15: 0$ & Autistic spectrum disorders \\
\hline Wasdell et al. 2008) & 50 & 31 & 19 & $7: 5$ & $2: 1-18: 10$ & Neurodevelopmental disability \\
\hline Braam et al. (2008-I) & 51 & 28 & 23 & $22: 2$ & $2: 0-78: 0$ & Intellectual disability \\
\hline Braam et al. (2008-II) & 8 & 3 & 5 & $10: 04$ & $4: 0-20: 0$ & Angelman syndrome \\
\hline
\end{tabular}

NS, not specified.

the first week with the alternate agent for the second week.

Various doses of melatonin were given. In four studies a fixed dose of $5 \mathrm{mg}$ melatonin was used (O'Callaghan et al. 1999; Dodge \& Wilson 2001; Garstang \& Wallis 2005; Wasdell et al. 2008). In four studies the melatonin dose was based either upon individual weight (ranging from 2.5-7.5 mg, McArthur \& Budden 1998 ), or age $(0.5[<6 y]$ or $1 \mathrm{mg}$ [ $\geq 6 y$ ] (Camfield et al.1996) respectively $2.5[<6 y]$ or 5 $\mathrm{mg}$ [ $\geq 6 y$ ] Braam et al. 2008-I, 2008-II). In one study (Coppola et al. 2004) melatonin was initiated at a daily dose of $3 \mathrm{mg}$. Parents were allowed to increase this dose in case of inefficacy up to $9 \mathrm{mg}$ during the following 2 weeks in increments of $3 \mathrm{mg} /$ week. In only four studies explicit information was given about the type of melatonin used. Three studies used fast release melatonin (McArthur \& Budden 1998; Braam et al. 2008-I, 2008-II) and in one study (Wasdell et al. 2008) a combination of $1 \mathrm{mg}$ fast and $4 \mathrm{mg}$ sustained release melatonin was given.

Time of administration of study medication also differed across studies, ranging from a fixed time of 6 PM (Camfield et al.1996), 8 PM (Dodge \& Wilson 2001), 7 PM, or 8 PM depending on age (Braam et al. 2008-I, 2008-II) or 1 hour before set bedtime (McArthur \& Budden 1998) to 20 to 30 minutes before the child's most desirable bedtime (Wasdell et al. 2008), 20 minutes before each participant's usual bedtime (O'Callaghan et al. 1999) or even at bedtime (Coppola et al. 2004). In one study, time of administration was not specified (Garstang \& Wallis 2006).

Studies differed in terms of the patients examined. In five studies, a heterogeneous group of patients with intellectual disabilities with different etiologies was included (Camfield et al. 1996; Dodge \& Wilson 2001; Coppola et al. 2004; Wasdell et al. 2008; Braam et al. 2008-I). Four studies were performed in patients with a specified diagnosis, in which sleep problems have a relative 
CHAPTER 2

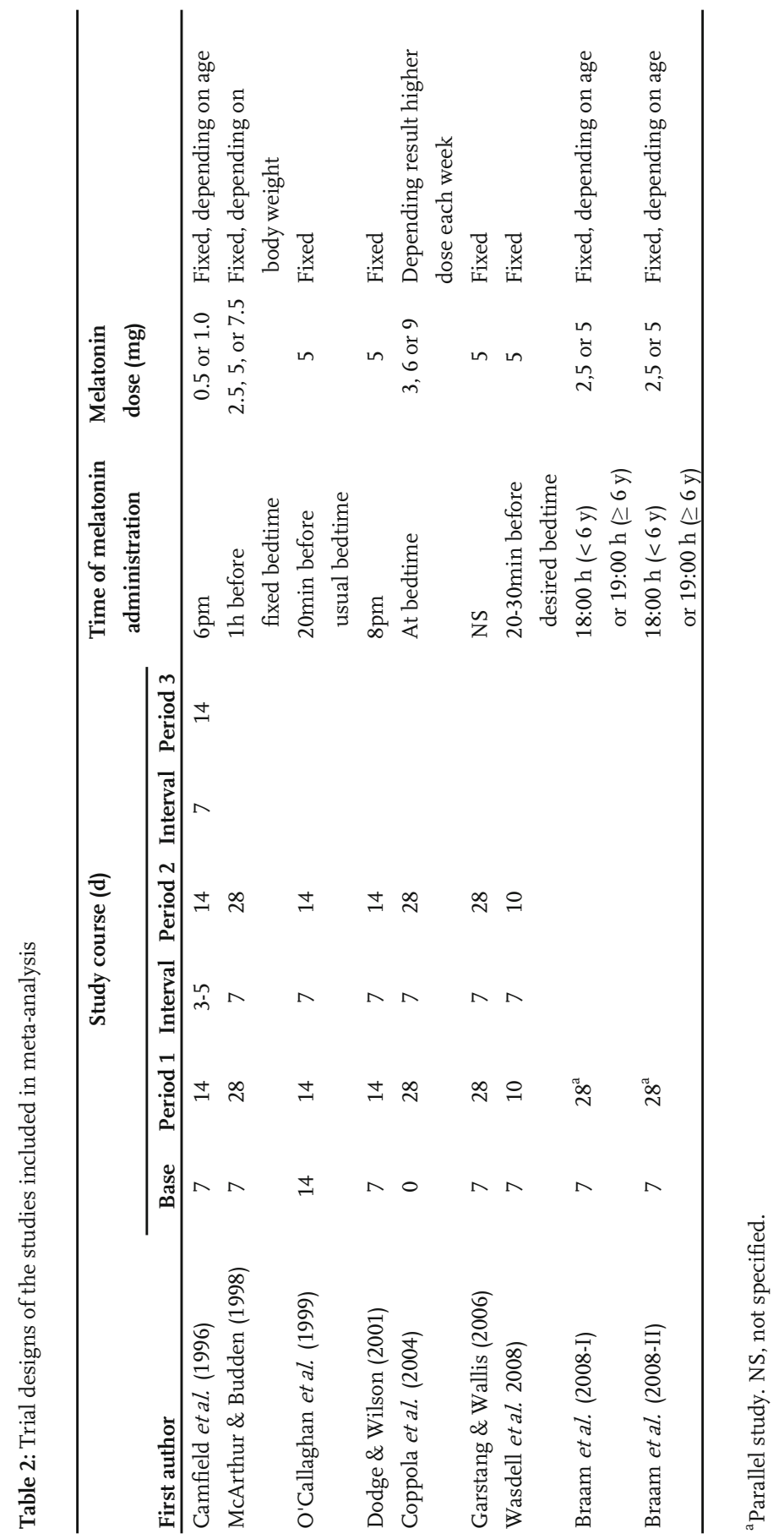




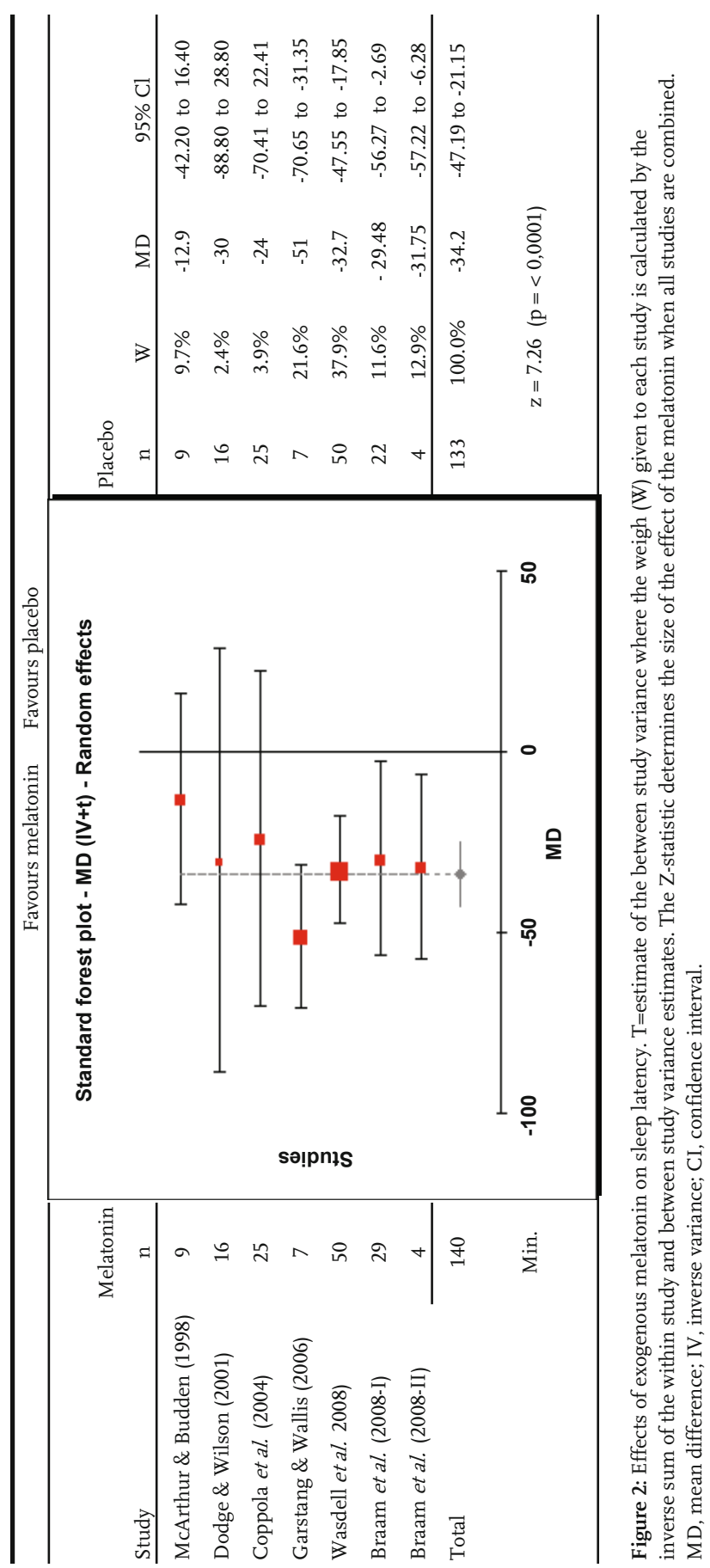


CHAPTER 2

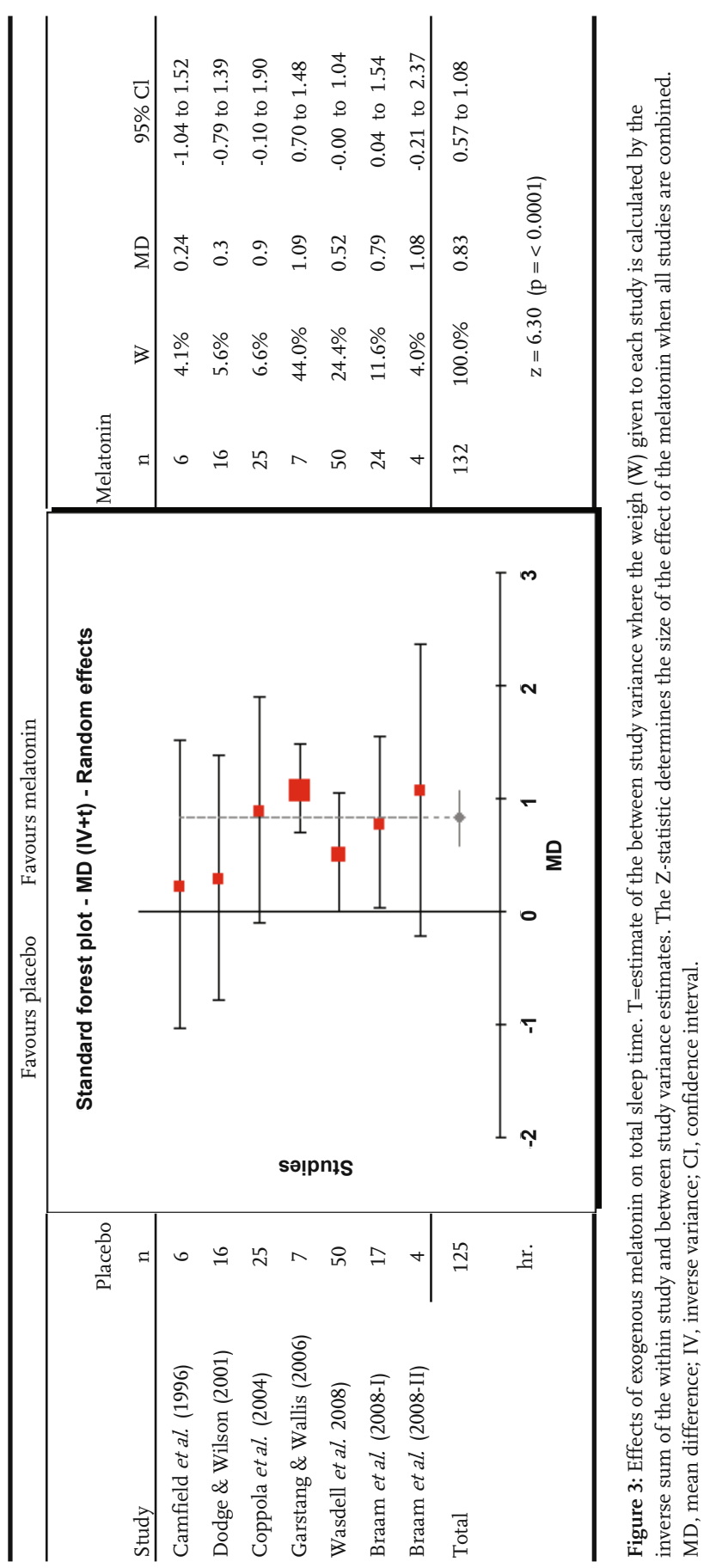




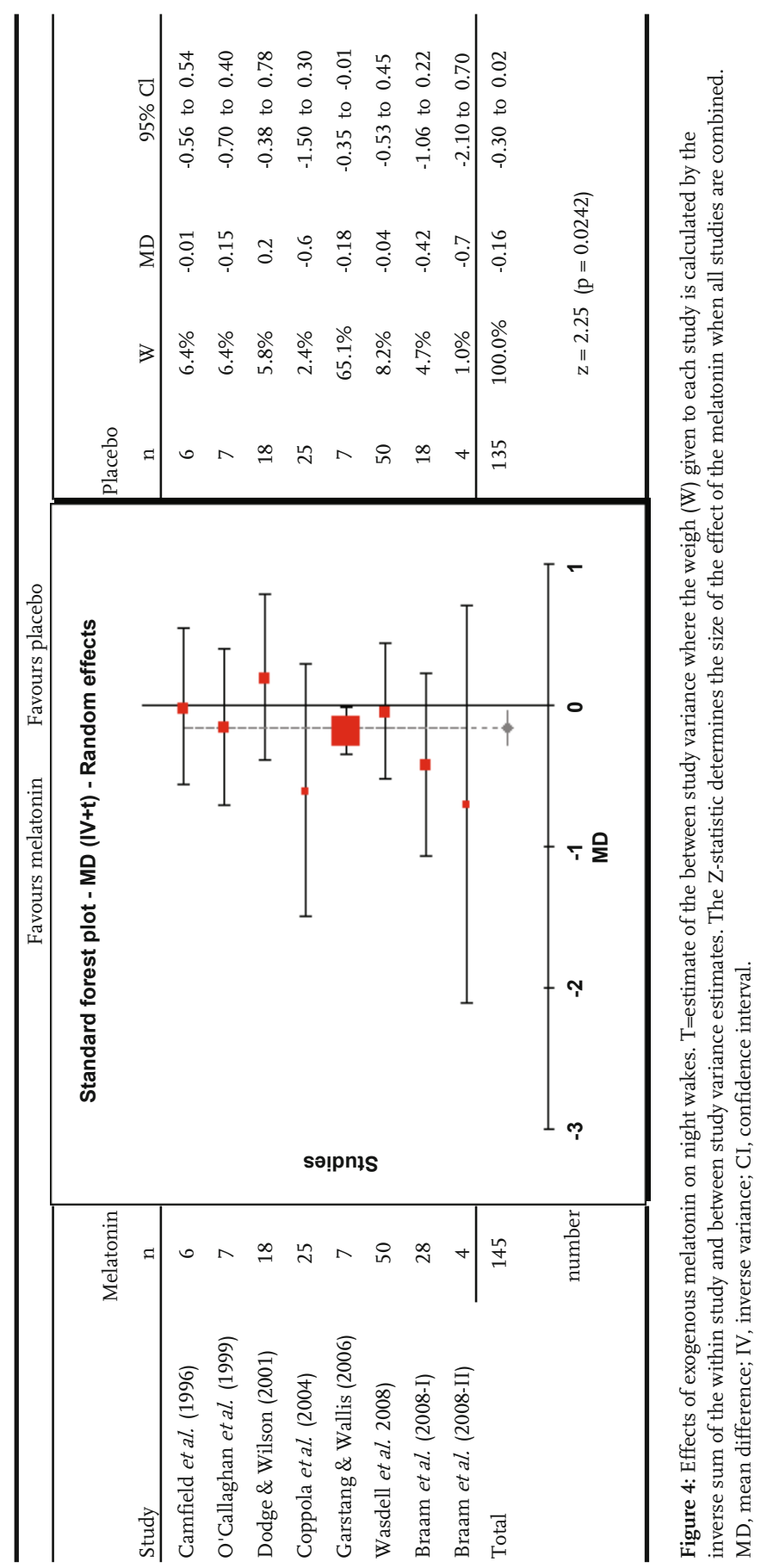


high prevalence. These were, Angelman syndrome (Braam et al. 2008-II), autism spectrum disorders (Garstang \& Wallis 2006), Rett syndrome (McArthur \& Budden 1998), and tuberous sclerosis (O'Callaghan et al. 1999). In all nine studies, sleep parameters were measured using sleep diaries. In two studies, data from actigraphic recordings were available (McArthur \& Budden 1998; Wasdell et al. 2008).

Melatonin decreased sleep latency by a mean of 34 minutes $(p<0.0001)$, significantly decreased mean number of wakes per night $(p=0.024)$, and increased total sleep time by 50 minutes $(p<0.0001)$. Figures 2,3 , and 4 summarize the means and SDs for sleep latency, total sleep time, and number of wakes per night for melatonin and placebo groups for the trials that provided data on this outcome.

The mean quality score on the Downs and Black checklist (Downs \& Black 1998) from the two reviewers of the included studies was 25.28 out of 32 ( $\mathrm{SD}=3.03$; range 19-31). Intraclass correlation (mean measures, two-way random effects model using an absolute agreement definition) between the two reviewers was 0.90 ( $p=0.002$; 95\% CI: 0.59-0.98).

Graphical examination of the funnel plots showed no substantial effect of publication bias. This finding was corroborated by the adjusted rank correlations, for sleep latency, $0.19(p=0.55)$; total sleep time, $0.00(p=1)$; and number of night awakenings $0.25(p=0.39)$. Publication bias did not substantially affect the results of the meta-analyses.

Inspection of Galbraith plots showed that there was some indication of statistical heterogeneity. For sleep latency and total sleep time two studies (Garstang \& Wallis 2006; Wasdell et al. 2008) had smaller variances than the other studies; for number of night awakenings this was the case for one study (Garstang \& Wallis 2006); however, the Tau-squared measure of heterogeneity was 0 for all three sleep parameters. As a result we conclude that heterogeneity of the studies did not affect the outcomes of the meta-analyses.

Adverse effects

Specified reports on adverse effects were given in four studies (Dodge \& Wilson 2001; Wasdell et al. 2008; Braam et al. 2008-I; Braam et al. 2008-II). Adverse effects were minor and their incidence in both melatonin and placebo phases were the same. In one study on children with Angelman syndrome (Braam et al. 2008-II), parents of one child reported an increase in night wakes in the fourth treatment week. Two studies reported that no significant adverse side effect was observed (McArthur \& Budden1998; Coppola et al. 2004), while in another three studies no information on side effects was given (O'Callaghan et al. 1999; Garstang \& Wallis 2006; Camfield et al. 1996). 


\section{DISCUSSION}

This meta-analysis showed that melatonin treatment significantly decreased sleep latency, increased total sleep time, and reduced the number of wakes per night in individuals with sleep problems and intellectual disability. It confirms earlier findings from case reports and open and randomized controlled studies, summarized in several reviews (see Turk 2003; Jan \& Freeman 2004; Phillips \& Appleton 2004; Wassmer \& Whitehouse 2006; Sajith \& Clarke 2007), with similar positive outcomes.

Getting to sleep a mean of 30 minutes earlier is a statistically significant difference, but one might ask whether this is of a meaningful benefit to the individuals and their parents or caregivers. In five studies information was given on parental perception of the results (Coppola et al. 2004; Garstang \& Wallis 2006; Wasdell et al. 2008; Braam et al. 2008-I; Braam et al. 2008-II). Parents and caregivers reported that they spent less time and effort in getting their child to stay in bed, while daytime behaviour and alertness on the part of the child also improved. Furthermore, compared to placebo, melatonin improved ratings on several functional and health dimensions as well as on ratings of severity and impact of sleep disorder on family stress.

Across studies, timing of melatonin administration was different and various doses of melatonin were given. Both could have influenced the efficacy of melatonin. Melatonin is a chronobiotic drug with hypnotic properties (WirzJustice \& Armstrong 1996). However, none of the included studies specifically mentioned which of these two properties was the main object of the study. This is an important issue, because time of administration of melatonin can influence the effect of melatonin therapy. Difference in timing of melatonin administration, however, did not affect the results of the meta-analysis. Outcomes of studies with fixed times of administration were similar to those of studies with varying times of administration. There was also no association between melatonin dose and the effect on sleep parameters in the studies that were included in this metaanalysis. This is in line with results of a randomized study (Laakso et al. 2007, not included in this meta-analysis), that compared the efficacy of three different melatonin doses (i.e. 1, 3, and 5mg) in adults with intellectual disability, given 30 minutes before the desired bedtime. It showed no difference in effectiveness among these three melatonin doses. Another study of elderly persons with sleep problems (Zhdanova et al. 2001), without intellectual disability, comparing 0.3 and $3.0 \mathrm{mg}$ of melatonin given half an hour before each participant's fixed bedtime, found that the lower dose was more effective. This suggests that the positive effect of exogenous melatonin in these two studies mainly resulted from its chronobiological effect. This is in contrast to results of a study on individuals with sleep problems and intellectual disability (Coppola et al. 2004), in which 
parents and caregivers were allowed to increase the dose up to $6 \mathrm{mg}$ or even $9 \mathrm{mg}$ in subsequent phases, in case of inefficacy of the $3 \mathrm{mg}$ dose in the first phase of the study. In the last phase of the study, in 17 out of 24 (70.8\%) participants, dose had been increased. Because in this study melatonin was given at bedtime, the tendency to increase the dose suggests that the positive effect of exogenous melatonin in this study mainly resulted from its hypnotic effect.

Patient groups in studies included in this meta-analysis were very heterogeneous. In five studies a mixed population of patients with intellectual disabilities was included (Camfield et al. 1996; Dodge \& Wilson 2001; Coppola et al. 2004; Wasdell et al. 2008; Braam et al. 2008-I), and four studies examined specified groups with disorders in which sleep problems have a relative high prevalence (i.e. Angelman syndrome [Braam et al. 2008-II], autism spectrum disorder [Garstang \& Wallis 2006], Rett syndrome [McArthur \& Budden 1998], and tuberous sclerosis [O'Callaghan et al. 1999]). In Angelman syndrome, Rett syndrome, and tuberous sclerosis, epileptic seizures are frequent and nocturnal seizures can cause poor sleep maintenance. This could have influenced the efficacy of melatonin treatment. Results of melatonin in these three studies, however, were in line with the results in the studies with a mixed population of patients with intellectual disability. This can, at least in part, be caused by an anticonvulsant effect of melatonin (Gupta et al. 2005).

Three recent meta-analyses on the efficacy of melatonin in individuals without intellectual disability found that there is no evidence that melatonin is effective in treating most sleep disorders (Buscemi et al. 2005 and 2006), or only found small differences that seem to be of minor clinical importance (Brzezinski et al. 2005). There are several possible explanations for this discrepancy between positive results with melatonin in individuals with sleep problems and intellectual disability and lack of positive results in individuals without intellectual disability. The first is that many studies in individuals without intellectual disability were performed in a sleep laboratory using polysomnography. Visual inspection of the standard forest plots, as presented in the three meta-analyses in individuals without intellectual disability, suggests that the change in sleep latency in studies in which measurements were performed in a sleep laboratory using polysomnography is smaller compared with studies that were performed under home conditions. Reanalyzing the data presented in these studies shows that the mean change in sleep latency in the studies using polysomnography is 10.1 minutes, whereas change in sleep latency in studies performed under home conditions is 16.8 minutes. The inclusion of a substantial number of studies using polysomnography in the metaanalyses in individuals without intellectual disability may have contributed to the smaller decrease in sleep latency compared with our meta-analysis, in which all studies were performed under home conditions. 
A second explanation is the inclusion of studies on individuals with noncircadian rhythm sleep disorders, or no sleep problems at all, in the meta-analyses in individuals without intellectual disability. A circadian rhythm sleep disorder (CRSD) is defined as a persistent or recurrent pattern of sleep disturbance due primarily to alterations in the circadian timekeeping system or a misalignment between the endogenous circadian rhythm and exogenous factors that affect the timing or duration of sleep (American Academy of Sleep Medicine 2005). Exogenous and endogenous factors can contribute to misalignment between the timing of internal circadian rhythms and the desired (from the parent's or caregivers perspective) time for sleep (Sack et al. 2007). In individuals with intellectual disability both endogenous as well as exogenous factors play an important part, whereby sleep problems caused by endogenous factors can be difficult to treat because they are externally maintained, for example by co-sleeping. In individuals with intellectual disability the prevalence of circadian rhythm sleep disorders is much higher than in individuals without intellectual disability (Jan \& Freeman 2004; Sajith \& Clarke 2007). Because melatonin is more effective in CRSD than other sleep disorders, it could be more effective in individuals with sleep problems and intellectual disability, than in some individuals with sleep problems without intellectual disability.

A third possible explanation for differences in results between studies in sleep problems in patients with and without intellectual disability may lie in the type of intellectual disability, i.e. the neurodevelopmental disorder, itself. First, maintaining a 24-hour circadian rhythm is based on a complex regulation system and many pathophysiological factors can disrupt this system (Claustrat $e t$ al. 2005). Second, sleep maintenance, i.e. getting back to sleep in case of wakes or arousals at night, has to be learned. Children with autism and patients with moderate or severe intellectual disability are easily aroused up to a stage that it becomes more difficult to fall asleep again independently. Also, low nocturnal melatonin levels can have a causal relation with sleep maintenance problems. For example, in Angelman syndrome, nocturnal melatonin levels are low (Zhdanova et al. 1999). The same applies to persons with autism, in whom, recently, an abnormal melatonin synthesis, leading to low nocturnal melatonin levels, was found (Melke et al. 2007). It is possible that increasing a low melatonin level to a more normal physiological level, leads to less arousals that interfere with sleep maintenance. This is supported by results of a study that found that response to melatonin treatment in patients with intellectual disability with lower endogenous melatonin levels was better than in such patients with higher melatonin levels (Laakso et al. 2007).

Except for two parallel studies (Braam et al. 2008-I, Braam et al. 2008-II) all other studies were crossover studies. A crossover design is inappropriate when 
evaluating the efficacy of melatonin (Kunz et al. 2004) because of the possibility of a carry-over effect. In two studies included in this meta-analysis, specific attention was given to this possibility, by analyzing the results by grouping the participants according to the drug-order (Coppola et al. 2004; Wasdell et al. 2008). Both studies found tendencies to carry-over effects on some parameters in participants who received placebo following melatonin. Laakso et al. (2007) in a study on individuals with sleep problems and intellectual disability (not included in this meta-analysis because no suitable quantitative data were provided), found tendencies to carryover effects on all parameters in participants who received placebo following melatonin. A carryover effect was also found in a study on individuals with sleep problems without intellectual disability in participants who received placebo after melatonin (Kunz et al. 2004). Although carry-over effects may have influenced the results in the crossover studies included in this meta-analysis, this does not threaten the validity of the conclusions of these studies, nor of this meta-analysis. After all, carry-over effects only lead to smaller differences in efficacy between melatonin and placebo groups, and as a result, to a smaller statistically significant difference in melatonin efficacy than in parallel studies.

This is the first meta-analysis of melatonin in individuals with sleep problems and intellectual disabilities. Quality of the studies included was thoroughly assessed. Nevertheless there were some limitations. First, conclusions in this meta-analysis are based on nine studies with relatively small numbers of participants. In connection with this limitation it should, however, be noted that this reflects the difficulties in recruitment of participants in these type of studies. Second, most studies in this meta-analysis included only or mainly children, and meta-analyses in individuals with sleep problems without intellectual disability have included mainly adult participants. Because there is a physiological decrease in melatonin amplitude with age, we specifically looked into this possible bias. Given the fact that melatonin amplitude decreases with age, one might expect that because of these lower levels, if related to sleep problems at all, exogenous melatonin in adults would have resulted in a better therapeutic result than in children. However, outcome of studies in adults with sleep problems and intellectual disability included in this meta-analysis was less favorable than studies in with children intellectual disability. Therefore, it is unlikely that the difference in results between this meta-analysis and the meta-analyses in patients with sleep problems without intellectual disability can be explained by the inclusion of different age-groups, although differences in melatonin receptor sensitivity (Pandi-Perumal et al. 2008) cannot be ruled out as the causative factor.

The included studies were of short duration (10-28 days), so that neither information on the effectiveness of long-term melatonin therapy, nor any indication on the time needed to resolve the sleep problems, can be given. However, in one long- 
term follow-up study (Carr et al. 2007) in which children with intellectual disability were followed every 3 months for up to 3 years 9 months after a randomized trial (Wasdell et al. 2008), all parents remained satisfied with the results and adverse reaction to melatonin therapy and development of tolerance were not evident.

Polysomnography, the criterion standard to establish the effects of melatonin on sleep, was not used in the included studies in this meta-analysis, because many children and adults with intellectual disability do not tolerate this procedure. However, the other methods (i.e. actigraphy and sleep diaries) are reliable methods to establish shifts in sleep-wake rhythm (Littner et al. 2002). In seven out of the nine included studies in this meta-analysis diaries to collect sleep parameters were used, while in two studies sleep diaries as well as actigraphy were used. In one of these two studies (Wasdell et al. 2008) the primary outcome measure was felt to be best measured by the caregiver-completed diaries, while in the other study (McArthur \& Budden 1998) actigraphy was said be more reliable at monitoring sleep parameters than caregiver diaries. Diary measures obviously have measurement errors, but are frequently used in non-clinical settings. Sleep diaries based on observations by others, however, yield more satisfactory data than sleep diaries based on self-report (Ancoli-Israel et al. 2003). Besides, parents of sleep-disturbed infants can be accurate reporters of actigraphically-assessed sleep onset and sleep duration. Sadeh et al. (1991) showed an 85.3\% agreement rate between actigraphic sleep-wake scorings and those of polysomnography. Therefore, we believe diary measures based on observations by parents and other caregivers can be used in assessing sleep parameters.

Publication bias and heterogeneity are major concerns for meta-analysis (Begg \& Berlin 1988; Greenland 1994). We included only studies that had good methodological quality as indicated by the Downs and Black checklist (Downs \& Black 1998). In addition, we examined publication bias and statistical heterogeneity and found that they did not substantially bias the outcomes of the meta-analyses reported. However, as can be seen from the low number of participants in some of the included studies, the statistical power is intrinsically not very high. As a result, the outcomes of this meta-analysis should only cautiously be applied in clinical practice. We advocate that more methodologically sound placebocontrolled randomized trials on melatonin should be conducted in the future, as this is of major importance for treating sleep problems in individuals with intellectual disability.

\section{CONCLUSION}

In spite of the heterogeneity of the studies, regarding patient groups, melatonin preparations, dosage, and timing of administration, the results of this meta- 
analysis indicate that melatonin is effective and safe in the treatment of sleep problems in individuals with intellectual disability, at least in short-term treatment. Although melatonin can be prescribed safely in individuals with sleep problems and intellectual disability, prescribers should realize that melatonin is a non-licensed drug in most countries, and that its long-term treatment effects are still unknown. Therefore, we advise the prescription of melatonin in individuals with sleep problems and intellectual disability preferably when it has been tried to assess the biological clock by (salivary) dim light melatonin onset measurements (Pandi-Perumal et al. 2007) and in randomized clinical trials. Future studies should assess melatonin dose and timing, circadian rhythm parameters, and quality of life of patients with intellectual disabilities and their caregivers.

\section{REFERENCES}

American Academy of Sleep Medicine (2005). The international classification of sleep disorders : diagnostic \& coding manual (2nd edn.). Westchester, IL: American Academy of Sleep Medicine.

Ancoli-Israel S., Cole R., Alessi C., Chambers M., Moorcroft W., \& Pollak C. P. (2003) The role of actigraphy in the study of sleep and circadian rhythms. Sleep 26, 342-92.

Bax L., Yu L. M., Ikeda N., Tsuruta H., Moons K. G. (2006) Development and validation of MIX: comprehensive free software for meta-analysis of causal research data. BMC Medical Research Methodology 6, 50.

Begg C. B., \& Berlin J. A. (1988) Publication bias: a problem in interpreting medical data. Journal of the Royal Statistical Society. [Series A] 151, 419-63.

Braam W., Didden R., Smits M. G., \& Curfs L. M. G. (2008-I) Melatonin treatment in individuals with intellectual disability and chronic insomnia: a randomized placebo-controlled study. Journal of Intellectual Disability Research 52, 256-64.

Braam W., Didden R., Smits M. G., Curfs L. M. G. (2008-II) Melatonin for chronic insomnia in Angelman syndrome: a randomized placebo-controlled trial. Journal of Child Neurology 23, 649-54.

Brzezinski A., Vangel M.G., Wurtman R.J., Norrie G., Zhdanova I., Ben-Shushan A., \& Ford I. (2005) Effects of exogenous melatonin on sleep: a meta-analysis. Sleep Medicine Reviews 9, 41-50.

Buscemi N., Vandermeer B., Hooton N., Pandya R., Tjosvold L., Hartling L., Baker G., Klassen T.P., \& Vohra S. (2005) The efficacy and safety of exogenous melatonin for primary sleep disorders. A meta-analysis. Journal of General Internal Medicine 20, 1151-8.

Buscemi N., Vandermeer B., Hooton N., Pandya R., Tjosvold L., Hartling L., Vohra S., Klassen T.P., \& Baker G. (2006) Efficacy and safety of exogenous 
melatonin for secondary sleep disorders and sleep disorders accompanying sleep restriction: meta-analysis. British Medical Journal 332, 385-93.

Camfield P., Gordon K., Dooley J., \& Camfield C. (1996) Melatonin appears ineffective in children with intellectual deficits and fragmented sleep: six ' $\mathrm{N}$ of 1' trials. Journal of Child Neurology 11, 341-3.

Carr R., Wasdell M.B., Hamilton D., Weiss M. D., Freeman R. D., Tai J., Rietveld W., \& Jan J. E. (2007) Long-term effectiveness of melatonin therapy in children with treatment-resistant circadian rhythm sleep disorders. Journal of Pineal Research 43, 351-9.

Claustrat B., Brun J., \& Chazot G. (2005) The basic physiology and pathophysiology of melatonin. Sleep Medicine Reviews 9, 11-24.

Coppola G., Iervolino G., Mastrosimone M., La Torre G., Ruiu F., \& Pascotto A. (2004) Melatonin in wake-sleep disorders in children, adolescents and young adults with mental retardation with or without epilepsy: a double-blind, crossover, placebo-controlled trial. Brain Q Development 26, 373-6.

Didden R., Korzilius H., Van Aperlo B., Van Overloop C., \& De Vries M. (2002) Sleep problems and daytime problem behaviours in children with intellectual disability. Journal of Intellectual Disability Research 46, 537-47.

Dodge N. N., \& Wilson G. A. (2001) Melatonin for treatment of sleep disorders in children with developmental disabilities. Journal of Child Neurology 16, 581-4.

Doran S., Harvey M., \& Horner R. (2006) Sleep and developmental disabilities: assessment, treatment, and outcome measures. Mental Retardation 44, $13-27$.

Downs S. H., \& Black N. (1998) The feasibility of creating a checklist for the assessment of the methodological quality both of randomized and nonrandomized studies of health care interventions. Journal of Epidemiology and Community Health 52, 377-84.

Elbourne D. R., Altman D. G., Higgins J. P., Curtin F., Worthington H. V., \& Vail A. (2002) Meta-analyses involving cross-over trials: methodological issues. International Journal of Epidemiology 31, 140-09.

Garstang J., \& Wallis M. (2006) Randomized controlled trial of melatonin for children with autistic spectrum disorders and sleep problems. Child: Care, Health and Development 32, 585-9.

Greenland S. (1994) Can meta-analysis be salvaged? American Journal of Epidemiology 140, 783-87.

Gupta M., Aneja S., \& Kohli K. (2005) Add-on melatonin improves sleep behavior in children with epilepsy: randomized, double-blind, placebo-controlled trial. Journal of Child Neurology 20, 112-5.

Hätönen T., Kirveskari E., Heiskala H., Sainio K., Laakso M. L., \& Santavuori P. (1999) Melatonin ineffective in neuronal ceroid lipofuscinosis patients with fragmented or normal motor activity rhythms recorded by wrist actigraphy. 
Molecular Genetics and Metabolism 66, 401-6.

Jan J. E., \& Freeman R. D. (2004) Melatonin therapy for circadian rhythm sleep disorders in children with multiple disabilities: what have we learned in the last decade? Developmental Medicine a Child Neurology 46, 776-82.

Kunz D., Mahlberg R., Müller C., Tilmann A., \& Bes F. (2004) Melatonin in patients with reduced REM sleep duration: two randomized trials. The Journal of Clinical Endocrinology Q Metabolism 89, 128-34.

Laakso M. L., Lindblom N., Leinonen L., \& Kaski M. (2007) Endogenous melatonin predicts efficacy of exogenous melatonin in consolidation of fragmented wristactivity rhythm of adult patients with developmental brain disorders: a doubleblind, placebo-controlled, crossover study. Sleep Medicine 8, 222-39.

Light R. J., \& Pillemer D. B. (1984) Summing up: the science of reviewing research. Cambridge: Harvard University Press.

Littner M., Kushida C.A., Anderson W.M., Bailey D., Berry R.B., Davila D.G., Hirshkowitz M., Kapen S., Kramer M., Loube D., Wise M., \& Johnson S.F. (2003) Practice parameters for the role of actigraphy in the study of sleep and circadian rhythms: an update for 2002. Sleep 26, 337-41.

McArthur A. J., \& Budden S. S. (1998) Sleep dysfunction in Rett syndrome: a trial of exogenous melatonin treatment. Developmental Medicine a Child Neurology 40, 186-92.

Melke J., Goubran Botros H., Chaste P., Betancur C., Nygren G., Anckarsäter H., Rastam M., Ståhlberg O., Gillberg I. C., Delorme R., Chabane N., MourenSimeoni M. C., Fauchereau F., Durand C. M., Chevalier F., Drouot X., Collet C., Launay J. M., Leboyer M., Gillberg C., \& Bourgeron T. (2007) Abnormal melatonin synthesis in autism spectrum disorders. Molecular Psychiatry 13, 1-9.

Montgomery P., Stores G., \& Wiggs L. (2004) The relative efficacy of two brief treatments for sleep problems in young learning disabled (mentally retarded) children: a randomized controlled trial. Archives of Disease in Childhood 89, 125-30.

Niederhofer H., Staffen W., Mair A., \& Pittschieler K. (2003) Brief report: Melatonin facilitates sleep in individuals with mental retardation and insomnia. Journal of Autism and Developmental Disorders 33, 469-72.

O’Callaghan F. J. K., Clarke A. A., Hancock E., Hunt A., \& Osborne J. P. (1999) Use of melatonin to treat sleep disorders in tuberous sclerosis. Developmental Medicine a Child Neurology 41, 123-6.

Pandi-Perumal S. R., Smits M., Spence W., Srinivasan V., Cardinali D. P., Lowe A. D., \& Kayumov L. (2007) Dim light melatonin onset (DLMO): a tool for the analysis of circadian phase in human sleep and chronobiological disorders. Progress in Neuro-Psychopharmacology a Biological Psychiatry 31, 1-11. 
Pandi-Perumal S. R., Trakht I., Srinivasan V., Spence D. W., Maestroni G. J., Zisapel N., \& Cardinali D. P. (2008) Physiological effects of melatonin: Role of melatonin receptors and signal transduction pathways. Progress in Neurobiology 85, 335-53.

Phillips L., \& Appleton R.E. (2004) Systematic review of melatonin treatment in children with neurodevelopmental disabilities and sleep impairment. Developmental Medicine Q Child Neurology 46, 771-5.

Sack R. L., Auckley D., Auger R. R., Carskadon M. A., Wright K. P. Jr, Vitiello M. V., Zhdanova I. V. (2007) Circadian rhythm sleep disorders: part I, basic principles, shift work and jet lag disorders. An American Academy of Sleep Medicine review. Sleep 30, 1460-83.

Sadeh A., Lavie P., Scher A., Tirosh E., \& Epstein R. (1991) Actigraphic homemonitoring sleep-disturbed and control infants and young children: a new method for pediatric assessment of sleep-wake patterns. Pediatrics 87, 494-9.

Sajith S. G., \& Clarke D. (2007) Melatonin and sleep disorders associated with intellectual disability: a clinical review. Journal of Intellectual Disability Research 51, 2-13.

Sterne J. A., Egger M., \& Smith G. D. (2001) Systematic reviews in health care. Investigating and dealing with publication and other biases. British Medical Journal 323, 101-5.

Sutton A. J., Abrams K. R., Jones D. R., Sheldon T. A., \& Song F. (2000). Methods for Meta-Analysis in Medical Research. London: John Wiley \& Sons.

TurkJ. (2003) Melatonin supplementation for severe and intractable sleep disturbance in young people with genetically determined developmental disabilities: short review and commentary. Journal of Medical Genetics 11, 793-6.

Wasdell M. B., Jan J. E., Bomben M. M., Freeman R. D., Rietveld W. J., Tai J., Hamilton D., \& Weiss M.D. (2008) A randomized, placebo-controlled trial of controlled release melatonin treatment of delayed sleep phase syndrome and impaired sleep maintenance in children with neurodevelopmental disabilities. Journal of Pineal Research 44, 57-64.

Wassmer E., \& Whitehouse W. P. (2006) Melatonin and sleep in children with neurodevelopmental disabilities and sleep disorders. Current Pediatrics 16, 132 8.

Wiggs L., \& Stores G. (1998) Behavioural treatment for sleep problems in children with severe learning disabilities and challenging daytime behaviour: effect on sleep patterns of mother and child. Journal of Sleep Research 7, 119-26.

Wirz-Justice A., \& Armstrong S. (1996) Melatonin: nature's soporific? Journal of Sleep Research 5, 137-41.

Zhdanova I. V., Wurtman R. J., \& Wagstaff J. (1999) Effects of low dose of melatonin on sleep in children with Angelman syndrome. Journal of Pediatric 
Endocrinology Q Metabolism 12, 57-67.

Zhdanova I. V., Wurtman R. J., Regan M. M., Taylor J. A., Shi J. P., \& Leclair O. U. (2001) Melatonin treatment for age-related insomnia. The Journal of Clinical Endocrinology \& Metabolism 86, 4727-30. 


\section{CHAPTER 3}

\section{MELATONIN TREATMENT IN INDIVIDUALS WITH INTELLECTUAL DISABILITY AND CHRONIC INSOMNIA: A RANDOMIZED PLACEBO-CONTROLLED STUDY}

Published as

Braam W., Didden R., Smits M., \& Curfs L. (2008) Melatonin treatment in individuals with intellectual disability and chronic insomnia: a randomized placebo-controlled study. Journal of Intellectual Disability Research 52, 256-64. 


\begin{abstract}
Background While several small-number or open-label studies suggest that melatonin improves sleep in individuals with intellectual disabilities (ID) with chronic sleep disturbance, a larger randomized control trial is necessary to validate these promising results.

Methods The effectiveness of melatonin for the treatment of chronic sleep disturbance was assessed in a randomized double-blind placebo-controlled trial with 51 individuals with ID. All of these individuals presented with chronic idiopathic sleep disturbance for more than 1 year. The study consisted of a 1 week baseline, followed by 4 weeks of treatment. Parents or other caregivers recorded lights off time, sleep onset time, night waking, wake up time and epileptic seizures. Endogenous melatonin cycle was measured in saliva before and after treatment.

Results Compared with placebo, melatonin significantly advanced mean sleep onset time by $34 \mathrm{~min}$, decreased mean sleep latency by 29 min, increased mean total sleep time by $48 \mathrm{~min}$, reduced the mean number of times the person awoke during the night by 0.4 , decreased the mean duration of these night waking periods by $17 \mathrm{~min}$ and advanced endogenous melatonin onset at night by an average of $2.01 \mathrm{~h}$. Lights off time, sleep offset time and the number of nights per week with night waking did not change. Only few minor or temporary adverse reactions and no changes in seizure frequency were reported.

Conclusions Melatonin treatment improves some aspects of chronic sleep disturbance in individuals with ID.
\end{abstract}




\section{INTRODUCTION}

Sleep problems are more common in persons with intellectual disabilities (ID) than among the general population. Prevalence rates for individuals with ID range from $15 \%$ to $88 \%$ depending on study design, participant characteristics and definition of sleep problems (e.g. Bartlett et al. 1985; Clements et al. 1986; Piazza et al. 1996; Didden et al. 2002). In contrast, the prevalence of sleep problems in the general population varies from $10 \%$ to $40 \%$ (Simon \& VonKorff 1997). Compared with persons with ID without sleep problems, persons with ID and sleep problems exhibit more daytime behavioural problems, irritability and lethargy. Furthermore, their ability to function optimally is diminished (e.g. Didden et al. 2002; Doran et al. 2006). Sleep problems do not only negatively affect the individuals themselves, but also affect their family and other caregivers (Quine 1991).

Sleep problems in individuals with ID are often characterized by disruptions in the circadian sleep-wake cycle. The prevalence of circadian rhythm disorders in individuals with ID is higher than in the general population (Jan \& Freeman 2004). Because of the presence of the ID it may be difficult to teach the child to develop and maintain an adequate sleep-wake behaviour and rhythm. Next to this, there are several somatic factors that may cause sleep problems, such as gastro-oesophageal reflux (Bohmer et al. 1999), epileptic seizures (Espie \& Tweedie 1998), periodic limb movement disorder (Miano et al. 2005) and sleep apnea syndrome (De Miguel-Diez et al. 2003).

Sleep problems in individuals with ID are often complex and usually more difficult to treat than in typically developing individuals. Behavioural treatments can be effective (Montgomery et al. 2004). Sedatives are often prescribed, but may cause serious side effects (Matson et al. 2000). Because individuals with ID often take other medications, the risk of drug interactions is increased. This may result in daytime sedation, increased risk of sleep related breathing disorder and increasing behavioural problems (Dodge \& Wilson 2001; Doran et al. 2006). Therefore, effective sleep medication that does not have adverse side effects is needed.

Melatonin, a hormone synthesized and released by the pineal gland during darkness, is a chronobiotic drug with hypnotic properties (Wirz-Justice \& Armstrong 1996). Melatonin secretion is regulated by an endogenous pacemaker in the suprachiasmatic nuclei of the hypothalamus. Information on the light/ dark cycle through the retino-hypothalamic tract is needed to synchronize its circadian rhythm to $24 \mathrm{~h}$. Many pathophysiological situations can disturb this complex regulation system and cause dysfunction of the sleep-wake system (Claustrat et al. 2005). Melatonin levels in serum or saliva, collected under dim light conditions, are used to assess the phase of the endogenous circadian 
pacemaker. Exogenous melatonin can affect the phase of the sleep-wake cycle. It causes a phase advance when administered before dim light melatonin onset (DLMO) in the late afternoon or early in the evening and a phase delay occurs after giving melatonin in the early morning (Lewy et al. 1992).

Several uncontrolled studies suggested that melatonin improves sleep in individuals with ID and sleep disturbance (Palm et al. 1997; Ishizaki et al. 1999; Miyamoto et al. 1999; Zhdanova et al. 1999; Jan 2000; Pillar et al. 2000; Ramstad \& Loge 2002; Ross et al. 2002; De Leersnijder et al. 2003). Clinical improvement was reported in 69-100\% of the cases, although results were mostly based on small samples. Up to now, only a few randomized trials with melatonin in persons with ID have been conducted, with mostly small numbers of participants (Camfield et al. 1996; McArthur \& Budden 1998; O'Callaghan et al. 1999; Dodge \& Wilson 2001; Niederhofer et al. 2003; Coppola et al. 2004; Garstang \& Wallis 2006). In most trials, a significant reduction of sleep latency and an increase in total sleep time were reported, whereas the influence on night wakes (NWs) was limited. Unfortunately in these studies conclusions were drawn on small sample sizes, DLMO was not measured, and the influence of exogenous melatonin on the endogenous melatonin rhythm was not studied. Therefore, in the present study effectiveness of exogenous melatonin is assessed in a randomized doubleblind placebo-controlled study in a relatively large sample of individuals with ID (i.e. $n=51$ ), measuring DLMO and the influence of exogenous melatonin on the endogenous melatonin rhythm.

\section{METHODS}

\section{Participants and selection}

Individuals with chronic sleep disturbance were referred to our sleep center by local general practitioners and ID physicians. Participants were examined by the first author, a physician for individuals with ID and specialized in sleep disorders in ID individuals. Participants were included when anamnesis ruled out somatic and psychiatric causes for the sleep disturbance and standard behavioural treatment and sleep hygiene measures had been unsuccessful. Individuals were included if they had (1) sleep latency of 30 min or more; or (2) two or more periods of NW that lasted more than 45 min each night; or (3) five or more NWs lasting more than $15 \mathrm{~min}$ each night, during at least five nights each week. Sleep disturbance was present for the duration of at least 1 year. The level of ID was based on the developmental age equivalent on the Social Functioning Scale for the Mentally Retarded, SRZ (Kraijer et al. 1994), which was administered as part of the study.

Exclusion criteria were prior use of melatonin, restless leg syndrome, sleep 
apnea syndrome, liver disease, renal failure, chronic pain and age less than 24 months. Individuals with Smith-Magenis syndrome were also excluded, because their sleep disorder is associated with an inversion of the circadian rhythm of melatonin and should be treated with both melatonin and a selective betaadrenergic blocker (De Leersnijder et al. 2003).

The trial consisted of two consecutive periods: (1) a 1-week qualification or baseline period; and (2) 4 weeks of treatment during which participants were randomly allocated to either the melatonin or placebo condition. Participants were allowed to go to bed if they asked for it or if they seemed obviously sleepy, instead of at a predetermined scheduled time. All medications were held constant during all study phases.

Participants were randomized in blocks of 10 to keep possible time effects to a minimum. All investigators involved in the present study were unaware of the treatment allocation. The code was broken when the data of all individuals were recorded in the database. The trial was performed in the home setting of each individual, and was conducted according to the European Guidelines for Good Clinical Research Practice in children (Committee for Proprietary Medicinal Products 1997) and followed the 1983 revised provisions of the 1975 Declaration of Helsinki. The study was approved by the local Medical Ethical Committee. Written informed assent was obtained for all carers.

\section{Treatment}

During the 4-week treatment, individuals aged 6 years and older daily received 5-mg melatonin (Duchefa Farma BV, Haarlem, the Netherlands) mixed with carboxymethylcellulose in a fast release tablet, or an identically looking placebo, at 7 p.m. A 5-mg dose was chosen because most placebo- controlled published trials with melatonin used this dose (see Dahlitz et al. 1991; Nagtegaal et al. 1998I; Smits et al. 2001; Van Wieringen et al. 2001). Individuals aged under 6 years received a daily dose of $2.5-\mathrm{mg}$ melatonin orally at 6 p.m. Compliance was tested by comparison of the number of tablets returned with the number prescribed.

\section{Outcome measures}

Primary outcome measures were sleep latency (min), sleep onset time, wake up time, total sleep time and number and duration of NWs. Secondary outcome measures were salivary melatonin concentrations, number of epileptic seizures (if applicable) and adverse reactions of trial medication. Parents or other caregivers recorded the time that the lights went off, sleep latency, number and duration of NWs and wake up time in a sleep diary. They were asked to listen to or observe their child or patient every $10 \mathrm{~min}$ from bedtime until the time they found their child or patient asleep. Furthermore, they reported the times at night when they 
heard or saw that the child or patient was awake. The parents or other caregivers were encouraged to describe any suspected adverse effects in the diary.

Results were discussed with parents or other caregivers at the end of the doubleblind phase. To assess a possible pro-convulsant effect of exogenous melatonin, seizure control was asked for at any visit (Sheldon 1998).

\section{Endogenous melatonin}

To assess change in circadian phase, salivary samples were collected hourly during five consecutive hours on the last night of the baseline week and the last night of the fourth treatment week, when no study medication has been given. In children aged 2-4 years samples were collected from 5 p.m., in children aged 5 and 6 years from 6 p.m., in children aged 7-14 years from 7 p.m. and in participants aged 15 years and older from 8 p.m. To prevent suppression of melatonin secretion by bright light (Bojkowski et al. 1987), children remained indoors with curtains closed during this period. Dim light ( $<50$ lux) was allowed. Saliva was collected in a cotton plug chewed on either by the patient, or by sweeping the cavity of the individuals' mouth by one of the parents or other caregivers.

The limit of detection of the assay, which had to contain at least $0.5 \mathrm{~mL}$ of saliva, was $0.39 \mathrm{pg} / \mathrm{mL}$ with an intra-assay variation of $14.5 \% / \mathrm{mL}$ (Ruger et al. 2003). The maximum detection level was $50 \mathrm{pg} / \mathrm{mL}$. DLMO was defined as the first time at which salivary melatonin reached $4 \mathrm{pg} / \mathrm{mL}$. DLMO was calculated as the linearly interpolated time of the first sample above $4 \mathrm{pg} / \mathrm{mL}$ that was preceded by a lower value (Nagtegaal et al. 1998-II). In several individuals it was not possible to calculate DLMO because their melatonin levels were either all lower than $4 \mathrm{pg} /$ $\mathrm{mL}$ or above $4 \mathrm{pg} / \mathrm{mL}$. Therefore, in case all samples of an individual patient were above $4 \mathrm{pg} / \mathrm{mL}$, we decided to set DLMO time at $0.5 \mathrm{~h}$ prior to the collection time of the first sample. In case all samples were lower than $4 \mathrm{pg} / \mathrm{mL}$, DLMO was set at $0.5 \mathrm{~h}$ after the time of the last sample.

\section{Statistical analyses}

Results of a one-sample Kolmogorov-Smirnov test showed that the data of each variable were normally distributed. T-tests for independent samples were conducted to test differences in change between melatonin and placebo treatment on the sleep variables. Statistical significance was accepted at $P<0.05$.

\section{RESULTS}

A total of 77 children and adults with ID and chronic sleep problems were referred to our sleep center (see Fig. 1). After receiving information on the design of the trial, parents or other caregivers of 10 individuals decided not to participate. 


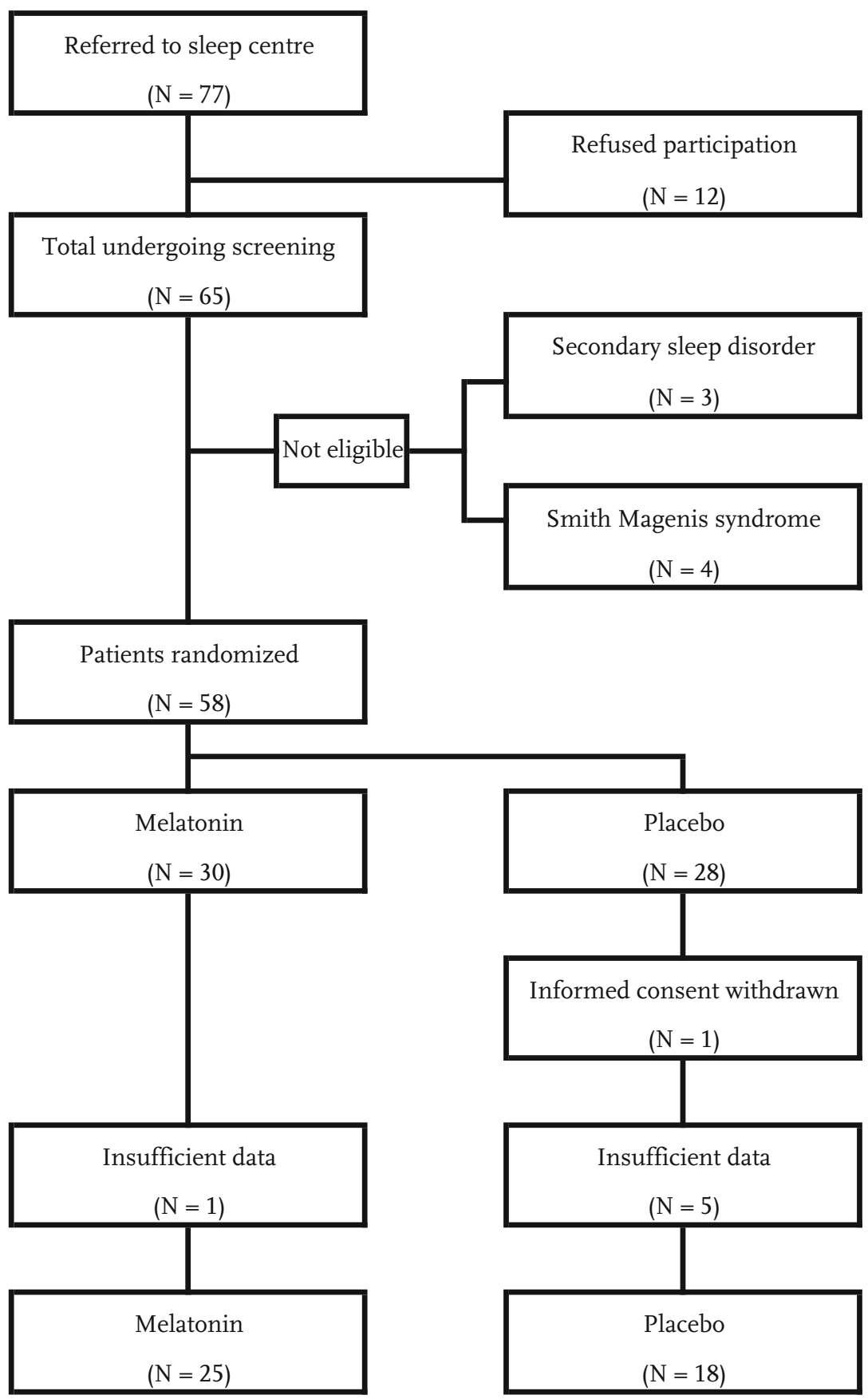

Figure 1: Selection and allocation of participants 
Table 1: Primary diagnoses intellectual disabilities

\begin{tabular}{|c|c|c|}
\hline Aetiology & $\begin{array}{c}\text { Melatonin } \\
(\mathrm{n}=29)\end{array}$ & $\begin{array}{c}\text { Placebo } \\
(\mathrm{n}=22)\end{array}$ \\
\hline Autism & 1 & \\
\hline Cerebral palsy & 5 & 4 \\
\hline Genetic syndrome & 10 & 9 \\
\hline 18q-deletion syndrome & 1 & \\
\hline Angelman syndrome & 4 & \\
\hline ATR-X syndrome & & 1 \\
\hline Bardet Biedl syndrome & 1 & \\
\hline Down syndrome & 3 & 5 \\
\hline Prader-Willi syndrome & & 1 \\
\hline Sanfilippo syndrome & 1 & 2 \\
\hline Other known causes & 2 & 3 \\
\hline Congenital hypothyreoidism & & 1 \\
\hline Hydrocephalus & 1 & \\
\hline Hypopituitarism & & 1 \\
\hline Rubella syndrome, congenital & 1 & 1 \\
\hline Mental retardation of unknown cause & 11 & 6 \\
\hline
\end{tabular}

Parents of two children thought that the trial was too burdensome for their children.

Sixty-five individuals were screened for possible inclusion in our study. Three individuals were excluded because of an untreated co-morbidity that probably was responsible for the chronic sleep problems (e.g. gastro-oesophageal reflux, congestive heart failure, anxiety disorder) and four children because of SmithMagenis syndrome.

Fifty-eight individuals were randomly assigned to melatonin or placebo conditions. During the baseline week parents of one child withdrew informed consent because their child refused to cooperate with saliva sampling. Five individuals in the placebo group and one in the melatonin group had to be excluded because parents or other caregivers did not complete the sleep logs.

The remaining melatonin treatment group consisted of 29 participants (19 males, 10 females), aged 2-78 years (mean age 23.2 years, SD =21.4), of whom 17 $(58.6 \%)$ were 19 years or younger and $12(41.4 \%)$ were 20 years or older. The severity of ID was assessed as profound $(n=9)$, severe $(n=11)$, moderate $(n=4)$ and mild $(n=5)$. Twenty-one individuals showed sleep onset as well as sleep maintenance 


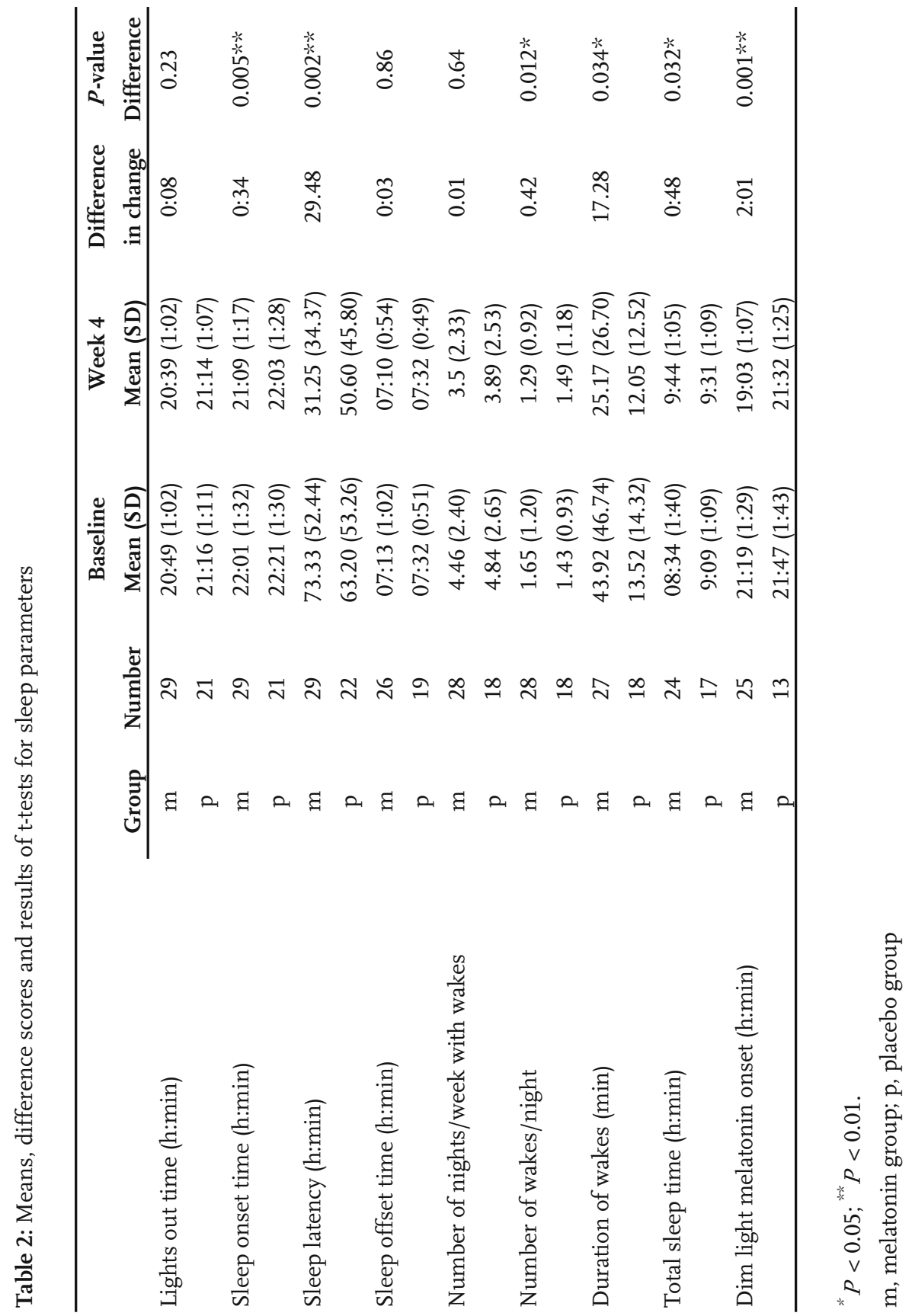


Table 3: Number of patients with different dim light melatonin onset (DLMO) calculations

\begin{tabular}{cccc}
\hline & Group & Baseline & Week 4 \\
\hline & m & 8 & 1 \\
$\mathrm{DLMO}_{<4}$ & $\mathrm{p}$ & 9 & 4 \\
$\mathrm{DLMO}_{\mathrm{N}}$ & $\mathrm{m}$ & 15 & 7 \\
& $\mathrm{p}$ & 4 & 9 \\
$\mathrm{DLMO}_{>4}$ & $\mathrm{~m}$ & 2 & 17 \\
& $\mathrm{p}$ & 2 & 2 \\
Insufficient saliva for $_{\text {melatonin analysis }}$ & $\mathrm{m}$ & 4 & 4 \\
& $\mathrm{p}$ & 7 & 7 \\
& & 51 & 51 \\
\hline
\end{tabular}

$\mathrm{DLMO}_{<4}$, not possible to calculate dlmo because all melatonin levels were $<4,0 \mathrm{pg} / \mathrm{mL}$

$\mathrm{DLMO}_{\mathrm{N}}$, dlmo calculated according to Nagtegaal et al. 1998b

$\mathrm{DLMO}_{>4}$, not possible to calculate dlmo because all melatonin levels were $>4,0 \mathrm{pg} / \mathrm{mL}$

problems, five individuals had sleep onset problems only and three suffered from sleep maintenance problems only. Sixteen individuals used anticonvulsants, of which nine were free of seizures for at least 1 month preceding the start of the trial.

The placebo group consisted of 22 individuals ( 9 males, 13 females), aged 2-58 years (mean age 20.9 years, SD = 18.2), of whom $13(59.1 \%)$ were 19 years or younger and $12(40.9 \%)$ were 20 years or older. The severity of ID was profound $(n=9)$, severe $(n=3)$, moderate $(n=3)$ and mild $(n=7)$. Ten individuals showed sleep onset as well as sleep maintenance problems, six had sleep onset problems only and six suffered from sleep maintenance problems only. Six individuals used anticonvulsants, of which three individuals were free of seizures for at least 1 month preceding the trial.

The primary diagnoses of the ID are summarized in Table 1.

Compared with placebo treatment, during melatonin treatment mean sleep latency decreased $29 \mathrm{~min}$, mean sleep onset advanced 34 min and mean total sleep time increased $48 \mathrm{~min}$. The mean number of NWs per night decreased with 0.42 and the mean duration of NWs decreased with 17 min (Table 2). DLMO, calculated according to Nagtegaal et al. (1998-II), advanced $1.39 \mathrm{~h}$ (Table 3). There was no significant change in lights out time, number of nights with NWs per week and sleep offset time compared with baseline.

There was a significant correlation between baseline DLMO and the change in 
DLMO between baseline and week 4 in the melatonin group $(r=0.75, P<0.001)$. In individuals with a late DLMO, melatonin treatment resulted in a greater advance of DLMO than in individuals with a normal DLMO. However, there were no significant correlations between baseline DLMO and change in the other sleep parameters.

Parents or caregivers of 20 individuals (i.e. 69\%) in the melatonin group and 19 (i.e. $90 \%$ ) individuals in the placebo group correctly identified at the end of week 4 whether melatonin or placebo was given. In the melatonin group, parents and caregivers of five individuals reported an increase of daytime crying, restlessness and burping and a decrease of appetite. Parents of one patient in the placebo group reported development of restless legs. The parents or caregivers considered these effects as temporarily and minor important. Parents and caregivers of 14 individuals in the melatonin group reported an improvement in mood, vigilance and/or daytime behavioural problems and found their children or individuals easier to manage with less settling problems at bedtime. These effects were not reported by parents or caregivers in the placebo group. Parents of one child with infantile spasms (West syndrome) in the melatonin group reported a $50 \%$ decrease in seizure frequency after 4 weeks of treatment. At follow-up consultation 1 month later, this beneficial effect on seizure frequency was still present. Seizure frequency in the other 15 individuals with epilepsy did not change.

\section{DISCUSSION}

In this study, melatonin was highly effective in the treatment of chronic sleep problems in a large sample of individuals with ID. Results from statistical analyses showed that compared with placebo melatonin decreased sleep latency, advanced both sleep onset and melatonin onset time and increased total sleep time. These results corroborate those found in other studies using melatonin.

In four out of five randomized trials in individuals with ID (i.e. McArthur \& Budden 1998; Dodge \& Wilson 2001; Coppola et al. 2004; Garstang \& Wallis 2006) there was a significant reduction in sleep latency, whereas O'Callaghan et al. (1999) reported only a small and non-significant reduction in sleep latency. Only one trial (i.e. Garstang \& Wallis 2006) reported a reduction in the number of NWs per night. In all five trials that presented information on total sleep time melatonin increased total sleep time (Camfield et al. 1996; McArthur \& Budden 1998; O'Callaghan et al. 1999; Coppola et al. 2004), although the increase was statistically significant in three trials only. Niederhofer et al. (2003) reported a significant increase in sleep efficiency, whereas Dodge \& Wilson (2001) did not find a significant increase in total sleep time.

The advanced sleep onset and DLMO after 4 weeks of treatment in the melatonin group are consistent with an advanced sleep-wake cycle owing to 
the chronobiotic properties of melatonin (Wirz- Justice \& Armstrong 1996). The decrease in sleep latency may be explained by both the soporific and chronobiotic properties of melatonin (Wirz-Justice \& Armstrong 1996).

In previous studies, melatonin has not been shown to influence sleep maintenance. It should be noted, however, that most of these placebo-controlled studies included individuals with so-called Delayed Sleep Phase syndrome. In this type of circadian rhythm disorder sleep maintenance is normal. The reduction of number and mean duration of wakes per night in the melatonin group in the present study suggests that melatonin may also influence sleep maintenance.

Exogenous melatonin affects the phase of the sleep-wake cycle (Lewy et al. 1992). Successful use of melatonin in order to shift sleep-wake rhythms requires correct timing of treatment relative to internal circadian rhythms (Lewy et al. 1992). Melatonin advances sleep-wake rhythms most powerfully when administered 5 $\mathrm{h}$ before endogenous melatonin starts to rise in dim light (DLMO) and delays sleep-wake rhythm most when given $10 \mathrm{~h}$ after DLMO.

An average of half an hour earlier getting to sleep and sleeping nearly $1 \mathrm{~h}$ longer is a statistical significant difference, but one might ask whether this is of a meaningful benefit to the individuals and their parents or caregivers. When asked whether they were satisfied with the results after 4 weeks of melatonin, parents and caregivers of all individuals with a decrease in sleep latency of $20 \mathrm{~min}$ or more were very satisfied with this result. They needed less time-consuming efforts to let their child or patient stay in bed. Also, a mean increase in total sleep time by $48 \mathrm{~min}$ resulted in fewer or no incidents in which others were disturbed in their sleep.

This is the first study with melatonin in which DLMO is reported for individuals with ID. DLMO measures circadian timing and is crucial for the chronobiotic properties of melatonin (Arendt 2006). The correlation between baseline DLMO and the advancement of DLMO during melatonin treatment found in our study is an expression of these chronobiotic properties (Van Der Heijden 2005). In this study, we used a parallel groups design. We did not use a crossover design because this design requires several weeks after discontinuing exogenous melatonin administration for symptoms of sleep disorders to return (Kunz et al. 2004). A crossover design may influence the results in the placebo phase in those who have started with melatonin in the first phase of the trial. This can be responsible for a less significant treatment result in a study with a crossover design, when only a 1 -week wash-out period is used.

Several limitations of our study need consideration. First, we used diaries to measure sleep. Diary measures obviously have measurement errors, but are frequently used in non-clinical settings. Sleep diaries based on observations by others, however, yield more satisfactory data than sleep diaries based on self- 
report (Ancoli-Israel et al. 2003). Besides, parents of sleep-disturbed infants were accurate reporters of actigraphically assessed sleep onset and sleep duration. Sadeh et al. (1991) showed an 85.3\% agreement rate between actigraphic sleepwake scorings compared with those of polysomnography. Therefore, we think diary measures based on observations by parents and other caregivers can be used in assessing sleep parameters. We did rule out sleep apnea, restless legs syndrome, chronic pain and other causes of insomnia, based on anamnesis. We could not perform polysomnography because the burden of this technique was too heavy for the individuals or their caregivers.

Second, successful salivary DLMO measurements were not possible in all individuals. In several individuals it was not possible to obtain enough saliva. In other individuals salivary melatonin concentrations were below the detection limit during the period of collecting. In these individuals saliva should also be collected later during the night. However, sufficient measurements could be made to draw conclusions.

A third limitation is that the influence of melatonin on daily health status, both of participants and caregivers, was not assessed systematically. Studies are needed to confirm the findings of the placebo-controlled trial in children (Smits et al. 2003) and the open-label study in adults suggesting that melatonin improves quality of life. And finally, the relative short baseline of 1 week could be mentioned as a limitation, as well as the randomization, that did not take account of age, gender and developmental stage. We recommend to do so in further studies. In conclusion, the present study indicates that melatonin improves sleep in individuals with ID that suffer from chronic sleep disturbance, probably mainly because of its chronobiotic effects. The limitations of our study, especially the way of randomization, limit the general applicability of its results. Nevertheless, we recommend to consider treatment with melatonin in individuals with ID that suffer from chronic sleep disturbance, especially when DLMO is delayed preferably in well-performed scientifically based trials.

\section{REFERENCES}

Ancoli-Israel S., Cole R., Alessi C., Chambers M., Moorcroft W., \& Pollak C. P. (2003) The role of actigraphy in the study of sleep and circadian rhythms. Sleep 26, 342-92.

Arendt J. (2006) Does melatonin improve sleep? Efficacy of melatonin. British Medical Journal 332, 550.

Bartlett L. B., Rooney V., \& Spedding S. (1985) Nocturnal difficulties in a population of mentally handicapped children. British Journal of Mental Subnormality 31, 54-9. 
Bohmer C., Niezen-de Boer M., Klinkenberg-Knol E., Deville W., Nadorp J., \& Meuwissen S. (1999) The prevalence of gastroesophageal reflux disease in institutionalized intellectually disabled individuals. American Journal of GastroenterologY 94, 804-10.

Bojkowski C., Aldhous M., English J., Franey C., Poulton A., Skene D., \& Arendt J. (1987) Suppression of nocturnal plasma melatonin and 6-sulphatoxymelatonin by bright and dim light in man. Hormone and Metabolic Research 19, 437-40.

Camfield P., Gordon K., Dooley J., \& Camfield C. (1996) Melatonin appears ineffective in children with intellectual deficits and fragmented sleep: six ' $\mathrm{N}$ of 1' trials. Journal of Child Neurology 11, 341-3.

Claustrat B., Brun J., \& Chazot G. (2005) The basic physiology and pathophysiology of melatonin. Sleep Medicine Reviews 9, 11-24.

Clements J., Wing L., \& Dunn G. (1986) Sleep problems in handicapped children: a preliminary study. Journal of Child Psychology and Psychiatry 27, 399-406.

Committee for Proprietary Medicinal Products (1997) Note for Guidance on Clinical Investigation of Medicinal Products in Children, CPMP/EWP/462/95. London: The European Agency for the Evaluation of Medicinal Products.

Coppola G., Iervolino G., Mastrosimone M., La Torre G., Ruiu F., \& Pascotto A. (2004) Melatonin in wake-sleep disorders in children, adolescents and young adults with mental retardation with or without epilepsy: a double-blind, crossover, placebo-controlled trial. Brain Q Development 26, 373-6.

Dahlitz M., Alvarez B., Vignau J., English J., Arendt J., \& Parkes J. (1991) Delayed sleep phase syndrome response to melatonin. Lancet 337, 1121-4.

De Leersnijder H., Bresson J. L., de Blois M-C., Souberbielle J-C., Mogenet A., Delhotal-Landes B., Salefranque F., \& Munnich A. (2003) Beta1-adrenergic antagonists and melatonin reset the clock and restore sleep in a circadian disorder, Smith-Magenis syndrome. Journal of Medical Genetics 40, 74-8.

De Miguel-Diez J., Villa-Asensi J. R., \& Alvarez-Sala J. L. (2003) Prevalence of sleep-disordered breathing in children with Down syndrome: polygraphic findings in 108 children. Sleep 26, 1006-9.

Didden R., Korzilius H., Van Aperlo B., Van Overloop C., \& De Vries M. (2002) Sleep problems and daytime problem behaviours in children with intellectual disability. Journal of Intellectual Disability Research 46, 537-47.

Dodge N. N., \& Wilson G. A. (2001) Melatonin for treatment of sleep disorders in children with developmental disabilities. Journal of Child Neurology 16, 581-4.

Doran S., Harvey M., \& Horner R. (2006) Sleep and developmental disabilities: assessment, treatment, and outcome measures. Mental Retardation 44, 13-27.

Espie C. A., \& Tweedie F. M. (1998) Sleep patterns and sleep problems amongst individuals with mental handicap. Journal of Mental Deficiency Research 35, 25-36. 
Garstang J., \& Wallis M. (2006) Randomized controlled trial of melatonin for children with autistic spectrum disorders and sleep problems. Child: Care, Health and Development 32, 585-9.

Ishizaki A., Sugama M., \& Takeuchi N. (1999) [Usefulness of melatonin for developmental sleep and emotional/behavior disorders. Studies of melatonin trial on 50 patients with developmental disorders] [Article in Japanese] No To Hattatsu 31, 428-37.

Jan J. E., \& Freeman R. D. (2004) Melatonin therapy for circadian rhythm sleep disorders in children with multiple disabilities: what have we learned in the last decade? Developmental Medicine and Child Neurology 46, 776-82.

Jan M. M. S. (2000) Melatonin for the treatment of handicapped children with severe sleep disorders. Pediatric Neurology 23, 229-32.

Kraijer D. W., \& Kema G. N. (1994). SRZ, Sociale Redzaamheidsschaal voor Zwakzinnigen: Handleiding. (Social Functioning Scale for the Mentally Retarded), 5th edn. Lisse: Swets \& Zeitlinger.

Kunz D., Mahlberg R., Müller C., Tilmann A., \& Bes F. (2004) Melatonin in patients with reduced REM sleep duration: two randomized trials. The Journal of Clinical Endocrinology Q Metabolism 89, 128-34.

Lewy A. J., Ahmed S., Jackson J. M., \& Sack R. L. (1992) Melatonin shifts human circadian rhythms according to a phase-response curve. Chronobiology International 9, 380-92.

McArthur A. J., \& Budden S. S. (1998) Sleep dysfunction in Rett syndrome: a trial of exogenous melatonin treatment. Developmental medicine and child neurology 40, 186-92.

Matson J. L., Bamburg J. W., Mayville E. A., Pinkston J., Bielecki J., Kuhn D., Smalls Y., \& Logan J. R. (2000) Psychopharmacology and mental retardation: a 10 year review (1990-1999). Research in Developmental Disabilities 21, 263-96.

Miano S., Bruni O., Elia M., Musumeci S., Verrillo E., \& Ferri R. (2005) Sleep breathing and periodic leg movement pattern in Angelman syndrome: a polysomnographic study. Clinical Neurophysiology 116, 2685-92.

Miyamoto A., Oki J., Takahashi S., \& Okuno A. (1999) Serum melatonin kinetics and long-term melatonin treatment for sleep disorders in Rett syndrome. Brain and Development 21, 59-62.

Montgomery P., Stores G., \& Wiggs L. (2004) The relative efficacy of two brief treatments for sleep problems in young learning disabled (mentally retarded) children: a randomised controlled trial. Archives of Disease in Childhood 89, 12530 .

Nagtegaal J., Kerkhof G., Smits M., Swart A., \& Van Der Meer Y. (1998-I) Delayed sleep phase syndrome: a placebo-controlled cross-over study on the effects of melatonin administered five hours before the individual dim light melatonin 
onset. Journal of Sleep Research 7, 135-43.

Nagtegaal E., Peeters T., Swart W., Smits M., Kerkhof G., \& Van Der Meer G. (1998-II) Correlation between concentrations of melatonin in saliva and serum in patients with delayed sleep phase syndrome. Therapeutic Drug Monitoring 20, 181-3.

Niederhofer H., Staffen W., Mair A., \& Pittschieler K. (2003) Brief report: Melatonin facilitates sleep in individuals with mental retardation and insomnia. Journal of Autism and Developmental Disorders 33, 469-72.

O’Callaghan F. J. K., Clarke A. A., Hancock E., Hunt A., \& Osborne J. P. (1999) Use of melatonin to treat sleep disorders in tuberous sclerosis. Developmental Medicine and Child Neurology 41, 123-6.

Palm L., Blennow G., \& Wetterberg L. (1997) Long-term melatonin treatment in blind children and young adults with circadian sleep-wake disturbances. Developmental Medicine and Child Neurology 39, 319-25.

Piazza C., Fisher W., \& Kahng S. (1996) Sleep patterns in children and young adults with mental retardation and severe behavior disorders. Developmental Medicine and Child Neurology 38, 335-44.

Pillar G., Shahar E., Peled N., Ravid S., Lavie P., \& Etzioni A. (2000) Melatonin improves sleep-wake patterns in psychomotor retarded children. Pediatric Neurology 23, 225-8.

Quine L. (1991) Sleep problems in children with mental handicap. Journal of Mental Deficiency Research 35, 269-90.

Ramstad K., \& Loge J. (2002) Melatonin behandling ved sovnforstyrrelser hos funksjonshemmede barn. Tidsskrift Norske Laegeforening 122, 1009-11.

Ross C., Davies P., \& Whitehouse W. (2002) Melatonin treatment for sleep disorders in children with neurodevelopmental disorders: an observational study. Developmental Medicine and Child Neurology 44, 339-44.

Ruger M., Gordijn M., Beersma D., De Vries B., \& Daan S. (2003) Acute and phaseshifting effects of ocular and extraocular light in human circadian physiology. Journal of Biological Rhythms 18, 409-19.

Sadeh A., Lavie P., Scher A., Tirosh E., \& Epstein R. (1991) Actigraphic homemonitoring sleep-disturbed and control infants and young children: a new method for pediatric assessment of sleep-wake patterns. Pediatrics 87, 494-9.

Sheldon S. (1998) Pro-convulsant effects of oral melatonin in neurologically disabled children. Lancet 351, 1254.

Simon G. E., \& VonKorff M. (1997) Prevalence, burden, and treatment of insomnia in primary care. American Journal of Psychiatry 154, 1417-23.

Smits M. G., Nagtegaal E. E., Van Der Heijden J, Coenen A. M., \& Kerkhof G. A. (2001) Melatonin for chronic sleep onset insomnia in children: a randomized placebo-controlled trial. Journal of Child Neurology 16, 86-92. 
Smits M. G., Van Stel H. F., Van Der Heijden K., Meijer A. M., Coenen A. M., \& Kerkhof G. A. (2003) Melatonin improves health status and sleep in children with idiopathic chronic sleep-onset insomnia: a randomized placebo-controlled trial. Journal of the American Academy of Child and Adolescent Psychiatry 42, 1286-93.

Van Der Heijden K. B., Smits M. G., Van Someren E. J., \& Gunning W. B. (2005) Prediction of melatonin efficacy by pre-treatment dim light melatonin onset in children with idiopathic chronic sleep onset insomnia. Journal of Sleep Research 14, 187-94.

Van Wieringen S., Jansen T., Smits M. G., Nagtegaal J. E., \& Coenen A. M. L. (2001) Melatonin for chronic whiplash syndrome with delayed melatonin onset. Randomised, placebo-controlled trial. Clinical Drug Investigation 21, 813-20.

Wirz-Justice A., \& Armstrong S. (1996) Melatonin: nature's soporific? Journal of Sleep Research 5, 137-41.

Zhdanova I. V., Wurtman R. J., \& Wagstaff J. (1999) Effects of low dose of melatonin on sleep in children with Angelman syndrome. Journal of Pediatric Endocrinology Q Metabolism 12, 57-67. 


\section{CHAPTER 4}

MELATONIN FOR CHRONIC INSOMNIA IN ANGELMAN SYNDROME: A RANDOMIZED PLACEBO-CONTROLLED TRIAL

Published as

Braam W., Didden R., Smits M. G., \& Curfs L. M. G. (2008) Melatonin for chronic insomnia in Angelman syndrome: a randomized placebo-controlled trial. Journal of Child Neurology 23, 649-54. 


\begin{abstract}
Background Previous studies suggested that melatonin improves sleep in insomniac patients with Angelman syndrome.

Method To assess the efficacy of melatonin, a randomized placebo-controlled study was conducted in 8 children with Angelman syndrome with idiopathic chronic insomnia. After a 1-week baseline period, patients received, depending on age, either melatonin 5 or $2.5 \mathrm{mg}$, or placebo, followed by 4 weeks of open treatment. Parents recorded lights off time, sleep onset time, wake-up time, and epileptic seizures in a diary. Salivary melatonin levels were measured at baseline and the last evening of the fourth treatment week.

Results Melatonin significantly advanced sleep onset by 28 minutes, decreased sleep latency by 32 minutes, increased total sleep time by 56 minutes, reduced the number of nights with wakes from 3.1 to 1.6 nights a week, and increased endogenous salivary melatonin levels. Parents were satisfied with these results.

Discussion Indications that melatonin dose in Angelman syndrome patients should be low, are discussed.
\end{abstract}




\section{INTRODUCTION}

Angelman syndrome is characterized by severe intellectual disability, motor impairment, seizures and subtle dysmorphic facial features and is associated with 4 types of chromosomal abnormalities involving the chromosome 15q11-q13 region (deletions, paternal uniparental disomy, methylation imprinting mutations, and UBE3A and other presumed single gene mutations). Most individuals with Angelman syndrome exhibit behavioral features such as excessive laughter, hyperactivity, noncompliance, speech impairment, and sleep problems (ClaytonSmith \& Laan 2003; Didden et al. 2004-I; Summers et al. 1995). Sleep problems include settling problems and frequent night waking (Didden et al. 2004-II; Bruni et al. 2004). They appear resistant to behaviour therapy and conventional sleep medication (Didden et al. 2004-II).

Melatonin, a hormone synthesized and released by the pineal gland during darkness, is a chronobiotic drug with hypnotic properties (Wirz-Justice \& Armstrong 1996). There is increasing evidence that chronic sleep problems in persons with intellectual disabilities are the result of circadian rhythm disorders and that melatonin therapy could be effective. However, only a few randomized trials with melatonin in persons with intellectual disabilities are performed (Phillips \& Appleton 2004). In insomniac patients with intellectual disabilities, melatonin decreases sleep latency, but does not influence sleep maintenance (Camfield et al. 1996; McArthur \& Budden 1998; Dodge \& Wilson 2001). An open-label trial of 13 children with Angelman syndrome found that melatonin decreased sleep latency and increased total sleep time as well (Zhdanova et al. 1999).

\section{METHOD}

Participants

Parents of patients with Angelman syndrome and chronic idiopathic insomnia that were referred to our sleep center by local general practitioners, were asked to participate in a placebo-controlled trial with melatonin. Criteria for participation were sleep latency more than 30 minutes, or 2 or more wakes, lasting more than 15 minutes a night, at least 5 nights a week, during more than 1 year preceding inclusion. Exclusion criteria were prior use of melatonin, liver disease, renal failure, chronic pain, and age less than 24 months. Patients were examined by a physician (first author) for patients with intellectual disabilities who is specialized in sleep disorders, assessing that behavioural and social sleep hygiene measures had been attempted unsuccessfully and no signs for a physical cause for the insomnia were present. The trial was performed in the home setting of each individual. It followed the 1983 revised provisions of the 1975 Declaration of Helsinki. The local Medical Ethical Committee approved the study. The patients' 
parents gave written informed consent.

The trial consisted of 2 consecutive periods: a 1-week qualification period and 4 weeks of treatment during which participants were randomly allocated to melatonin or placebo therapy. Saliva specimens for measuring melatonin concentrations were collected in the qualification period (baseline) to examine whether there was a delayed sleep phase syndrome or another disturbance in melatonin circadian rhythm and at the end of the last week of the treatment period to examine whether 4 weeks of treatment had changed endogenous melatonin circadian rhythm. After the 4-week placebo controlled phase of the study, all patients received 4 weeks open treatment with melatonin. At follow-up parents were asked to tell if they were satisfied with the result of the treatment. Patients were not allowed to change their co-medication. All investigators involved in the study were unaware of the treatment allocation. The code was broken when the data of all patients were recorded in the database.

\section{Treatment}

During the 4 treatment weeks, patients 6 years of age and older received a daily dose of $5 \mathrm{mg}$ of melatonin (Duchefa Farma BV, Haarlem, The Netherlands) orally at 7 PM, mixed with carboxymethylcellulose in a fast-release tablet, or an identically looking placebo. A 5-mg dose was chosen because most placebocontrolled trials with melatonin used this dose (Nagtegaal et al. 1998; Dahlitz et al. 1991; Smits et al. 2001). Patients under 6 years of age received a daily dose of $2.5 \mathrm{mg}$ of melatonin orally at $6 \mathrm{PM}$. Compliance was tested by comparison of the number of tablets returned with the number prescribed.

\section{Outcome Measures}

Primary outcome measures were the between-group differences of sleep latency, sleep onset, wake up time, and number and length of wakes. Secondary outcome measures were the between group differences of salivary melatonin concentrations, number of epileptic seizures, as well as adverse reactions of melatonin. Sleep variables were assessed by parents and recorded in a sleep diary. Parents were asked to listen or watch their child every 10 minutes from bedtime until the time they found their child asleep. Furthermore, they reported the times at night when they heard or saw that their child was awake. The parents were encouraged to describe any suspected adverse effects in the diary. Results were discussed with parents at the end of the double-blind phase and after 4 weeks of open treatment. At both times, parents were asked to judge the result as small, moderate, or strong improvement or unchanged. Because of contradictory reports of proconvulsant and anticonvulsant effects of exogenous melatonin (Sheldon 1998; Peled et al. 2001), seizure control was asked for at any visit. 


\section{Endogenous Melatonin}

On the last night of the baseline week and the last night of the fourth treatment week (at which night no melatonin was given) salivary samples were collected hourly during 5 consecutive hours. In children 2-4 years of age from 5 PM, in children 5 and 6 years of age from 6 PM, and in older children from 7 PM. To prevent suppression of melatonin secretion by bright light (Bojkowski 1987) the children remained indoors with curtains closed during that period. Dim light ( $<50$ lux) was allowed. Saliva was collected in a cotton plug either chewed on by the patient or by sweeping the cavity of the patients' mouth by 1 of the parents. The limit of detection of the assay, which had to contain at least $0.5 \mathrm{~mL}$ of saliva, was $0.39 \mathrm{pg} / \mathrm{mL}$ with an intra-assay variation of $14.5 \% / \mathrm{mL}$ (Ruger et al. 2003). The maximum detection level was $50 \mathrm{pg} / \mathrm{mL}$.

\section{Statistical Analyses}

Results of a 1-sample Kolmogorov-Smirnov analysis showed that data of each variable were normally distributed. Unpaired t-tests were conducted to test differences in change between melatonin versus placebo treatment on the sleep variables. Statistical significance was accepted at $P<.05$.

\section{RESULTS}

A total of 13 children and adults with Angelman syndrome and chronic sleep problems were referred to our sleep center. Four of them were not included because their sleep problems did not meet criteria for inclusion. After receiving information on the design of the trial, the parents of 1 patient decided not to participate because they thought that the trial was too burdensome for their child. The remaining 8 patients were randomly assigned to melatonin or placebo conditions. Thus, the melatonin and the placebo group each consisted of 4 patients.

Seven patients showed sleep onset as well as sleep maintenance problems, and 1 patient suffered from sleep onset problems only (Table 1). There were no statistically significant differences between patients who were allocated to melatonin and placebo group on all parameters during baseline week.

During melatonin treatment, sleep latency decreased by 32 minutes, sleep onset advanced by 28 minutes, and total sleep time increased by 56 minutes on average. The mean number of nights with wakes decreased from 3.1 to 1.6 a week on average. These changes significantly differed from those during placebo treatment (Table 2). There was no significant change in lights out time and sleep offset time.

The parents of 2 children (\#4 and 8) who received melatonin considered the 
CHAPTER 4

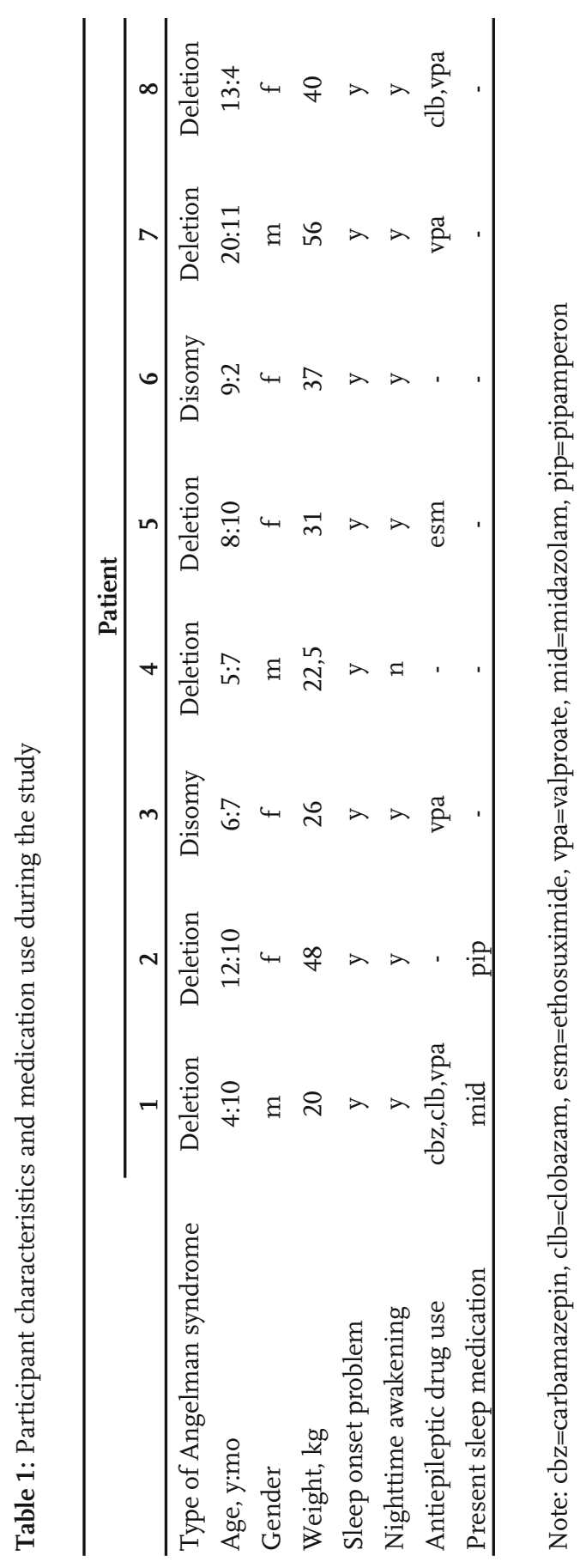

64 


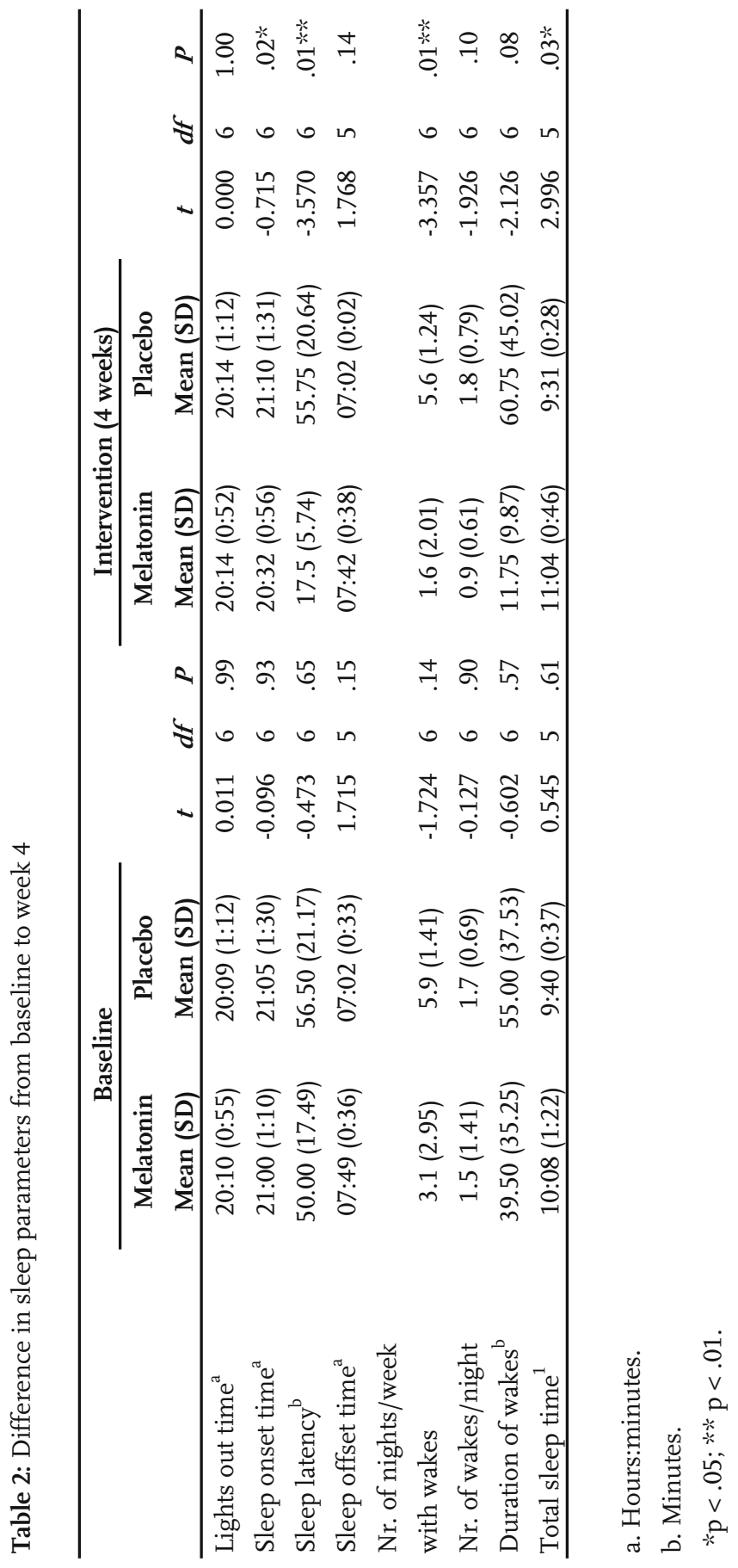


CHAPTER 4

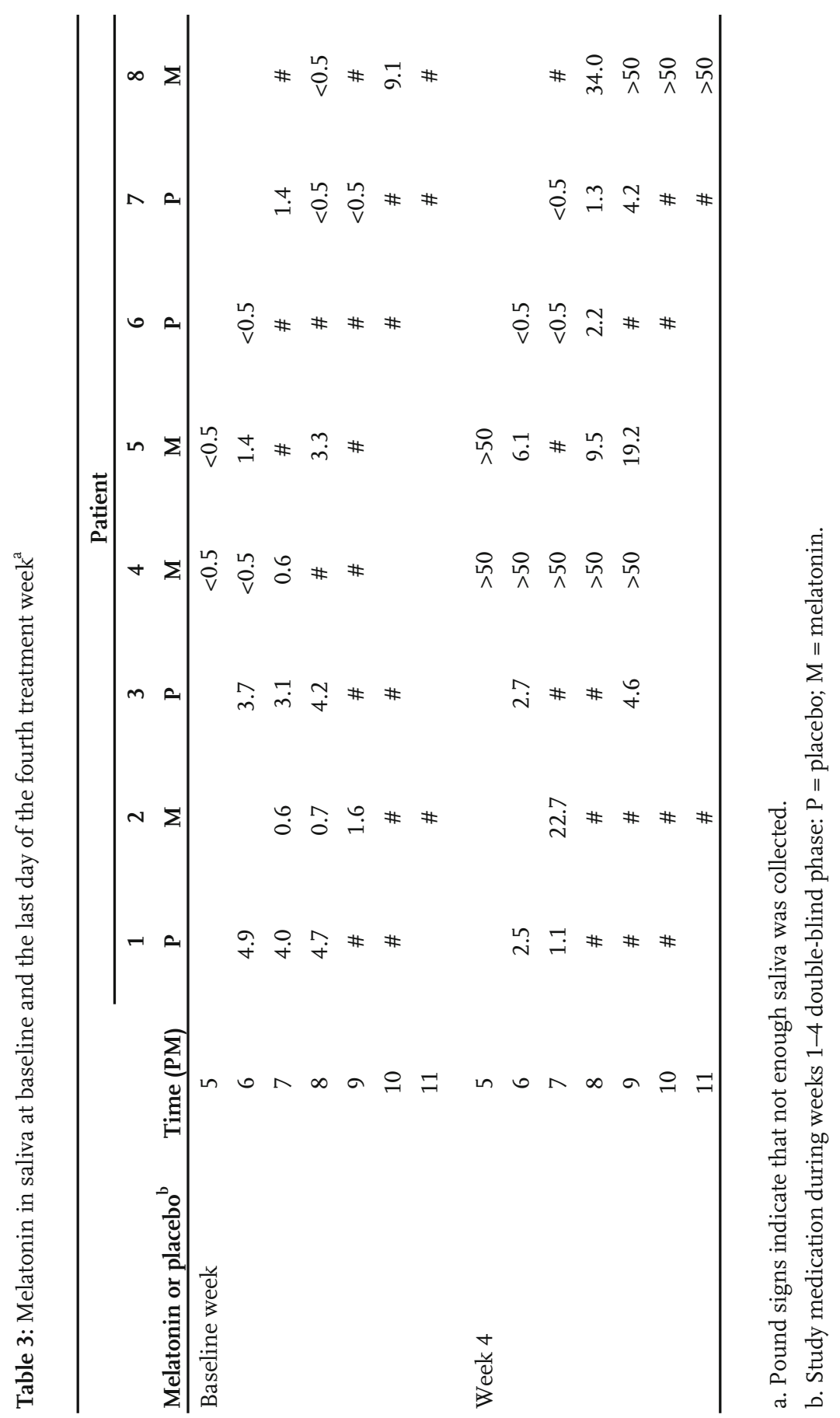


treatment outcome as a moderate improvement, and 2 (\#2 and 5) as a strong improvement. After 4 weeks of open treatment with melatonin, the parents of 2 children (\#2 and 8) decided upon continuation of the treatment. The parents of 1 child (\#5), however, reported an increase of the number of night wakes and stopped treatment. The parents of the fourth child (\# 4) did not want to continue treatment, because they were disappointed with the treatment result.

The parents of the 4 children who received placebo reported that the sleep problems of their children did not change. After 4 weeks of open melatonin treatment, the parents of 3 children (\#1, 3, and 6) wanted to continue melatonin treatment because of the strong improvement of the sleep of their child, whereas the parents of 1 child (\#7) stopped treatment because the sleep problems in their child remained unchanged.

In 35 of 80 salivary samples, the amount of saliva was too low for a melatonin analysis. Visual inspection of the data on the remaining 45 samples (Table 3) shows that salivary melatonin concentrations, on a day no study medication was given, increased substantially after melatonin treatment (i.e., child 2, 4, 5, and 8), whereas melatonin concentrations after placebo treatment (i.e., child 1, 3, 6, and 7) did not change. In patients 4 and 8 , salivary melatonin concentrations were above $50 \mathrm{pg} / \mathrm{mL}$ at the first evening after discontinuation of 4 weeks of melatonin treatment. In patient 5 , the first sample (collected at $5 \mathrm{PM}$ ) contained more than $50 \mathrm{pg} / \mathrm{mL}$.

Of 4 patients receiving melatonin in the melatonin group, 2 used anti-epileptic drugs (i.e., child 5 and 8; see Table 1). Last reported seizure was, respectively, 3 months and 2 years before entering the study. No seizures were reported by their parents during the present study, or by parents of the other 6 patients.

\section{DISCUSSION}

Four weeks of melatonin treatment in Angelman syndrome children with chronic insomnia was more effective in decreasing sleep latency, advancing sleep onset, and increasing total sleep time than placebo. Furthermore, the number of nights per week with wakes decreased more during melatonin treatment. The reduction in sleep latency and the advance of sleep-onset is consistent with earlier findings in studies with melatonin in children with chronic sleep onset (Smits et al. 2001; Smits et al. 2003). The beneficial effect on night waking and total sleep time differed from findings in earlier studies showing that melatonin does not influence sleep maintenance (Oldani et al. 1994; Camfield et al. 1996; Dodge et al. 2001; McArthur et al. 1998).

An average of half an hour earlier getting to sleep and sleeping 1 hour longer is a statistically significant difference. However, one might ask whether this is 
of a meaningful benefit to the patients and their parents. When asked whether they were satisfied with the results after 4 weeks of melatonin (or in the case of placebo after 4 weeks of open melatonin use), parents responded positively. Half an hour earlier, getting to sleep meant that parents needed less time-consuming efforts to try to let their child stay in bed. A mean increase in total sleep time by approximately 1 hour, meant less or not waking up anymore in the middle of the night and waking up by parents and siblings. But next to this, parents reported that their children's behaviour was easier to manage and that they were less sleepy and more attentive at daytime. This latter finding is consistent with another placebo-controlled study showing that melatonin improved health status (Smits et al. 2003).

Diary measures have measurement error, but are frequently used in nonclinical settings. Sleep diaries based on observations by others, however, yield more satisfactory data compared with actigraphy than sleep diaries based on self-report (Ancoli-Israel et al. 2003). Besides, parents of sleep-disturbed infants were accurate reporters of actigraphically assessed sleep onset and sleep duration (Sadeh 1996). Sadeh et al. (1999) showed an 85.3\% agreement rate between actigraphic sleepwake scorings compared with those of polysomnography. Measures were only used to compare between the results of the 2 consecutive periods and not used to determine sleep parameters per se.

Melatonin levels in the baseline week were low. It is possible that in our patients melatonin levels increased after the last sampling time. Late melatonin onset is a key characteristic of the delayed sleep phase syndrome (Smits et al. 2003). Consequently, sleep onset insomnia in Angelman syndrome could be the result of a delayed sleep phase syndrome. Delayed sleep phase syndrome is defined as an abnormally delayed sleep-wake rhythm. The major symptoms of this syndrome are extreme difficulty to initiate sleep at a conventional hour of the night and great difficulty to wake up on time in the morning. Delayed sleep phase syndrome is associated with late dim light melatonin onset (Nagtegaal et al. 1998). This circadian rhythm disorder responds very well to melatonin treatment. Zhdanova et al. (1999) also found low melatonin levels in children with Angelman syndrome in the baseline week. They attributed these low levels, in part, to the use of valproate. Sodium valproate is known to suppress plasma melatonin levels (Monteleone et al. 1997). In our study, 4 children used valproate, but their melatonin levels in the baseline week were not lower than those of children who did not use valproate.

The question whether melatonin influences seizure frequency remains a matter of discussion. Melatonin may increase seizure frequency (Sheldon 1998). However, melatonin also has anticonvulsant effects (Peled et al. 2001). The melatonin treatment period in our patients was perhaps too short to draw 
conclusions about the influence of melatonin on seizure frequency.

In 3 of the 4 children who received melatonin, salivary melatonin levels were extremely high after 4 weeks of treatment. The parents of these children reported the return or increase of night wakes when visiting the clinic after week 4 of the open melatonin treatment phase, or at the next evaluation 1 month later.

The postmelatonin high levels of salivary melatonin could be due to a supraphysiological dose of exogenous melatonin. However, the elimination halflife of melatonin has been reported as 0.8 hours with an absorption half-life of 0.4 hours, while melatonin levels ranged from 350 to 10000 times those occurring physiologically (Waldhauser et al. 1984) Furthermore, in children 6-12 years of age who participated in a study using $5 \mathrm{mg}$ of melatonin in a similar study design as in the present study, salivary melatonin levels measured 24 hours after the last exogenous melatonin intake, were normal and only showed a phase advance (Smits et al. 2001, 2003) If there were a large advance of the endogenous melatonin rhythm, so that endogenous melatonin started to increase largely before 5 PM, patients should have been sleepy in the afternoon. Parents did not report this. Another explanation for the high salivary melatonin levels approximately 24 hours after the last intake of melatonin is that the melatonin metabolism is disturbed in Angelman syndrome. Melatonin is metabolized in the liver by cytochrome P450 $1 \mathrm{~A} 2$ to its main primary metabolite 6 -hydroxymelatonin. Exogenous melatonin has a half-life between 30 and 50 minutes. Genetic variations influence the expression of specific cytochrome P450 isoenzymes in individuals and this finding influences their capacity to metabolize certain drugs (Claustrat et al. 2005). Assuming that exogenous melatonin does not stimulate endogenous melatonin secretion, it is likely that the high melatonin levels after 4 weeks of treatment with melatonin in 3 of 4 children in this study, found 24 hours after the last oral melatonin dose, were caused by a low activity of cytochrome P450 1A2 or another disturbance in the metabolism of melatonin. However, the possibility that the elevated levels were the result of down-regulation of endogenous melatonin or enzyme inhibition by anti-seizure medication can in some cases not be ruled out. Only $3-4 \%$ of the white population is a poor metabolizer of cytochrome P450 1A2. That 3 of 4 children with Angelman syndrome in the melatonin group had elevated melatonin levels after 4 weeks of treatment raises the question whether a low activity of cytochrome P450 1A2 is part of the Angelman syndrome phenotype.

We are studying the above-discussed explanations for a possible disturbed melatonin metabolism in Angelman syndrome patients. Until the results are published, we suggest testing melatonin metabolism in each individual Angelman syndrome patient before considering (long-term) melatonin treatment, for instance by measuring salivary melatonin hourly during 24 hours after melatonin administration. Consequently, the best pharmacotherapeutic dose can 
be determined, taking into account the individually measured elimination half-life of melatonin. If salivary melatonin levels do not reach basal values within 12 hours after melatonin administration, consider lowering the dose with at least $50 \%$.

This first placebo-controlled study of melatonin in insomniac Angelman syndrome patients has several shortcomings. The number of patients (i.e., $n=8$ ) was low. Many parents referred to our sleep clinic, when asked for permission to let their child participate in this study, refused to do so because they only wanted immediate help for their child's problems instead of risking the possibility of another 4 weeks of disturbed sleep due to placebo treatment. In this study, sample size was very small and the power of the $t$-test was low. Despite low power, significant and meaningful differences were found between placebo and melatonin conditions. It should be noted that a randomized controlled trial with a larger sample size would have a larger statistical power. However, it is extremely difficult if not impossible to include a large number of participants with Angelman syndrome in any randomized controlled trial, because Angelman syndrome is a relatively rare genetic disorder.

We relied on parental sleep diaries rather than more objective measures, such as actigraphy. Melatonin levels would better have been measured more than 24 hours, for example, 48 hours, after the last intake of exogenous melatonin. The sample was biased by referrals to a highly specialized outpatient clinic for insomniac patients with intellectual disabilities. These shortcomings threaten the validity of our conclusions. Nevertheless, the results show that melatonin treatment may help insomniac Angelman syndrome patients. However, further studies need to be performed on melatonin metabolism in Angelman syndrome to establish the best dose. This study indicates that it is possible that melatonin dose in Angelman syndrome should be lower than generally prescribed.

\section{REFERENCES}

Ancoli-Israel S., Cole R., Alessi C., Chambers M., Moorcroft W., \& Pollak C. P. (2003) The role of actigraphy in the study of sleep and circadian rhythms. Sleep 26, 342-92.

Bojkowski C., Aldhous M., English J., Franey C., Poulton A., Skene D., \& Arendt J. (1987) Suppression of nocturnal plasma melatonin and 6-sulphatoxymelatonin by bright and dim light in man. Hormone and Metabolic Research 19, 437-40.

Bruni O., Ferri R., D’Agostino G., Miano S., Roccella M., \& Elia M. (2004) Sleep disturbances in Angelman syndrome: a questionnaire study. Brain Q Development 26, 233-40.

Camfield P., Gordon K., Dooley J., \& Camfield C. (1996) Melatonin appears ineffective in children with intellectual deficits and fragmented sleep: six ' $\mathrm{N}$ of 
1' trials. Journal of Child Neurology 11, 341-3.

Claustrat B., Brun J., \& Chazot G. (2005) The basic physiology and pathophysiology of melatonin. Sleep Medicine Reviews 9, 11-24.

Clayton-Smith J, \& Laan L. (1993) Angelman syndrome. A review of the clinical and genetic aspects. Journal of Medical Genetics 40, 87-95.

Dahlitz M., Alvarez B., Vignau J., English J., Arendt J., \& Parkes J. (1991) Delayed sleep phase syndrome response to melatonin. Lancet 337, 1121-4.

Didden R., Korzilius H., Duker P., \& Curfs L. M. G. (2004-I) Communicative functioning of individuals with Angelman syndrome: a comparative study. Disability \& Rehabilitation 26 1263-1267.

Didden R., Korzilius H., Smits M.G., \& Curfs L. M. G. (2004-II) Sleep problems in individuals with Angelman syndrome. American Journal of Mental Retardation 109, 275-284.

Dodge N. N., \& Wilson G. A. (2001) Melatonin for treatment of sleep disorders in children with developmental disabilities. Journal of Child Neurology 16, 581-4.

Nagtegaal J. E., Kerkhof G. A., Smits M. G., Swart A. C., \& Van Der Meer Y. G. (1998-I) Delayed sleep phase syndrome: a placebo-controlled cross-over study on the effects of melatonin administered five hours before the individual dim light melatonin onset. Journal of Sleep Research 7, 135-43.

McArthur A. J., \& Budden S. S. (1998) Sleep dysfunction in Rett syndrome: a trial of exogenous melatonin treatment. Developmental Medicine a Child Neurology 40, 186-92.

Phillips L., \& Appleton R.E. (2004) Systematic review of melatonin treatment in children with neurodevelopmental disabilities and sleep impairment. Developmental Medicine Q Child Neurology 46, 771-5.

Monteleone P., Tortorella A., Borriello R., Natale M., Cassandro P., \& Maj M. (1997) Suppression of nocturnal plasma melatonin levels by evening administration of sodium valproate in healthy humans. Biological Psychiatry 41, 336-41.

Oldani A., Ferini-Strambi L., Zucconi M., Stankov B., Fraschini F., \& Smirne S. (1994) Melatonin and delayed sleep phase syndrome: ambulatory polygraphic evaluation. Neuroreport 6, 132-4.

Peled N., Shorer Z., Peled E., \& Pillar G. (2001) Melatonin effect on seizures in children with severe neurologic deficit disorders. Epilepsia 42, 1208-10.

Ruger M., Gordijn M., Beersma D., De Vries B., \& Daan S. (2003) Acute and phaseshifting effects of ocular and extraocular light in human circadian physiology. Journal of Biological Rhythms 18, 409-19.

Sadeh A. (1996) Evaluating night wakings in sleep-disturbed infants: a methodological study of parental reports and actigraphy. Sleep 19, 757-62.

Sadeh A., Lavie P., Scher A., Tirosh E., \& Epstein R. (1991) Actigraphic homemonitoring sleep-disturbed and control infants and young children: a new 
method for pediatric assessment of sleep-wake patterns. Pediatrics 87, 494-9.

Sheldon S. H. Pro-convulsant effects of oral melatonin in neurologically disabled children. (1998) Lancet 351, 1254.

Smits M. G., Nagtegaal E. E., Van Der Heijden J, Coenen A. M., \& Kerkhof G. A. (2001) Melatonin for chronic sleep onset insomnia in children: a randomized placebo-controlled trial. Journal of Child Neurology 16, 86-92.

Smits M. G., Van Stel H. F., Van Der Heijden K., Meijer A. M., Coenen A. M., \& Kerkhof G. A. (2003) Melatonin improves health status and sleep in children with idiopathic chronic sleep-onset insomnia: a randomized placebo-controlled trial. Journal of the American Academy of Child and Adolescent Psychiatry 42, 1286-93.

Summers J. A., Allison D. B., Lynch P. S., \& Sandler L. (1995) Behaviour problems in Angelman syndrome. Journal of Intellectual Disability Research 39, 97-106.

Waldhauser F., Waldhauser M., Lieberman H. R., Deng M. H., Lynch H. J., \& Wurtman R. J. (1984) Bioavailability of oral melatonin in humans. Neuroendocrinology 39, 307-13.

Wirz-Justice A., \& Armstrong S. (1996) Melatonin: nature's soporific? Journal of Sleep Research 5, 137-41.

Zhdanova I. V., Wurtman R. J., \& Wagstaff J. (1999) Effects of low dose of melatonin on sleep in children with Angelman syndrome. Journal of Pediatric Endocrinology ar Metabolism 12, 57-67. 


\section{CHAPTER 5}

MELATONIN DECREASES DAYTIME CHALLENGING BEHAVIOUR IN PERSONS WITH INTELLECTUAL DISABILITY AND CHRONIC INSOMNIA

\section{Published as:}

Braam, W., Didden, R., Maas, A.P.H.M., Korzilius, H., Smits, M., \& Curfs, L.M.G. (2009). Melatonin decreases daytime challenging behaviour in persons with intellectual disability and chronic insomnia. Journal of Intellectual Disability Research 54, 52-9. 


\begin{abstract}
Background Persons with intellectual disability (ID) and sleep problems exhibit more daytime challenging behaviours than persons with ID without sleep problems. Several anecdotal reports suggest that melatonin is not only effective in the treatment of insomnia, but also decreases daytime challenging behaviour. However, the effect of melatonin treatment on daytime challenging behaviour in persons with ID has not been investigated in a randomized controlled trial.

Method We investigated the effects of melatonin on challenging behaviour using data from two randomized controlled trials on the efficacy of melatonin on sleep problems in 49 persons (25 men, 24 women; mean age 18.2 years, SD $=17.1$ ) with ID and chronic insomnia. Participants received either melatonin $5 \mathrm{mg}$ ( $<6$ years $2.5 \mathrm{mg}$ ) or placebo during 4 weeks. Daytime challenging behaviour was measured by the Storend Gedragsschaal voor Zwakzinnigen - Maladaptive Behaviour Scale for the Mentally Retarded (SGZ; Kraijer \& Kema, 1994) at baseline week and the end of the fourth treatment week. Salivary dim light melatonin onset (DLMO) was measured at baseline and the last day of the fourth treatment week. Sleep logs were used to gather information on sleep parameters.

Results Melatonin treatment significantly reduced SGZ scores, sleep latency, and number and duration of night wakes, and treatment increased total sleep time and advanced DLMO. However, after 4 weeks of treatment, change in SGZ scores did not significantly correlate with change in sleep parameters, nor with change in DLMO. Relatively strong correlations were found between change in SGZ scores, change in DLMO and number of night wakes.

Conclusions Melatonin treatment in persons with ID and chronic insomnia decreases daytime challenging behaviour, probably by improving sleep maintenance or by improving circadian melatonin rhythmicity.
\end{abstract}




\section{INTRODUCTION}

Sleep problems are more common in persons with intellectual disabilities (ID) than among the general population. Prevalence rates range from $15 \%$ to $88 \%$ depending on study design, participant characteristics and definition of sleep problems (Didden \& Sigafoos 2001). Compared with persons with ID, but without sleep problems, persons with ID and sleep problems exhibit more daytime challenging behaviours, irritability and lethargy, and their ability to function optimally is diminished (Wiggs \& Stores 1996; Chadwick et al. 2000; Didden et al. 2002).

The relationship between challenging behaviour and sleep problems is complex. Daytime challenging behaviour may both be a cause as well as a result of sleep problems, or be caused by a third independent variable (Didden et al. 2002).

Behavioural treatment can be effective in treating sleep problems in individuals with ID. However, evidence of a significant reduction in coexisting daytime challenging behaviour is lacking (Wiggs \& Stores 1999; Thackeray \& Richdale 2002). Melatonin improves sleep in patients with ID (Braam et al. 2009). There are several anecdotal reports suggesting that melatonin also decreases daytime challenging behaviour ( Jan et al. 1994; Jan 2000; Ivanenko et al. 2003; Coppola et al. 2004; Jan \& Freeman 2004; Carr et al. 2007), but randomized controlled trials have not been published yet.

The aim of this study therefore was to investigate the effects of melatonin treatment on daytime challenging behaviour and to explore associations between daytime challenging behaviour, chronic insomnia and melatonin circadian rhythm in a sample of 49 persons with ID. For this purpose, we evaluated data in patients with ID with chronic insomnia who participated in two randomized controlled trials in which we measured sleep parameters, circadian melatonin rhythm and daytime challenging behaviour. The sleep data of these trials were published elsewhere (Braam et al. 2008-I; Braam et al. 2008-II).

The first hypothesis of the present study was that melatonin treatment would be more effective in reducing daytime challenging behaviour in persons with ID and chronic insomnia than placebo. The second hypothesis was that there would be a significant correlation between the presence and severity of challenging behaviour and the severity of sleep problems at baseline, as well as a significant correlation between changes in challenging behaviour and changes in sleep problems between baseline and the end of the treatment period.

\section{METHODS}

Patients with ID and chronic insomnia were referred to our sleep center by local general practitioners and physicians for individuals with ID. Participants were included if no somatic and psychiatric causes for the insomnia were found, and 
general behavioural treatment and sleep hygiene measures had been unsuccessful. Patients were included if they had: (1) sleep latency of 30 min or more; or (2) two or more wakes lasting more than 45 min each night; or (3) five or more wakes lasting more than 15 min each night, during at least five nights each week. Insomnia had to be present for the duration of at least 1 year. Exclusion criteria were prior use of melatonin, restless legs, sleep apnea syndrome, liver disease, renal failure, chronic pain and age younger than 24 months. The trial consisted of two consecutive periods: (1) a 1-week qualification period; and (2) 4 weeks of treatment during which participants were randomly allocated to melatonin or placebo conditions. All medications were held constant during all study phases. During the baseline week and consecutive treatment weeks caregivers completed daily a sleep log to assess sleep. To assess circadian melatonin rhythmicity (Lewy \& Sack 1989), dim light melatonin onset (DLMO) was measured in saliva on the last night of the baseline week and on the last night of the last treatment week, as described by Nagtegaal et al. (1998).

The trial was performed in the home setting of each individual and was conducted according to the European Guidelines for Good Clinical Research Practice in Children (Committee for Proprietary Medicinal Products 1997) and followed the 1983revised provisions of the 1975 Declaration of Helsinki. The study was approved by the local Medical Ethical Committee. Written informed consent was obtained for all patients. Parents or other caregivers recorded lights off time, sleep latency, number and duration of night wakes, and wake up time in a sleep diary. Results on the efficacy of melatonin on insomnia were published previously (Braam et al. 2008-I; Braam et al. 2008-II).

\section{Treatment}

During the 4-week treatment, patients aged 6 years and older daily received 5mg melatonin (Duchefa Farma BV, Haarlem, the Netherlands) mixed with carboxymethylcellulose in a fast release tablet, or an identically looking placebo, at 7 PM. A 5-mg dose was chosen because most placebo-controlled published trials with melatonin used this dose (see Dahlitz et al. 1991; Nagtegaal et al. 1998; Smits et al. 2001; Van Wieringen et al. 2001). Patients aged under 6 years received a daily dose of $2.5-\mathrm{mg}$ melatonin at $6 \mathrm{PM}$. Compliance was tested by comparing the number of tablets returned with the number prescribed.

\section{Daytime challenging behaviour}

Parents or other caregivers completed the Storend Gedragsschaal voor Zwakzinnigen (SGZ; Maladaptive Behaviour Scale for the Mentally Retarded, Kraijer \& Kema 1994) in the baseline week and at the end of the fourth treatment week, to assess daytime challenging behaviour. The SGZ is widely used in the 
Netherlands and Dutch-speaking regions in Belgium. The scale consists of 32 items, and factor analysis has yielded three sub-scales: (1) aggressive maladaptive behaviour (SGZ-A, maximum score of 72); (2) verbal aggressive behaviour (SGZ-V, maximum score of 28); and (3) mixed maladaptive behaviour (SGZ-M, maximum score of 160). The SGZ-A contains eight items on scratching, pinching, biting, pushing, hitting, kicking, spitting or pulling hair of parents, caregivers, siblings and/or other persons. The five items of the SGZ-V are on abusive language and nagging towards caregivers and/or other persons. The SGZ-M contains 19 items on self-injurious behaviour, stealing food, pica, tearing clothes, throwing or destroying objects, hyperactivity, screaming, nagging, noncompliance, public masturbating, faeces smearing and stereotyped behaviours. Each item is rated on a 4-point Likert-type scale, ranging from ' 0 ' (behaviour did not occur) to '4' (behaviour occurs at least 5 days per week). Scores are then multiplied by 2 or 3 , depending on the degree that the specific item is more or less disturbing to others. Total scores on the three sub-scales are based upon summing up the scores of the sub-scale items. Scores from the three sub-scales may be summed to attain a total SGZ score (i.e. SGZ-T), which reflects the overall severity level of challenging behaviour (maximum score 260). The SGZ is validated for persons with ID, aged 3 years and over, and IQ 70 or less. The SGZ was found to satisfy the rigorous criteria used by the Dutch Psychological Association; its reliability and validity have been proven good (Evers 2001).

\section{Outcome measures}

Primary outcome measures were SGZ sub-scale and total scale scores, time lights went out, sleep latency, total sleep time, and number and duration of night wakes. Secondary outcome measure was DLMO to assess circadian rhythmicity (Lewy $\&$ Sack 1989). DLMO was defined as the first time at which salivary melatonin reached $4 \mathrm{pg} / \mathrm{mL}$ (Nagtegaal et al. 1998), and is the most reliable marker of circadian phase position (Lewy et al. 1999; Pandi- Perumal et al. 2007). Statistical analyses Independent samples $t$-tests were used to test whether there were differences in age and outcome measures between the melatonin and placebo group at baseline. $T$-tests for independent samples were also conducted to test differences in change between melatonin versus placebo treatment on the SGZ scores, DLMO and sleep parameters. In cases where equal variances could not be assumed (tested with Levene's test), results of $t$-tests with adjusted degrees of freedom are reported. General Linear Modelling (GLM) analysis corroborated the findings of the $t$-tests. Relationships between SGZ scores, DLMO and sleep variables were explored using Pearson's correlation coefficient. A $\chi^{2}$-test was conducted to control if the melatonin and placebo groups differed in degree of ID. Statistical significance was accepted at $P<0.05$. 


\section{RESULTS}

Sixty-six children and adults with ID and chronic insomnia were randomly assigned to melatonin or placebo conditions (Fig. 1). During the baseline week parents of one child withdrew informed consent because their child refused to cooperate with saliva sampling. Nine individuals in the placebo group and seven in the melatonin

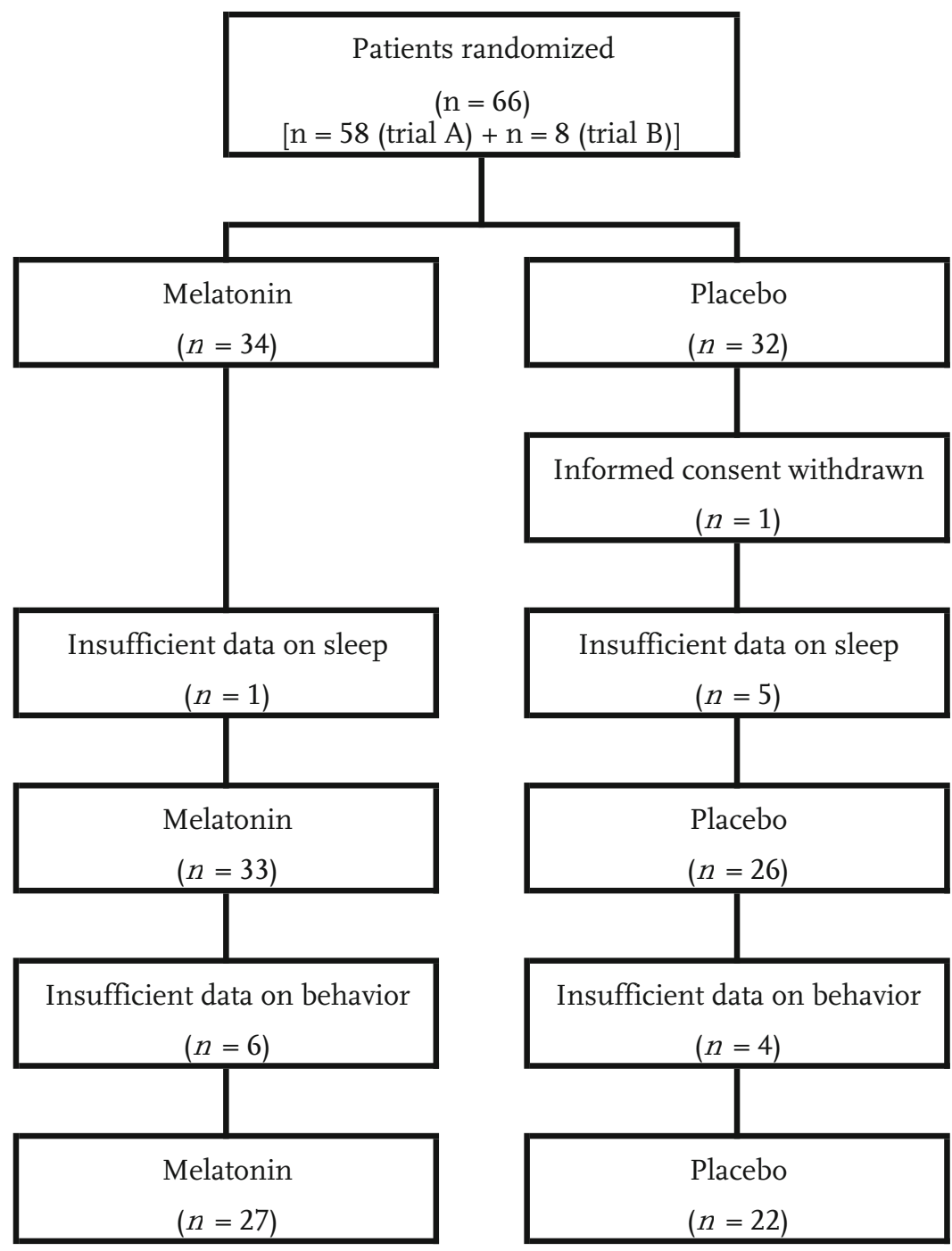

Figure 1: Trial profile.Trial A: Braam et al. (2008a); trial B: Braam et al. (2008b). 
group were excluded because parents or other caregivers did not complete the sleep log or SGZ scale.

The melatonin group consisted of 27 patients (16 men, 11 women), aged 4-78 years (mean age 18.8 years, $\mathrm{SD}=18.0)$, of whom $21(67 \%)$ were 13 years or younger and $12(33 \%)$ were 20 years or older. The degree of ID was profound $(n=11)$, severe $(n=9)$, moderate $(n=3)$ and mild $(n=4)$.

The placebo group consisted of 22 patients ( 9 men, 13 women), aged $2-58$ years (mean age 17.5 years, $\mathrm{SD}=16.5)$, of whom $16(68 \%)$ were 14 years or younger and 10 $(32 \%)$ were 20 years or older. The degree of ID was profound $(n=9)$, severe $(n=4)$, moderate $(n=3)$ and mild $(n=6)$. Mean baseline SGZ scores, sleep parameters and DLMO did not significantly differ between melatonin and placebo groups (Table 1 ). Mean age did not significantly differ between the melatonin and the placebo groups $[t(47)=0.27, P=0.79]$, as well as degree of $\operatorname{ID}\left[\chi^{2}(3)=2.03, P=0.62\right]$.

Compared with placebo, melatonin treatment significantly reduced mean SGZT and SGZ-M scores, but scores on the SGZ-V sub-scale remained unchanged. Although some items of the SGZ-A sub-scale showed a clinical improvement, mean SGZ-A score did not decrease significantly $(P=0.076)$ (Table 1$)$. SGZ items that showed a significant reduction $(\mathrm{P}<0.05)$ were hitting/kicking of parents/ caregivers $\left[\mathrm{M}_{\text {melatonin }}=-0.33, \mathrm{SD}_{\text {melatonin }}=0.68 ; \mathrm{M}_{\text {placebo }}=0.00, \mathrm{SD}_{\text {placebo }}=0.00 ; \mathrm{t}\right.$ (26) $=2.55, \mathrm{P}=0.017]$, hitting/kicking of others $\left[\mathrm{M}_{\text {melatonin }}=-0.26, \mathrm{SD}_{\text {melatonin }}=0.53\right.$; $\left.\mathrm{M}_{\text {placebo }}=0.05, \mathrm{Sd}_{\text {placebo }}=0.21 ; t(35.75)=2.75, P=0.009\right]$ and destroying objects $\left[\mathrm{M}_{\text {melatonin }}=-0.63, \mathrm{SD}_{\text {melatonin }}=1.12 ; \mathrm{M}_{\text {placebo }}=-0.09, \mathrm{SD}_{\text {placebo }}=0.29 ; t(30.36)=2.41\right.$, $P=0.022]$.

Mean sleep latency, mean duration of wakes and mean number of nights with wakes per week decreased during melatonin treatment more than during placebo treatment (mean of the difference was $34 \mathrm{~min}, 9 \mathrm{~min}$ and 0.66 respectively). Mean total sleep time increased during melatonin treatment 34 min more than during placebo, while mean DLMO advanced significantly 1:57 h more. Time patients went into bed, as well as time they woke up, did not differ significantly between baseline and the end of the fourth treatment week. So increase in total sleep time could be contributed mostly to the reduction of sleep latency and the reduction in number and duration of night wakes.

Relationship between age and Storend Gedragsschaal voor Zwakzinnigen, sleep parameters and dim light melatonin onset

At baseline there were significant correlations between age and SGZ-A scores $(r=$ -0.37, $P=0.009)$, SGZ-T scores $(r=-0.30, P=0.037)$, DLMO $(r=0.34, P=0.023)$, time lights out $(r=0.60, P \leq 0.001)$ and total sleep time $(r=-0.36, P=0.018)$. However, after 4 weeks of treatment no significant correlations between age and change in SGZ-T, sleep parameters or DLMO in the melatonin group were found. 


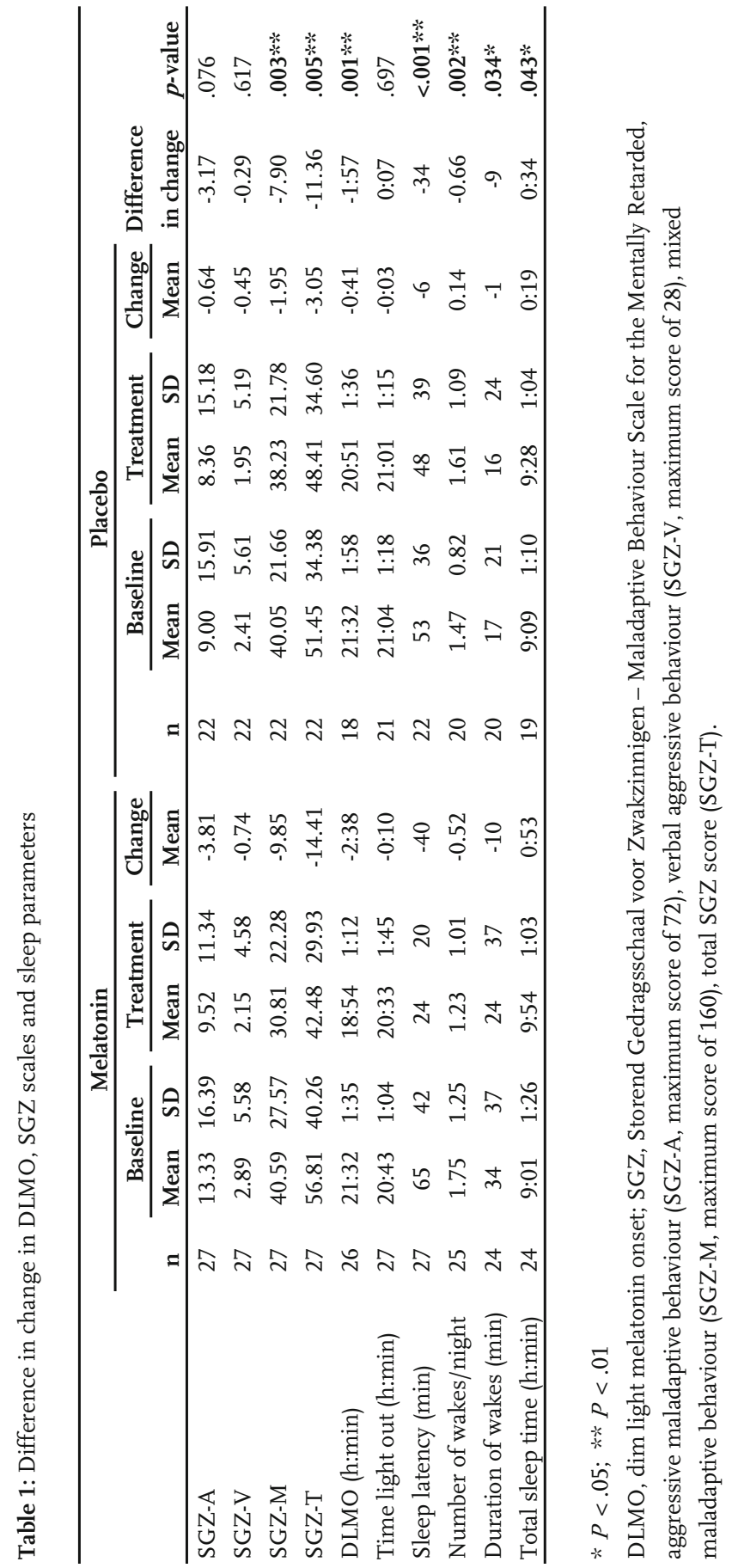


Table 2: Correlations between change in SGZ-T scores and change in DLMO and sleep parameters after 4 weeks of melatonin treatment

\begin{tabular}{lccc}
\hline & \multicolumn{3}{c}{ Change in SGZ-T scores } \\
\cline { 2 - 4 } Change in: & $\mathbf{n}$ & $\boldsymbol{r}$ & $\boldsymbol{p}$ \\
\hline DLMO & 23 & -.35 & .104 \\
Sleep latency & 27 & -.07 & .733 \\
Nights with wakes / week & 23 & .35 & .103 \\
Total sleep & 23 & .02 & .936 \\
\hline
\end{tabular}

DLMO, dim light melatonin onset; SGZ-T, total Storend Gedragsschaal voor Zwakzinnigen score.

Relationship between Storend Gedragsschaal voor Zwakzinnigen and sleep parameters and dim light melatonin onset

At baseline there were no significant correlations between SGZ-T scores, DLMO and sleep parameters except for a negative correlation between SGZ-T scores and time lights went out at bedtime $(r=-0.37, P=0.017)$. After 4 weeks of melatonin treatment, change in SGZ-T scores did not correlate significantly with change in DLMO, nor with change in any of the sleep parameters (Table 2).

\section{DISCUSSION}

Four weeks of treatment with melatonin in patients with ID with chronic insomnia was more effective in reducing challenging behaviour and sleep problems than placebo. Challenging behaviour was more prominent in children than adults, but effectiveness of melatonin treatment (in terms of difference scores) did not correlate with age. Other correlations with age at baseline were to be expected, as DLMO and sleep variables are age-related in non-disabled persons.

This is the first randomized study to support clinical experience ( Jan et al. 1994; Jan 2000; Ivanenko et al. 2003; Coppola et al. 2004; Jan \& Freeman 2004; Carr et al. 2007) that melatonin treatment not only improves sleep, but also reduces daytime challenging behaviour in persons with ID with chronic insomnia. These findings are in agreement with two other studies showing that melatonin improves daytime functioning: (1) a study in patients with neurodevelopmental disorders in which slow release melatonin improved sleep and caregiver ratings of global functioning (Wasdell et al. 2008); and (2) a study in children with chronic sleep onset insomnia and late DLMO in which melatonin improved sleep and health status (Smits et al. 2003). 
Reduction of daytime challenging behaviour after effective treatment of disordered sleep in persons with ID is generally assumed to be caused by the improvement of sleep. However, in the present study presence and severity of challenging behaviour did not correlate with severity of sleep problems at baseline, nor did we find significant correlations between change in SGZ scores and improvement in sleep at the end of the treatment period. Patients with severe sleep problems did not show more challenging behaviours than patients with milder sleep problems. And patients that showed a larger reduction of sleep problems after 4 weeks of treatment did not show a larger reduction of daytime challenging behaviour either.

Although the correlation coefficients between change in SGZ-T scores and change in number of nights with wakes per week and with change in DLMO were not statistically significant, the relative strong correlations between both $(>0.30)$ may be of interest (Table 2). It is plausible that the reduction of daytime challenging behaviour is not caused by one single factor, such as the improvement of sleep (i.e. reduced sleep latency and increased total sleep time), but also by the correction of a disturbed melatonin circadian rhythm, as a second variable. The relation between change in SGZ-T scores and change in DLMO, respectively, number of nights with wakes per week points in this direction. Melatonin is a chronobiotic drug with some hypnotic properties (Wirz-Justice \& Armstrong 1996). Therefore, it is plausible that the reduction of daytime challenging behaviour could be attributed to the chronobiotic action of melatonin. This also implies that it is possible that daytime challenging behaviours in our patients with ID not only were caused by poor sleep maintenance, but more or less also were related to a misalignment or other disturbance of the circadian melatonin rhythm.

One other possibility needs consideration, that is, a direct influence of melatonin on mood as a possible underlying cofactor causing problem behaviour. Sleep-wake disorders are frequently seen in persons with affective and depressive disorders. They may provoke manic episodes and can act as an independent risk factor for depression recurrence. This means that circadian sleep-wake rhythm dysfunction can play an aetiological role rather than being the result of psychiatric disorders (Leibenluft 2008). Maybe melatonin reduces daytime challenging behaviour indirectly by influencing mood.

The timing of the administration of melatonin is very important in its efficacy. We administered melatonin at a fixed time. Consequently, an age-dependent treatment effect could be expected. However, we could not demonstrate this, probably because the number of patients was too small and the measurements of treatment effects too rough. Although SGZ, DMLO and sleep parameters were not significantly different between the melatonin and placebo groups at baseline, there were age differences and differences in severity within the groups. However, 
we controlled for these differences analyzing the treatment effects and found no influence at the outcome measures.

Some limitations of the present study need consideration. First, we pooled data of two studies (Braam et al. 2008-I; Braam et al. 2008-II). However, both had the same study design and were performed at the same time window. A second limitation is that we used diaries to measure sleep. Diary measures obviously have measurement errors, but are frequently used in non-clinical settings. However, the measurement error is the same for treatment and placebo. Sleep diaries based on observations by others yield more satisfactory data than sleep diaries based on self-report (Ancoli-Israel et al. 2003). Besides, parents of sleep-disturbed infants have been shown to be accurate reporters of actigraphically assessed sleep onset and sleep duration (Sadeh et al. 1991). Therefore, we think that diary measures based on observations by parents and other caregivers can be used in assessing sleep parameters.

We included only participants that fulfilled strict criteria for duration and severity of their sleep problems. Next to this, for participants to be included both sleep hygiene measures and behavioural approaches had been implemented but remained unsuccessful in decreasing their sleep problems. Future studies should assess generality of our conclusions. In this study also sleep efficacy could be taken into account. We failed to measure sleep efficiency, for example, by using actigraphy. In our clinical study, we could not calculate sleep efficiency because parents only recorded the time their child woke up but failed to record the time their child went out of his/her bed. As a result, sleep efficiency could not be calculated.

\section{CONCLUSIONS}

Results of our study suggest that melatonin treatment can be effective in patients with ID with daytime challenging behaviour and chronic insomnia. Further studies are needed to confirm these findings.

\section{REFERENCES}

Ancoli-Israel S., Cole R., Alessi C., Chambers M., Moorcroft W., \& Pollak C. P. (2003) The role of actigraphy in the study of sleep and circadian rhythms. Sleep 26, 342-92.

Braam W., Didden R., Smits M. G., \& Curfs L. M. G. (2008-I) Melatonin treatment in individuals with intellectual disability and chronic insomnia: a randomized placebo-controlled study. Journal of Intellectual Disability Research 52, 256-64.

Braam W, Didden R, Smits M G, Curfs L M. G. (2008-II) Melatonin for chronic insomnia in Angelman syndrome: a randomized placebo-controlled trial. 
Journal of Child Neurology 23, 649-54.

Braam W., Smits M. G., Didden R., Korzilius H., Van Geijlswijk I. M., \& Curfs L. M. G. (2009) Exogenous melatonin for sleep problems in individuals with intellectual disability: a meta-analysis. Developmental Medicine a Child Neurology 51, 340-9.

Carr R., Wasdell M.B., Hamilton D., Weiss M.D., Freeman R.D., Tai J., Rietveld W., \& Jan J.E. (2007) Long-term effectiveness of melatonin therapy in children with treatment-resistant circadian rhythm sleep disorders. Journal of Pineal Research 43, 351-9.

Chadwick O., Piroth N., Walker J., Bernard S., \& Taylor E. (2000) Factors affecting the risk of behaviour problems in children with severe intellectual disability. Journal of Intellectual Disability Research 44, 108-23.

Committee for Proprietary Medicinal Products (1997) Note for guidance on clinical investigation of medicinal products in children, CPMP/EWP/462/95. London: The European Agency for the Evaluation of Medicinal Products.

Coppola G., Iervolino G., Mastrosimone M., La Torre G., Ruiu F., \& Pascotto A. (2004) Melatonin in wake-sleep disorders in children, adolescents and young adults with mental retardation with or without epilepsy: a double-blind, crossover, placebo-controlled trial. Brain \& Development 26, 373-6.

Dahlitz M., Alvarez B., Vignau J., English J., Arendt J., \& Parkes J. (1991) Delayed sleep phase syndrome response to melatonin. Lancet 337, 1121-4.

Didden R., \& Sigafoos J. (2001) A review of the nature and treatment of sleep disorders in individuals with developmental disabilities. Research in Developmental Disabilities 22, 255-72.

Didden R., Korzilius H., Van Aperlo B., Van Overloop C., \& De Vries M. (2002) Sleep problems and daytime problem behaviours in children with intellectual disability. Journal of Intellectual Disability Research 46, 537-47.

Evers A. (2001) Improving test quality in the Netherlands: results of 18 years of test ratings. International Journal of Testing 1, 137-53.

Ivanenko A., McLaughlin Crabtree V., Tauman R., \& Gozal D. (2003) Melatonin in children and adolescents with insomnia: a retrospective study. Clinical Pediatrics 42, 51-8.

Jan M. M. S. (2000) Melatonin for the treatment of handicapped children with severe sleep disorders. Pediatric Neurology 23, 229-32.

Jan J. E., \& Freeman R. D. (2004) Melatonin therapy for circadian rhythm sleep disorders in children with multiple disabilities: what have we learned in the last decade. Developmental Medicine a Child Neurology 46, 776-82.

Jan J. E., Espezel H., \& Appleton R. E. (1994) The treatment of sleep disorders with melatonin. Developmental Medicine Q Child Neurology 36, 97-107.

Kraijer D. W., \& Kema G. N. (1994). SGZ, Storend Gedragsschaal voor Zwakzinnigen: 
Handleiding. (Maladaptive Behaviour Scale for the Mentally Retarded), 5th edn. Lisse: Swets \& Zeitlinger.

Leibenluft E. (2008) The rhythm of the blues. The American Journal of Psychiatry $165,1501-4$.

Lewy A. J., \& Sack R. L. (1989) The dim light melatonin onset as a marker for circadian phase position. Chronobiology International 6, 93-102.

Lewy A. J., Cutler N. L., \& Sack R. L. (1999) The endogenous melatonin profile as a marker for circadian phase position. Journal of Biological Rhythms 14, 227-36.

Nagtegaal J. E., Kerkhof G. A., Smits M. G., Swart A. C., \& Van Der Meer Y. G. (1998) Delayed sleep phase syndrome: a placebo-controlled cross-over study on the effects of melatonin administered five hours before the individual dim light melatonin onset. Journal of Sleep Research 7, 135-43.

Pandi-Perumal S. R., Smits M., Spence W., Srinivasan V., Cardinali D. P., Lowe A. D., \& Kayumov L. (2007) Dim light melatonin onset (DLMO): a tool for the analysis of circadian phase in human sleep and chronobiological disorders. Progress in Neuro-Psychopharmacology a Biological Psychiatry 31, 1-11.

Sadeh A., Lavie P., Scher A., Tirosh E., \& Epstein R. (1991) Actigraphic homemonitoring sleep-disturbed and control infants and young children: a new method for pediatric assessment of sleep-wake patterns. Pediatrics 87, 494-9.

Smits M. G., Nagtegaal E. E., Van Der Heijden J, Coenen A. M., \& Kerkhof G. A. (2001) Melatonin for chronic sleep onset insomnia in children: a randomized placebo-controlled trial. Journal of Child Neurology 16, 86-92.

Smits M. G., Van Stel H. F., Van Der Heijden K., Meijer A. M., Coenen A. M., \& Kerkhof G. A. (2003) Melatonin improves health status and sleep in children with idiopathic chronic sleep-onset insomnia: a randomized placebocontrolled trial. Journal of the American Academy of Child and Adolescent Psychiatry 42, 1286-93.

Thackeray E. J., \& Richdale A. L. (2002) The behavioural treatment of sleep difficulties in children with an intellectual disability. Behavioral Interventions 17, 211-31.

Van Wieringen S., Jansen T., Smits M. G., Nagtegaal J. E., \& Coenen A. M. L. (2001) Melatonin for chronic whiplash syndrome with delayed melatonin onset. Randomized, placebo-controlled trial. Clinical Drug Investigation 21, 813-20.

Wasdell M. B., Jan J. E., Bomben M. M., Freeman R. D., Rietveld W. J., Tai J., Hamilton D., \& Weiss M.D. (2008) A randomized, placebo-controlled trial of controlled release melatonin treatment of delayed sleep phase syndrome and impaired sleep maintenance in children with neurodevelopmental disabilities. Journal of Pineal Research 44, 57-64.

Wiggs L., \& Stores G. (1996) Severe sleep disturbance and daytime challenging behaviour in children with severe learning disabilities. Journal of Intellectual 
Disability Research 40, 518-28.

Wiggs L., \& Stores G. (1999) Behavioural treatment for sleep problems in children with severe learning disabilities and challenging daytime behaviour: effect on daytime behaviour. Journal of Child Psychology and Psychiatry and Allied Disciplines 40, 627-35.

Wirz-Justice A., \& Armstrong S. (1996) Melatonin: nature's soporific? Journal of Sleep Research 5, 137-41. 


\title{
CHAPTER 6
}

\author{
LOSS OF RESPONSE TO MELATONIN TREATMENT \\ IS ASSOCIATED WITH SLOW MELATONIN METABOLISM
}

\section{Published as}

Braam W., Van Geijlswijk I., Keijzer, H., Smits M.G., Didden R., Curfs L. M. G. (2010) Loss of response to melatonin treatment is associated with slow melatonin metabolism. Journal of Intellectual Disability Research 54, 547-55. 


\begin{abstract}
Background In some of our patients with intellectual disability (ID) and sleep problems, the initial good response to melatonin disappeared within a few weeks after starting treatment, while the good response returned only after considerable dose reduction. The cause for this loss of response to melatonin is yet unknown. We hypothesize that this loss of response is associated with slow melatonin metabolism.

Method In this study we determined melatonin clearance in two female (aged 61 and 6 yr.) and one male (aged 3 yr.) patients who had chronic insomnia, late melatonin onset and mild ID, and whose sleep quality worsened a few weeks after initial good response to melatonin treatment, suggesting melatonin tolerance. After a 3 week washout period, patients received melatonin 1.0, 0.5 or $0.1 \mathrm{mg}$ respectively. Salivary melatonin level was measured just before melatonin administration, and 2 and 4 hours thereafter. After this melatonin clearance test, melatonin treatment was resumed with a considerably lower dose.

Results In all patients melatonin concentrations remained $>50 \mathrm{pg} / \mathrm{ml}$ at 2 and 4 hours after melatonin administration. After resuming melatonin treatment sleep problems disappeared. The same procedure was followed in 3 patients who did not show loss of response to melatonin after 6 months of treatment. In all patients in the control group melatonin concentrations decreased between 2 and 4 hours after melatonin administration with a mean of $83 \%$.

Conclusion We hypothesize that loss of response to melatonin treatment can be caused by slow metabolization of exogenous melatonin. As melatonin is metabolized in the liver almost exclusively by cytochrome P450 enzyme CYP1A2, this slow melatonin metabolism is probably due to decreased activity/ inducibility of CYP1A2. In patients with loss of response to melatonin, a melatonin clearance test should be considered and a considerably dose reduction is advised.
\end{abstract}




\section{INTRODUCTION}

In our double-blind, placebo-controlled, parallel study in children with Angelman syndrome, some parents reported loss of response (i.e. return of night wakes) after 4 weeks of melatonin $(5.0 \mathrm{mg} \geq 6$ year and $2.5 \mathrm{mg}<6$ year) treatment (Braam et al. 2008). Evening salivary melatonin levels were measured at baseline and after 4 weeks of treatment on a day no study medication was given. Melatonin levels in 3 of the 4 patients who received melatonin, were extremely high $(>50 \mathrm{pg} /$ $\mathrm{ml}$ ) after 4 weeks of treatment, while they were very low at baseline. In response to these high levels we lowered the melatonin dose to $0.1 \mathrm{mg}$, which resulted in substantially improved sleep. We postulated that these patients with loss of response to melatonin treatment, possibly as a result of enduring high melatonin levels, were CYP1A2 poor metabolizers.

From that time we have seen several patients with an intellectual disability (ID) who responded initially well on melatonin in the adequately timed dose (3-5 $\mathrm{mg}$ in adults and 1-2.5 $\mathrm{mg}$ in children aged 5-12 yr). The initial good response disappeared after a few weeks of treatment, but returned when the dose was lowered considerably ( $0.1-0.5 \mathrm{mg}$ ), while time of administration did not change.

Exogenous melatonin is a chronobiotic drug with some hypnotic properties (Zhdanova et al.1997). It advances sleep onset in adults (Nagtegaal et al. 1998) and children (Smits et al. 2003; Van der Heijden et al. 2007) with chronic sleep onset insomnia and late endogenous dim light melatonin onset (DLMO), and it improves sleep in patients with ID (Braam et al. 2009). Melatonin advances sleepwake and other circadian rhythms maximally in adults when it is administered 5 to 6 hours before DLMO (Lewy et al. 1992), while soporific effects occur within 30 to 60 minutes after intake (Zhdanova 2005).

The effective dose of melatonin still remains a matter of discussion. When the dose is too low, melatonin does not influence circadian rhythmicity. When the dose is too high melatonin does not work anymore because melatonin levels remain high and lose rhythmicity (Lewy et al. 2005). Dollins et al. (1994), in a study comparing the effects of a wide range of melatonin doses $(0.1-10 \mathrm{mg})$, reported that the efficacy of low $(0.1-0.3 \mathrm{mg})$ 'physiological doses' (i.e. doses resulting in serum melatonin levels within normal nocturnal range), did not significantly differ from the efficacy of pharmacological doses $(1.0-10 \mathrm{mg})$ in promoting sleep when administered during the day to young healthy subjects. According to Zhdanova (2005) doses to induce physiologic circulating melatonin levels $(0.1$ $-0.5 \mathrm{mg}$ ) are sufficient to promote sleep and to induce circadian phase shift, whereas too high doses may cause side effects, i.e. circadian rhythm alterations and possibly desensitize melatonin receptors.

Melatonin is metabolized in the liver almost exclusively by cytochrome P450 enzyme CYP1A2 to its main primary metabolite 6-hydroxymelatonin, than 
conjugated to sulphate, and excreted in urine (Claustrat et al. 2005). In most individuals exogenous melatonin has a half-life between 35 and 45 minutes (Fourtillan et al. 2000). Caffeine clearance is considered as the gold standard for assessment of the CYP1A2 activity, because more than $90 \%$ of the primary metabolism of caffeine depends on CYP1A2 (Härtter et al. 2006). However, as melatonin is metabolized more exclusively by CYP1A2, melatonin has been proposed as an alternative probe drug for CYP1A2 activity (Härtter et al. 2001).

There are large inter-individual differences in plasma levels after oral administration of melatonin as high as 37 -fold, as well as a 2.5 -fold difference in bioavailability of melatonin between females and males. These differences can be attributed to inter-individual variation of the first-pass effect through the liver and the activity of gastrointestinal CYP (Fourtillan et al. 2000).

Reports on loss of response, after initial good response to melatonin treatment are scarce, and in some reports the development of tolerance to melatonin was suggested, because sleep improved temporary when increasing the melatonin dose. We hypothesize that, what we call loss of response to melatonin treatment can be explained by slow metabolism of melatonin, resulting in such an increase of melatonin levels that melatonin rhythmicity disappears. Consequently melatonin loses its chronobiotic and hypnotic effects. Therefore the melatonin dose has to be reduced instead of being increased. To evaluate this hypothesis, we studied melatonin metabolism in three patients showing loss of response to melatonin treatment, and in three patients that did not show signs of loss of response after 6 months of melatonin use.

\section{METHODS}

We studied three patients with loss of response to melatonin treatment, i.e. patients who initially responded very well to melatonin therapy, but in whom this effect was lost after several weeks of therapy and sleep problems eventually became worse than before therapy started. They visited our expert center for patients with sleep disturbances and ID. In these patients parents and other caregivers completed daily a sleep log to assess sleep. The rate of melatonin metabolization was assessed with a clearance test. At 11 a.m., 1 p.m. and 3 p.m. saliva samples were collected in Salivette $₫$ tubes (Sarstedt, Nümbrecht, Germany) by chewing on a cotton swab for 1-2 minutes. Immediately after the first sample collection melatonin $(1 \mathrm{mg}, 0.5 \mathrm{mg}$ or $0.1 \mathrm{mg}$ respectively) was taken. Melatonin levels were measured in saliva with a Radio Immuno Assay (RIA) (Buhlmann laboratories, Schönenbuch, Switzerland) as previous described (Nagtegaal et al. 1998). Radio activity was counted with the PerkinElmer 1470 Wizard gamma counter (PerkinElmer Nederland B.V., Groningen, The Netherlands). The linear range is between 0.5 and $50 \mathrm{pg} / \mathrm{ml}$. When 
exceeding the linear range the samples were diluted, provided that there was sufficient sample amount.

From the time we became aware of possible slow melatonin metabolism, we perform the melatonin clearance test in all patients who are going to be treated with melatonin. Patients who did not show loss of response to melatonin after 6 months of treatment were considered normal melatonin metabolizers. Initial data from three patients, who did not show signs of loss of response to melatonin after 6 months of treatment, were used as controls in this study.

\section{RESULTS}

Case 1

Case 1 is a 61 year old woman with a mild ID, for which no cause had been identified, who was admitted to our sleep clinic because of severe sleep onset problems. She lived in a group home for over 20 years and had never been able to fall asleep before $1 \mathrm{AM}$ In the morning however, she was sleepy when she had to get up at 8 AM There were no physical problems that could account for her sleep onset problems. She suffered from epilepsy which was treated by carbamazepine (800 $\mathrm{mg})$, lamotrigine $(200 \mathrm{mg}$ ) and phenobarbital $(35 \mathrm{mg})$. Despite this medication, she had a generalized epileptic attack two or three times a year on average.

DLMO occurred at 10:58 pm (Table 1), consistent with a delayed sleep phase syndrome. She was prescribed $5 \mathrm{mg}$ melatonin at $9 \mathrm{PM}$, the usual time evening medication was given by her caregivers. She was advised to go to bed at $10 \mathrm{PM}$, but she refused to do so as this would result in a major change in her lifestyle. So we compromised at $11 \mathrm{PM}$ and to go to bed at midnight. Two weeks later she told us that she was very satisfied with the result. She now took her melatonin at 10 PM and fell asleep before 11 PM Moreover, she told, she felt no longer sleepy the next morning.

Three months later she returned to our sleep clinic, complaining that since 4 weeks "her sleeping pill did not work anymore". She told us that she could not fall asleep before 0:30 AM and felt sleepy again in the morning. A caregiver accompanying her, informed us that she was very irritable and had mood swings at daytime.

The results of the melatonin measurements are summarized in Table 1. Melatonin levels at the end of the evening, on an evening we asked her to take no melatonin, and in the middle of the next day, were $>50 \mathrm{pg} / \mathrm{ml}$. The melatonin clearance test, using $1 \mathrm{mg}$ melatonin, performed three weeks after stopping the melatonin treatment, showed that salivary melatonin concentration remained $>50 \mathrm{pg} / \mathrm{ml}$ during 6 hours after administration of melatonin (Table 2; Fig. 1). We concluded that she was CYP1A2 poor metabolizer. Therefore we lowered the 


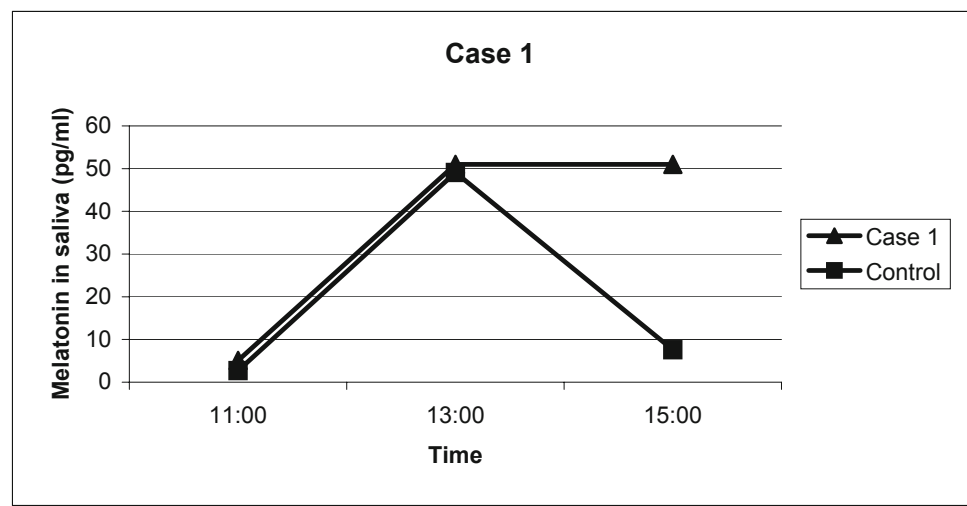

Figure 1: Melatonin clearance test in Case 1 and control. Melatonin in saliva before and after 1mg melatonin at 11:00 AM.

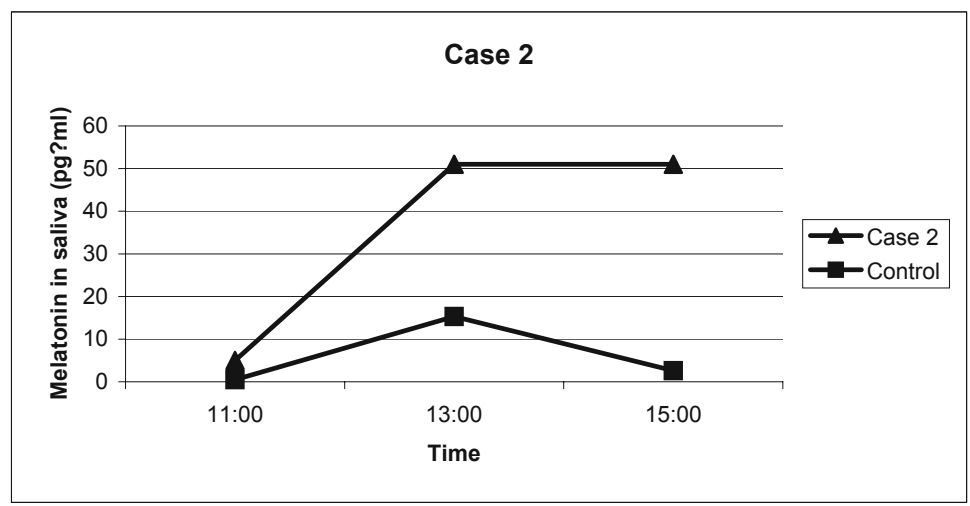

Figure 2: Melatonin clearance test in Case 2 and control. Melatonin in saliva before and after 0,5mg melatonin at 11:00 AM.

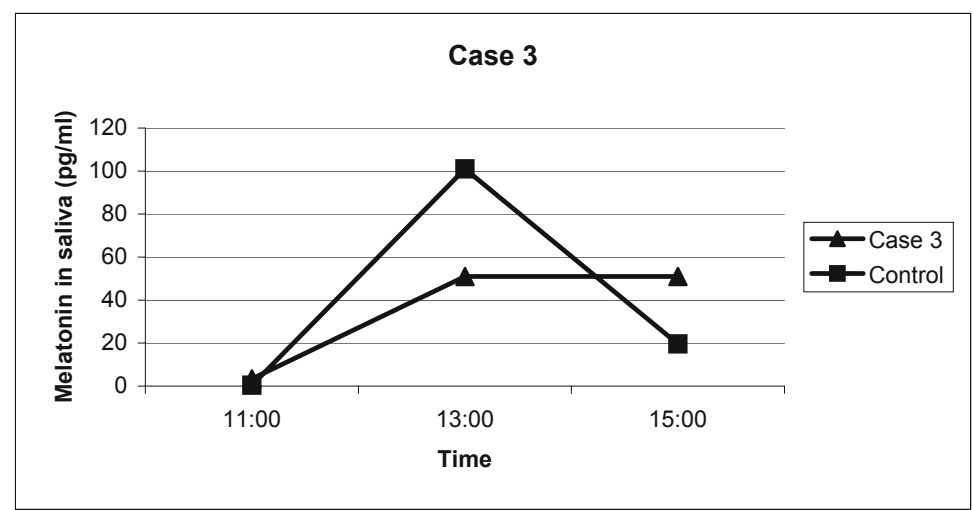

Figure 3: Melatonin clearance test in Case 3 and control. Melatonin in saliva before and after 0,1mg melatonin at 11:00 AM. 
melatonin dose to $0.5 \mathrm{mg}$. As a result her sleep onset problems disappeared, as did her complaints about feeling sleepy in the morning. Her irritability and mood swings also had disappeared. Six months later positive effect of melatonin was still present with $0.5 \mathrm{mg}$ melatonin at $10 \mathrm{PM}$.

\section{Case 2}

Case 2 is a 6 year old girl, who was referred to our sleep center because of sleep onset and sleep maintenance problems, that existed for several years. She had a mild ID, for what a comprehensive genetic examination had not revealed a cause. She was put to bed at 8:30 PM and could only fall asleep when her mother was sitting at her bedside. Even then it took over one hour for her to fall asleep. One or two times every night she went to her mother's bedroom and tried to get into her bed. Her mother had to force her to go back to her own bed, and it took another hour to put her back to sleep.

At admission, DLMO occurred at 9:18 p.m. (Table 1). Melatonin $2.5 \mathrm{mg}$ was administered at 7:30 PM. Four weeks after start of melatonin treatment, her mother informed us that she was very satisfied with the results. Her daughter became sleepy within half an hour after taking melatonin and fell asleep before 8:30 PM. Only two or three nights a week she went to her mother's bed in the middle of the night, but could easily be brought back to her own bed. At daytime she played with more concentration and was not hyperactive anymore.

One month later, however, her mother complained that her daughter's sleep maintenance problems had slowly returned. She even woke up more often during the night, and earlier in the morning, than before melatonin treatment. Also, sleep latency had become longer and at daytime she again showed hyperactive behaviours. Her mother had doubled melatonin dose on her own initiative, because she thought her daughter had developed tolerance to the treatment, but this failed to have an effect on her daughter's sleep problems. Salivary melatonin levels during the day and night were all $>50 \mathrm{pg} / \mathrm{ml}$, on a day no exogenous melatonin was taken (Table 1). After a wash-out period of 2 weeks, the melatonin clearance test showed that salivary melatonin levels remained $>50 \mathrm{pg} / \mathrm{ml}$ during 6 hours after administration of melatonin $0.5 \mathrm{mg}$ (Table 2; Fig. 2). Therefore we concluded that she was CYP1A2 poor metabolizer. Melatonin treatment was resumed with $0.5 \mathrm{mg}$ at 8:30 PM. This resulted in advancement of sleep onset and better sleep maintenance. Her mother told that she had not slept as well as now since many years. She also was not hyperactive anymore. These positive effects were still present 6 months later.

\section{Case 3}

Case 3 is a 3 -year old boy with Down syndrome, who attended the sleep center because of sleep maintenance problems and early waking since one year. He also 
Table 1: Melatonin $(\mathrm{pg} / \mathrm{ml})$ in saliva before treatment start and during treatment when response was lost.

\begin{tabular}{|c|c|c|c|}
\hline & \multicolumn{3}{|c|}{ Prior to treatment start } \\
\hline & Case 1 & Case 2 & Case 3 \\
\hline 6:00 PM & & $<0.5$ & $*$ \\
\hline 7:00 PM & & $<0.5$ & $*$ \\
\hline 8:00 PM & & \# & $*$ \\
\hline 9:00 PM & 2.6 & 2.0 & $*$ \\
\hline 10:00 PM & 1.1 & 8.8 & $*$ \\
\hline 11:00 PM & 4.1 & & \\
\hline 12:00 AM & 5.1 & & \\
\hline 1:00 AM & 7.6 & & \\
\hline \multirow[t]{3}{*}{ DLMO } & 10:58 PM & 9:18 PM & $*$ \\
\hline & \multicolumn{3}{|c|}{ After loss of response } \\
\hline & Case 1 & Case 2 & Case 3 \\
\hline 12:00 PM & $>50.0$ & $>50.0$ & $>50$ \\
\hline 4:00 PM & $>50.0$ & $>50.0$ & \# \\
\hline 6:00 PM & & $>50.0$ & $>50$ \\
\hline 7:00 PM & & $>50.0$ & $>50$ \\
\hline 8:00 PM & & $>50.0$ & $>50$ \\
\hline 9:00 PM & $>50.0$ & $>50.0$ & $>50$ \\
\hline 10:00 PM & $>50.0$ & $>50.0$ & $\#$ \\
\hline 11:00 PM & $>50.0$ & & \\
\hline 12:00 AM & $>50.0$ & & \\
\hline 1:00 AM & $>50.0$ & & \\
\hline
\end{tabular}

* No melatonin levels measured prior to start melatonin treatment.

\# Not enough saliva collected for assessment melatonin levels.

had settling problems since his mother had stopped breastfeeding when he was 6 months old. He could only fall asleep when in the arms of his mother. Because of recommendations of friends, who also had a disabled child, his mother had asked her general practitioner for a melatonin prescription. Melatonin $1 \mathrm{mg}$ had an instant success. Unfortunately, frequent night wakes returned after four weeks, and the boy's parents stopped giving him melatonin. But because he did not fall asleep before $10 \mathrm{PM}$, parents started to give him melatonin again, in spite of the sleep maintenance worsening. At our sleep center we saw a hyperactive boy with Down syndrome. We advised to stop melatonin medication, and asked parents to take salivary samples. Two days after discontinuing melatonin treatment, melatonin levels were $>50 \mathrm{pg} / \mathrm{ml}$ at noon as well as in the afternoon and evening (Table 1). Two weeks later, without melatonin, parents told that night wakes had 
Table 2: Melatonin clearance test in Case 1, 2 and 3 and in 3 control patients

\begin{tabular}{|c|c|c|c|c|c|c|}
\hline \multirow{4}{*}{$\begin{array}{r}\text { Melatonin dose } \\
\text { Melatonin }(\mathrm{pg} / \mathrm{ml}) \text { in saliva }\end{array}$} & \multicolumn{6}{|c|}{ Melatonin clearance test } \\
\hline & \multirow{2}{*}{$\begin{array}{c}\text { Case } 1 \\
1 \mathrm{mg}\end{array}$} & \multirow{2}{*}{$\begin{array}{l}\text { Case } 2 \\
0.5 \mathrm{mg}\end{array}$} & \multirow{2}{*}{$\begin{array}{l}\text { Case } 3 \\
0.1 \mathrm{mg}\end{array}$} & \multirow{2}{*}{$\begin{array}{c}\text { Control } 1 \\
1 \mathrm{mg}\end{array}$} & \multirow{2}{*}{$\begin{array}{c}\text { Control } 2 \\
0.5 \mathrm{mg} \\
\end{array}$} & \multirow{2}{*}{$\begin{array}{c}\text { Control } 3 \\
0.5 \mathrm{mg} \\
\end{array}$} \\
\hline & & & & & & \\
\hline & & & & & & \\
\hline 11:00 AM & 5.1 & 5.0 & 3,4 & 2,7 & 0,5 & 0,4 \\
\hline 1:00 PM & $>50.0$ & $>50.0$ & $>50$ & 49,1 & 15,3 & $>100$ \\
\hline 3:00 PM & $>50.0$ & $>50.0$ & $>50$ & 7,6 & 2,6 & 19,6 \\
\hline Melatonin half time (min) & \# & \# & \# & 44 & 46 & $<50$ \\
\hline
\end{tabular}

\# $\mathrm{T}^{\mathrm{T}} / 2$ can not be determined

disappeared, but that sleep onset problems still existed. At that time melatonin levels had returned to normal low levels. The melatonin clearance test, performed 3 days later, using $0.1 \mathrm{mg}$ melatonin, showed that salivary melatonin levels remained $>50 \mathrm{pg} / \mathrm{ml}$ during 6 hours after administration of melatonin (Table 2; Fig. 3). Therefore we concluded that he was CYP1A2 poor metabolizer.

Two weeks later sleep latency became longer than 2 hours and parents asked for medication. We resumed melatonin in a lower dose $(0.1 \mathrm{mg})$. As a result of this, sleep latency was reduced to 15 minutes or shorter. Only once a week their son woke up in the middle of the night, but could be brought back to his bed easily. At follow up 6 months later, these results were still preserved.

\section{Control subjects}

Three patients that visited our sleep center, aged 40, 12 and 8 years of age respectively, that did not show signs of loss of response to melatonin treatment after 6 months of treatment, served as control patients. Their melatonin clearance tests prior to the start of the melatonin treatment, showed a normal profile with a mean $83 \%$ decline in melatonin levels. Half-life of melatonin was 44,46 and $<50$ minutes respectively (Table 2 ).

\section{DISCUSSION}

Melatonin metabolism was measured in three ID patients that showed a remarkable return of sleep problems after an initial about 4-weeks lasting good response to melatonin treatment. In these patients sleep improved again after lowering the melatonin dose considerably. The melatonin clearance test in these three patients showed very high levels of melatonin even 6 hours after intake of melatonin, supporting the view that exogenous melatonin was metabolized much slower than in control patients who remained good melatonin responders during 
at least 6 months of melatonin treatment. Therefore we concluded that these three patients are CYP1A2 poor metabolizers.

For CYP1A2, metabolism of most substrates can be described using the Michaelis-Menten equation, demonstrating saturation kinetics. For some substrates in higher concentration the model seems inadequate, suggestive of a two binding sites model, either inhibitory or cooperative (Miller \& Guengerich 2001; Lin 2001). Saturation will fortify the effects of exogenous melatonin in poor metabolizers. Poor metabolizers will initially experience disproportional long lasting higher serum levels after normal doses resulting in effective therapy. During the first stage of saturation they will experience disproportional increase in serum levels after a normal dose, thus still resulting in effective therapy. Finally such a high level will be reached, that a next dose won't result in an effective increase of serum level. This could be the explanation for delayed onset of these effects and the huge impact of dosage reduction. The delay in the loss of response to melatonin treatment and the effectiveness of dose reduction with restoration of rhythmicity can be attributed to the saturation phenomenon, with eventually much extended elimination half life values for melatonin.

Several reports indicate that single nucleotide polymorphisms in the CYP1A2 gene are associated with increased inducibility, decreased activity or inducibility or even loss of activity of the CYP1A2 enzyme as compared tot the wild type (Sachse et al. 1999; Nakajima et al. 1999; Chevalier et al. 2001; Zhou et al. 2009-I; Zhou et al. 2009-II). The (sub)variant alleles associated with decreased of absent activity of CYP1A2 are *1C, *1K, *3, *4,*5,*6 and *7.The CYP1A2 locus is found on chromosome 15q24.1 (NCBI 2010). The proportion of individuals with the slow phenotype narrowly ranges from 12 - 14\% (Butler et al. 1992; Nakajima et al. 1994), but varies among ethnic populations (Zhou et al. 2009-I).

As far as we know this is the first study on the association between loss of response to melatonin treatment, and slow metabolization of melatonin. Until now, there are only a few anecdotal reports that melatonin can lose its effect during long term use, all in ID persons. McArthur \& Budden (1998), in a doubleblind, placebo-controlled, crossover study in 9 children (age 4 - 17 years) with Rett syndrome, found melatonin (2.5 - $7.5 \mathrm{mg}$ depending on age and body weight) to be effective in reducing sleep latency during the first 3 weeks of the study. However, this positive effect was lost in the fourth treatment week, when mean sleep latency became even worse than with placebo. Also Ishizaki et al. (1999), in a study on 50 children and young adults with ID, reported that in some cases the effectiveness of melatonin was diminished in the course of the study. Jan et al. (2000), in a study to examine effective doses of controlled-release melatonin in 42 children with chronic sleep-wake cycle disorders and severe neurodevelopmental difficulties, reported that 4 children developed tolerance to the treatment, but that 
this was difficult to prove because in patients with neurodevelopmental disorders other unrecognized causes of sleep disturbance can emerge, incorrectly suggesting tolerance. Andersen et al. (2008), in a retrospective study on 107 children with autism spectrum disorders that were prescribed melatonin for insomnia, found 7 cases in which sleep initially improved, but sleep problems returned, despite dose escalation. In these four studies, however, possible causes were not studied. In some reported cases of loss of response to melatonin treatment the development of tolerance to melatonin was suggested, because sleep improved temporarily when increasing the melatonin dose. Results from our study, however, show that loss of response to melatonin treatment is not caused by melatonin tolerance, but by slow metabolizing of melatonin. In tolerance (also called tachyphylaxis, i.e. with nitrates) there is a diminution of the response to a drug after continued use, necessitating larger doses to restore the response. Wearing-off is normally spoken used in context of end of dose phenomenon: e.g. in Parkinson's disease, prior to the next dose of levodopa. In the last hours before the next dose of levodopa, especially the kinetic symptoms of Parkinson worsen seriously. In our patients, however, a lasting melatonin effect only returned after lowering of the dose; therefore we probably best describe this observation as loss of response.

Results from this study indicate that loss of response to melatonin treatment is associated with slow melatonin metabolization. This may result in increasing daily melatonin levels. Consequently after some time this will lead to highly cumulated melatonin levels and the circadian melatonin rhythm is lost. This loss of circadian rhythm might explain why exogenous melatonin in our cases lost its effectiveness. Lewy et al. (2002), describing a blind patient with a free-running circadian rhythm, who could be entrained to $0.5 \mathrm{mg}$ of melatonin but not to 20 mg, was the first who showed that melatonin loses its chronobiotic activity when the dose is too high.

There are several other possible causes of the loss of response to melatonin treatment. When the patients do not take melatonin the treatment will not be effective. Therefore we always ask parents to be sure that their child takes melatonin indeed. The timing of melatonin administration is very important. To advance sleep-wake rhythm and consequently advance sleep onset, melatonin should be administered 5-6 hours before DLMO in adults (Lewy et al. 2002; Van Der Heijden et al. 2005). Melatonin advances the DLMO. When melatonin is administered close to the DLMO, DLMO cannot be advanced. Consequently melatonin loses its chronobiotic activity. In that case exogenous melatonin should be administered earlier. In case 1 melatonin was administered about 2 hours before DLMO. Therefore it cannot be ruled out that exogenous melatonin lost its effectiveness because it was administered too close to the advanced DLMO. Another explanation could be a probable desensitization of melatonin receptors 
during prolonged elevation of circulating melatonin to supraphysiologic levels, as was suggested earlier by Zhdanova (2005). However, the results of the melatonin clearance test and the improvement of the sleep after considerably lowering the melatonin dose strongly suggest that the increased melatonin levels, due to the slow metabolization of melatonin, were the main cause of the recurrence of the sleep problems in our cases

Some limitations of this study need consideration. First, we only studied three patients and three controls. However our robust results can be explained by a clear well funded theory. Furthermore, the time at which melatonin was admitted needs discussion. This time was not in accordance with usual recommendations i.e. 5 hours before DLMO in adults (Pandi-Perumal et al. 2007). However in children the optimal time of melatonin administration has not yet been established. The results of the melatonin clearance test and the improvement of the sleep after considerably lowering the melatonin dose strongly suggest that the slow metabolization of melatonin was the main cause of the recurrence of the sleep problems, and not the time of administration. And lastly, our patients had mild ID. However, to our knowledge, there are no reports on altered pharmacokinetics of melatonin in individuals with an ID.

In many cases melatonin is prescribed by non-melatonin specialized family physicians. Observations like described above will be attributed to inadequate dosing and wrongly lead to dose escalation. Experience with the relationship of medication timing with DLMO and the awareness of the complicated pharmacokinetics are required for appropriate evaluation of therapy. Therefore melatonin therapy should be initiated and initially be controlled by experienced sleep professionals. This way only we can extend effectively our knowledge of this chronobiotic, and prevent negative experiences and resulting prejudices. Melatonin is in several countries available as an over-the-counter drug. A considerable number of people are CYP1A2 poor metabolizer and unaware of this. These circumstances are strong arguments for the need of further research to verify our findings.

Based on the results of this study we are performing melatonin clearance tests in all patients who are going to be treated with melatonin. Furthermore we study CYP1A2 polymorphisms in all these patients. When the clinically relevant slow melatonin metabolization phenotypes can be associated with polymorphisms of the CYP1A2 gene, it will be possible to determine the optimal melatonin dose individually by genotyping CYP1A2 alone (without the melatonin challenge). We already knew that the timing of melatonin should be individually determined by the individual DLMO (Van Der Heijden et al. 2005). The present study shows that also the appropriate dose probably should be individually determined, by any means for a substantial part of the population with above described polymorphisms. We 
expect to be able to determine CYP1A2 status in the same saliva samples as in which DLMO is measured, This makes it possible to individualize timing and dose of melatonin easily.

Pending the results of future studies on the significance of melatonin metabolization, clinicians who treat patients with melatonin should be aware of the possibility of slow melatonin metabolization. When it is not possible to perform a melatonin clearance test, it is strongly advised to lower the melatonin dose instead of increasing the melatonin dose, in case melatonin treatment effectiveness decreases considerably after an initially few weeks lasting good response to melatonin treatment.

\section{REFERENCES}

Andersen I. M, Kaczmarska J., McGrew S. G., \& Malow B. A. (2008) Melatonin for insomnia in children with autism spectrum disorders. Journal of Child Neurology 23, 482-5.

Braam W, Didden R, Smits M. G., Curfs L. M. G. (2008) Melatonin for chronic insomnia in Angelman syndrome: a randomized placebo-controlled trial. Journal of Child Neurology 23, 649-54.

Braam W., Smits M. G., Didden R., Korzilius H., Van Geijlswijk I. M., \& Curfs L. M. G. (2009) Exogenous melatonin for sleep problems in individuals with intellectual disability: a meta-analysis. Developmental Medicine \& Child Neurology 51, 340-9.

Butler M. A., Lang N. P., Young J. F., Caporaso N. E., Vineis P., Hayes R. B., Teitel C. H., Massengill J. P., Lawsen M. F., \& Kadlubar F. F. (1992) Determination of CYP1A2 and NAT2 phenotypes in human populations by analysis of caffeine urinary metabolites. Pharmacogenetics 2, 116-27.

Chevalier D., Cauffiez C., Allorge D., Lo-Guidice J. M., Lhermitte M., Lafitte J. J., \& Broly F. (2001) Five novel natural allelic variants-951A $>$ C, 1042G $>$ A (D348N), $1156 \mathrm{~A}>\mathrm{T}$ (I386F), 1217G $>\mathrm{A}(\mathrm{C} 406 \mathrm{Y})$ and $1291 \mathrm{C}>\mathrm{T}$ (C431Y)-of the human CYP1A2 gene in a French Caucasian population. Human mutation 17, 355-6.

Claustrat B., Brun J., \& Chazot G. (2005) The basic physiology and pathophysiology of melatonin. Sleep medicine reviews $9,11-24$.

Dollins A. B., Zhdanova I., Wurtman V. R. J., Lynch H. J., \& Deng M. H. (1994) Effect of inducing nocturnal serum melatonin concentrations in daytime on sleep, mood, body temperature, and performance. Proceedings of the National Academy of Sciences of the United States of America 91, 1824-8.

Fourtillan J. B., Brisson A. M., Gobin P., Ingrand I., Decourt J. Ph., \& Girault J. (2000) Bioavailability of melatonin in humans after day-time administration of D(7) melatonin. Biopharmaceutics \& Drug Disposition 21, 15-22. 
Härtter S., Korhonen T., Lundgren S., Rane A., Tolonen A., Turpeinen M., \& Laine K. (2006) Effect of caffeine intake 12 or 24 hours prior to melatonin intake and CYP1A2*1F polymorphism on CYP1A2 phenotyping by melatonin. Basic Q Clinical Pharmacology \& Toxicology 99, 300-4.

Härtter S., Ursing C., Morita S., Tybring G., von Bahr C., Christensen M., Röjdmark S, \& Bertilsson L. (2001) Orally given melatonin may serve as a probe drug for cytochrome P450 1A2 activity in vivo: a pilot study. Clinical Pharmacology and Therapeutics 70, 10-6.

Ishizaki A., Sugama M., \& Takeuchi N. (1999) [Usefulness of melatonin for developmental sleep and emotional/behavior disorders. Studies of melatonin trial on 50 patients with developmental disorders] [Article in Japanese] No To Hattatsu 31, 428-37.

Jan J. E., Hamilton D., Seward N., Fast D. K., Freeman R. D., \& Laudon M. (2000) Clinical trials of controlled-release melatonin in children with sleep-wake cycle disorders. Journal of Pineal Research 29, 34-9.

Lewy A. J., Ahmed S., Jackson J. M., \& Sack R. L. (1992) Melatonin shifts human circadian rhythms according to a phase-response curve. Chronobiology International 9, 380-92.

Lewy A. J., Emens J. S., Sack R. L., Hasler B. P., \& Bernert R. A. (2002) Low, but not high, doses of melatonin entrained a free-running blind person with a long circadian period. Chronobiology International 19, 649-58.

Lewy A. J., Emens J. S., Lefler B. J., Yuhas K., \& Jackman A. R. (2005) Melatonin entrains free-running blind people according to a physiological dose-response curve. Chronobiology International 22, 1093-1106.

Lin Y., Lu P., Tang C., Mei Q., Sandig G., Rodrigues A. D., Rushmore T.H., \& Shou M. (2001) Substrate inhibition kinetics for cytochrome P450-catalyzed reactions. Drug Metabolism Q Disposition 29, 368-74.

McArthur A. J., \& Budden S. S. (1998) Sleep dysfunction in Rett syndrome: a trial of exogenous melatonin treatment. Developmental Medicine \& Child Neurology 40, 186-92.

Miller G.P., \& Guengerich F. P. (2001) Binding and Oxidation of Alkyl 4Nitrophenyl Ethers by Rabbit Cytochrome P450 1A2: Evidence for Two Binding Sites. Biochemistry 40, 7262-72.

Nagtegaal E., Peeters T., Swart W., Smits M. G., Kerkhof G., \& Van Der Meer G. (1998) Correlation between concentrations of melatonin in saliva and serum in patients with delayed sleep phase syndrome. Therapeutic Drug Monitoring 20, 181-3.

Nakajima M., Yokoi T., Mizutani M., Kinoshita M., Funayama M., \& Kamataki T. (1999) Genetic polymorphism in the 5'-flanking region of human CYP1A2 gene: effect on the CYP1A2 inducibility in humans. Journal of Biochemistry 125, 
803-8.

Nakajima M., Yokoi T., Mizutani M., Shin S., Kadlubar F.F., \& Kamataki T. (1994) Phenotyping of CYP1A2 in Japanese population by analysis of caffeine urinary metabolites: Absence of mutation prescribing the phenotype in the CYP1A2 gene. Cancer Epidemiology, Biomarkers \& Prevention 30, 413-21.

National Center for Biotechnology Information. Viewed 28 February (2010) < http://www.ncbi.nlm.nih.gov/gene/1544? $\log \$=$ activity >

Pandi-Perumal S. R., Smits M. G., Spence W., Srinivasan V., Cardinali D. P., Lowe A. D., \& Kayumov L. (2007) Dim light melatonin onset (DLMO): a tool for the analysis of circadian phase in human sleep and chronobiological disorders. Progress in Neuro-Psychopharmacology a Biological Psychiatry 31, 1-11.

Sachse C., Brockmöller J., Bauer S., \& Roots I. (1999) Functional significance of a C-->A polymorphism in intron 1 of the cytochrome P450 CYP1A2 gene tested with caffeine. British Journal of Clinical Pharmacology 47, 445-9.

Smits M. G., Van Stel H. F., Van Der Heijden K., Meijer A. M., Coenen A. M., \& Kerkhof G. A. (2003) Melatonin improves health status and sleep in children with idiopathic chronic sleep-onset insomnia a randomized placebo-controlled trial. Journal of the American Academy of Child and Adolescent Psychiatry 42, 1286-93.

Van Der Heijden K. B., Smits M. G., Van Someren E. J., \& Gunning W. B. (2005) Prediction of melatonin efficacy by pre-treatment dim light melatonin onset in children with idiopathic chronic sleep onset insomnia. Journal of Sleep Research 14, 187-94.

Van Der Heijden K. B., Smits M. G., Van Someren E. J., Ridderinkhof K. R., \& Gunning W. B. (2007) Effect of melatonin on sleep, behavior, and cognition in ADHD and chronic sleep-onset insomnia. Journal of the American Academy of Child and Adolescent Psychiatry 46, 233-41.

Zhdanova I. V., Lynch H. J., \& Wurtman R. J. (1997) Melatonin: a sleep-promoting hormone. Sleep 20, 899-907.

Zhadanova I.V. (2005) Melatonin as a hypnotic: Pro. Sleep Medicine Reviews 9, 51-65.

Zhou S. F., Liu J. P., \& Chowbay B. (2009-I) Polymorphism of human cytochrome P450 enzymes and its clinical impact. Drug Metabolism Reviews 41, 89-295.

Zhou S. F., Yang L. P., Zhou Z. W., Liu Y. H., \& Chan E. (2009-II) Insights into the Substrate Specificity, Inhibitors, Regulation, and Polymorphisms and the Clinical Impact of Human Cytochrome P450 1A2. The AAPS Journal 11, 48194. 


\title{
CHAPTER 7
}

\author{
DISCUSSION
}


CHAPTER 7 


\section{INTRODUCTION}

The main conclusion of our studies is that melatonin is effective in the treatment of sleep problems in individuals with intellectual disabilities. Furthermore, melatonin may result in the reduction of daytime challenging behaviour in this target group. Melatonin is also an effective treatment option for sleep problems in individuals with Angelman syndrome, a genetic cause of intellectual disability. Finally, we present a hypothesis on a not yet well-understood phenomenon of melatonin treatment: its disappearing effectiveness after several weeks. We suggest that this might be caused by slow melatonin metabolization, possibly due to dysfunction of the CYP1A2 gene.

\section{META-ANALYSIS}

Our meta-analysis on the efficacy of exogenous melatonin for sleep problems in individuals with intellectual disability (see chapter 2) represents the first analysis on the efficacy of melatonin treatment of chronic insomnia in this target group. We found melatonin to be effective in reducing sleep latency, increasing total sleep time, and reducing the number of waking per night. These findings are in line with the outcome of our clinical studies, but in stark contrast to outcomes of three meta-analyses on the efficacy of exogenous melatonin in predominantly persons without intellectual disability (Brzezinski et al. 2005; Buscemi et al. 2005; Buscemi et al. 2006). We criticized several aspects of these three meta-analyses and discussed possible explanations for the discrepancies between the outcomes of our meta-analysis and those of the other three meta-analyses. First, in most studies in these three meta-analyses data were collected within a cross-over design which results in less favorable results in studies with melatonin. Secondly, many of these studies were performed in a sleep laboratory using polysomnography, resulting in smaller therapeutical results than in trials that were performed under home conditions. And thirdly, several studies were performed on healthy volunteers without sleep problems. This means that several included studies did not qualify for inclusion in a meta-analysis on the efficacy of melatonin in the treatment of chronic insomnia.

Results of the three meta-analyses in predominantly persons without intellectual disability were largely influenced by the inclusion criteria and the design and measurement methods of the included studies. Based on these metaanalyses the Dutch insurance companies do not reimburse costs of melatonin treatment, because they state that the efficacy of melatonin as to improvement of sleep has up to now not been convincingly demonstrated. Our meta-analysis indicates that this decision was based on the outcome of studies whose methodology was flawed. Moreover, this decision of the Dutch insurance companies may 
encourage physicians to resort to the prescription of less effective drugs with greater risk of daytime sedation and other unwanted side effects.

\section{TREATMENT WITH MELATONIN}

Our conclusion that melatonin is effective in the treatment of sleep problems is also based on positive outcomes of our placebo controlled studies. In these intervention studies, we used a parallel study design, because a cross-over study design with intra-individual comparison of melatonin and placebo is inappropriate when evaluating the efficacy of melatonin. Exogenous melatonin can cause a phase shift advance of the endogenous melatonin rhythm and this effect can last for several days or weeks after melatonin is withdrawn. Therefore, participants who receive melatonin in the first phase of the study may experience a carry-over effect of the melatonin phase into the placebo phase (Kunz et al. 2004; Laakso et al. 2007). By consequence, carry-over effects can result in a smaller difference in parameters between melatonin and placebo phases of the study, and therefore be responsible for not finding a statistically significant difference between melatonin and placebo. This was the main reason why we opted for a parallel study design for our three studies.

In the first study (see chapter 3), we found melatonin to be effective in shortening sleep latency and increasing total sleep time, as well as reducing the mean number and duration of night wakings. Melatonin treatment also resulted in an advance of endogenous melatonin onset (DLMO). This reflects the main effect of melatonin, being a chronobiotic drug (Wirz-Justice \& Armstrong 1996). The improvement of sleep maintenance is an interesting finding, because it is not in line with results of studies in insomniac individuals without intellectual disability, and in whom sleep maintenance problems are reported not to be influenced by melatonin treatment.

In the second study (see chapter 4) we found that melatonin was effective in reducing sleep problems in children with Angelman syndrome. We were unexpectedly confronted with the phenomenon that in some individuals the treatment effect disappeared after a few weeks of treatment. After a one week drug holiday, the efficacy of melatonin returned after resuming therapy with a substantially lower dose. In chapter 6 we have explored causes of this effect and generated hypotheses for this effect.

In the third study (see chapter 5) we found that melatonin treatment not only reduced sleep problems, but also reduced daytime challenging behaviour. This is the first blinded study that shows such an effect. The reduction in daytime challenging behaviour after effective treatment of sleep problems in persons with intellectual disability is generally assumed to be caused by the improvement of 
sleep (i.e. increase of total sleep time and reduction of sleep latency). However, we found that the severity of challenging behaviour did not correlate with the severity of sleep problems at baseline, nor did we find significant correlations between changes in challenging behaviour and improvements in sleep at the end of the treatment period, except for a correlation between change in challenging behaviour and change in the melatonin rhythm (DLMO) and the number of nights with wakings per week, respectively. It is plausible that the reduction in daytime challenging behaviour is not only caused by the improvement of sleep (e.g. increase in total sleep time), but also by the correction of a disturbed circadian melatonin rhythm as a second variable. This hypothesis needs to be evaluated in further studies.

\section{LOSS OF RESPONSE TO EXOGENOUS MELATONIN}

In our pilot study on the loss of response to melatonin after an initial successful therapy (see chapter 6) we hypothesized that the decline in effectiveness was caused by extremely high melatonin levels, and that this was caused by a disturbance in melatonin metabolism due to a decreased activity / inducibility of CYP1A2. We found daytime salivary melatonin levels to be abnormally high after several weeks of melatonin treatment. The melatonin clearance test showed at least five hours lasting high melatonin levels after one single dose of melatonin, suggesting slow metabolization of melatonin.

Slow metabolization of melatonin results after a short treatment period $(2-6$ weeks) with melatonin in 24-hour lasting high melatonin levels. Consequently the normal biphasic circadian melatonin rhythm disappears. Another explanation could be that exogenous melatonin might spill over onto the wrong zone of the melatonin phase response curve, as was suggested by Lewy et al. (2002). They were unable to entrain one out of seven totally blind people with free-running endogenous melatonin rhythms to $10 \mathrm{mg}$ of exogenous melatonin. They found that this person could be entrained to $0.5 \mathrm{mg}$ of melatonin, but not to $20 \mathrm{mg}$. This person had the longest circadian period $(24.9 \mathrm{~h})$ of the group. Subsequently Lewy et al. suggested that too much melatonin may spill over onto the wrong zone of the melatonin phase-response curve.

If melatonin should induce sleep pharmacologically, like benzodiazepine hypnotics do, these high serum melatonin levels would result in prolonged sleep, instead of poor sleep maintenance and early waking. This shows that melatonin is not just a hypnotic, but mainly a chronobiotic drug. Melatonin acts as a regulating switch, shifting the circadian phase (sleep-wake cycle) forward or backward, depending on the time when melatonin is taken (melatonin administered 5-6 hours before Dim Light Melatonin Onset (DLMO) advances the melatonin rhythm 
and its associated sleep-wake rhythm maximally, while melatonin delays these rhythms maximally, if administered 10 hours after DLMO). Therefore, increased melatonin levels at both morning and evening hours can induce opposite circadian shifts and disturb the sleep-wake cycle.

\section{CLINICAL IMPLICATIONS}

First, we have evidently shown that melatonin is effective in treating chronic insomnia in persons with intellectual disability. Furthermore melatonin did improve co-morbid challenging behaviour. Secondly we found that in some cases the efficacy of melatonin treatment can disappear after a short period of treatment, probably because of slow metabolization, possibly by the CYP1A2 enzyme. Melatonin, however, is not just a hypnotic drug. Melatonin is a chronobiotic drug, influencing circadian biological clock rhythm, and has only slight soporific properties. These findings have consequences for prescription of melatonin by physicians, because they should be aware of the complicated pharmacokinetics for appropriate evaluation of the effectiveness of melatonin therapy. As long as melatonin is a non-licensed drug, melatonin therapy should be initiated and initially be controlled by physicians experienced in the treatment with this chronobiotic drug (with some slight hypnotic properties). This way only we can extend effectively our knowledge, and prevent negative experiences and resulting prejudices in physicians and policy makers.

The melatonin dose needs to be substantially lower in individuals who are CYP1A2 poor metabolizer, in order to prevent high melatonin levels. To identify CYP1A2 poor metabolizers prior to melatonin treatment, a melatonin clearance test has to be performed. This test could consist of collecting saliva at 10:00 am, immediately followed by intake of melatonin $(1 \mathrm{mg}, 0.5 \mathrm{mg}$ or $0.1 \mathrm{mg}$, depending on age). Subsequently, saliva samples for melatonin measurements are collected at noon, 2:00 pm, 4:00 pm, and 08:00 am the next morning. Further studies should deal with the question whether the melatonin clearance test is a valid tool to determine at what dose melatonin should be prescribed, or that for this purpose CYP1A2 genotyping is necessary. Further studies are also needed to determine if CYP1A2 poor metabolizers have a higher incidence of (specific) sleep problems, are more prevalent in specific genetic syndromes, and can be recognized by more simple tests than a clearance test. We are aware that the clearance test often is not possible for practical reasons. In that case it is important to recognize the symptoms of the emergence of high melatonin levels, i.e. the return of sleep problems after an initial successful treatment effect.

Several patients treated in our sleep centre, that are CYP1A2 poor metabolizer, do not respond well to melatonin treatment in a substantially lower dose. We 
are studying now the question if these patients respond better if omeprazole is prescribed next to the melatonin. The reason is that omeprazole has been shown to induce CYP1A2 activity (Rost \& Roots 1994).

Finally, the following advices can be given:

- Melatonin is indicated for the treatment of chronic sleep problems, due to a circadian rhythm sleep disorder occurring (almost) daily, that does not respond to sleep hygiene measures, strengthening time cues (zeitgebers) and adequately timed bright light treatment. Melatonin has to be prescribed preferably after measurement of evening melatonin levels to assess DLMO.

- Administration of melatonin without measuring DLMO may cause a doctor's delay of at least 3 months in patients who do not respond adequately on melatonin treatment, because it may last at least 3 months after stopping melatonin treatment, before the pretreatment endogenous melatonin rhythm is reached and a precise circadian rhythm sleep disorder can yet be diagnosed.

- In patients with late dim light melatonin onset (DLMO) time of intake of melatonin should be 5 hours prior to time of DLMO but usually not earlier than $6 \mathrm{pm}$. In some exceptional cases melatonin administered 1 hour before sleep onset might improve sleep maintenance.

- Melatonin dose should be the lowest possible effective dose.

- In case sleep problems return after an initial successful therapy, poor metabolizing of melatonin should be considered among other causes, such as inappropriate time of intake, intercurrent somatic or psychiatric disorders etc. In case of suspected slow metabolization of melatonin, melatonin day-time levels could be measured. In case poor metabolizing of melatonin is diagnosed, melatonin treatment effect usually returns when melatonin treatment is stopped during 1 tot 2 weeks and melatonin treatment is started again in a dose of about $20 \%$ of the prior given dose.

\section{FINAL REMARK}

Melatonin is effective in reducing sleep problems in persons with intellectual disability. It should be considered an evidence-based treatment option for sleep problems in this target group. While it is effective for most individuals, it may however lose its effectiveness in some individuals. In this thesis we have presented a hypothesis on the cause of the disappearing effect of melatonin and provided clinical guideline how to approach this. 


\section{REFERENCES}

Brzezinski A., Vangel M.G., Wurtman R. J., Norrie G., Zhdanova I., Ben-Shushan A., \& Ford I. (2005) Effects of exogenous melatonin on sleep: a meta-analysis. Sleep Medicine Reviews 9, 41-50.

Buscemi N., Vandermeer B., Hooton N., Pandya R., Tjosvold L., Hartling L., Baker G., Klassen T. P., \& Vohra S. (2005) The efficacy and safety of exogenous melatonin for primary sleep disorders. A meta-analysis. Journal of General Internal Medicine 20, 1151-8.

Buscemi N., Vandermeer B., Hooton N., Pandya R., Tjosvold L., Hartling L., Vohra S., Klassen T. P., \& Baker G. (2006) Efficacy and safety of exogenous melatonin for secondary sleep disorders and sleep disorders accompanying sleep restriction: meta-analysis. British Medical Journal 332, 385-93.

Kunz D., Mahlberg R., Müller C., Tilmann A., \& Bes F. (2004) Melatonin in patients with reduced REM sleep duration: two randomized trials. The Journal of Clinical Endocrinology \& Metabolism 89, 128-34.

Laakso M. L., Lindblom N., Leinonen L., \& Kaski M. (2007) Endogenous melatonin predicts efficacy of exogenous melatonin in consolidation of fragmented wristactivity rhythm of adult patients with developmental brain disorders: a doubleblind, placebo-controlled, crossover study. Sleep Medicine 8, 222-39.

Lewy A. J., Emens J. S., Sack R. L., Hasler B. P., \& Bernert R. A. (2002) Low, but not high, doses of melatonin entrained a free-running blind person with a long circadian period. Chronobiology International 19, 649-658.

Rost K. L., \& Roots I. (1994) Accelerated caffeine metabolism after omeprazole treatment is indicated by urinary metabolite ratios: coincidence with plasma clearance and breath test. Clinical Pharmacology Q Therapeutics 55, 402-11.

Wirz-Justice A., \& Armstrong S. (1996) Melatonin: nature's soporific? Journal of Sleep Research 5, 137-41. 


\section{SUMMARY}

\section{BACKGROUND}

Results of several studies suggested that melatonin may be effective in the treatment of sleep problems in individuals with intellectual disability and chronic insomnia. Its efficacy in these individuals, however, had not been firmly and unequivocally established. Furthermore, it remained unclear whether challenging behaviour reduced as a result of successful treatment of sleep problems with melatonin.

In some individuals, effectiveness of melatonin decreased several weeks after melatonin treatment had started. In these cases, effectiveness of melatonin returned following substantial reduction in dosage. It was unclear what may account for this wearing-off effect of melatonin.

To investigate efficacy of melatonin in individuals with intellectual disability who have sleep problems, to assess influence of melatonin treatment of challenging behaviour and to generate hypotheses about the cause of the wearing-off effect of melatonin we performed the studies described below.

\section{STUDIES ON MELATONIN}

Results of a meta-analysis of the effectiveness of melatonin for sleep problems in individuals with intellectual disabilities are reported in chapter 2. Nine placebocontrolled randomized studies were included that were published between 1990 and 2008. Analyses revealed that melatonin treatment significantly decreased sleep latency by a mean of 34 minutes, increased total sleep time by a mean of 50 minutes, and decreased the number of wakings per night.

In chapter 3, effectiveness of melatonin for sleep problems was assessed within a randomized double-blind placebo-controlled study. Participants were 51 individuals with intellectual disabilities who presented with chronic idiopathic sleep problems for more than one year. Data on several sleep parameters were collected during a 1-week baseline and after 4 weeks of treatment. Endogenous dim light melatonin onset (DLMO) was measured in saliva before and after treatment. After a 1-week baseline, participants were given either melatonin 5 or $2.5 \mathrm{mg}$ (depending on age) or placebo. Results showed that compared with placebo, melatonin significantly advanced mean sleep onset time by 34 minutes, decreased mean sleep latency by 29 minutes, increased mean total sleep time by 48 minutes, reduced the mean number of night-time waking and advanced DLMO by an average of 2 hours. Lights off time, sleep offset time and the number of nights per week with night waking did not change. Only few minor or temporary adverse reactions and no changes in seizure frequency were reported. 
This study was replicated in 8 children with Angelman syndrome who had idiopathic chronic insomnia (chapter 4). Data were also collected in a randomized placebo-controlled double-blind study. Results showed that on average melatonin significantly advanced sleep onset by 28 minutes, decreased sleep latency by 32 minutes, increased total sleep time by 56 minutes, reduced the number of nights with wakings from 3.1 to 1.6 nights a week, and increased endogenous salivary melatonin levels. It was noteworthy that in 3 of the 4 children who received melatonin, salivary melatonin levels were extremely high after 4 weeks of treatment and their parents reported the return or increase of night wakings. After reducing the dosage sleep problems were reduced.

In chapter 5 , we investigated effects of melatonin on challenging behaviour using data from trials reported in chapter 2 and 3. Participants were 49 individuals with intellectual disabilities who had a mean age of 18 years and who had chronic insomnia. They received either melatonin $5 \mathrm{mg}(<6$ years $2.5 \mathrm{mg}$ ) or placebo for 4 weeks. Daytime challenging behaviour was measured by the Storend Gedragsschaal voor Zwakzinnigen at baseline week and the end of the fourth treatment week. Salivary dim light melatonin onset (DLMO) was measured at baseline and the last day of the fourth treatment week. Sleep logs were used to gather information on sleep parameters. Results showed that on average melatonin treatment significantly reduced SGZ scores, sleep latency, and number and duration of night wakings, and increased total sleep time and advanced DMLO. Strong correlations were found between change in SGZ scores, change in DLMO and number of night wakings. These results indicate that melatonin treatment in persons with intellectual disabilities and chronic insomnia decreased daytime challenging behaviour probably by improving sleep maintenance or by improving circadian melatonin rhythmicity.

Initial good response to melatonin in some participants disappeared within a few weeks after starting melatonin treatment, while the good response returned only after considerable dose reduction. In a pilot study (chapter 6) we measured metabolism of melatonin in two female (aged 61 and 6 yr.) and one male (aged 3 yr.) patient with mild intellectual disability. They had chronic insomnia and a late melatonin onset. Their sleep quality had worsened a few weeks after initial good response to melatonin treatment. This suggested melatonin tolerance. After a 3 week washout period, these patients received melatonin 1.0, 0.5 or 0.1 mg respectively. Salivary melatonin level was measured just before melatonin administration, and 2, 4 and 6 hours thereafter. After the melatonin clearance test, melatonin treatment was resumed with a considerably lower dose. In all patients melatonin concentrations remained $>50 \mathrm{pg} / \mathrm{ml}$ at 2, 4 and 6 hours after melatonin administration. After resuming melatonin treatment sleep problems disappeared. The same procedure was followed in 3 patients who did not show a loss 
of response to melatonin treatment. In all patients in the control group melatonin concentrations decreased between 2 and 4 hours after melatonin administration with a mean decrease of $76 \%$. We hypothesize that loss of response to melatonin treatment is caused by slow metabolism of exogenous melatonin, probably due to decreased activity/inducibility of CYP1A2.

\section{GENERAL CONCLUSION}

Our studies show that melatonin improves sleep (i.e. reduces severe sleep problems) and daytime behaviour (i.e., reduced challenging behaviour) in individuals with intellectual disabilities (including those with Angelman syndrome) and chronic insomnia. The wearing-off phenomenon of melatonin treatment in some cases might be caused by slow metabolism of melatonin, possibly associated with dysfunction of the CYP1A2 gene. 


\section{SAMENVATTING}

\section{ACHTERGROND}

Uit diverse studies blijkt dat melatonine effectief kan zijn bij de behandeling van slaap problemen bij mensen met een verstandelijke beperking. De effectiviteit bij deze groep mensen is echter tot nu toe niet duidelijk en ondubbelzinnig aangetoond. Daarnaast is niet duidelijk vastgesteld of gedragsproblemen bij mensen met een verstandelijke beperking die slaapproblemen hebben, afnemen wanneer deze slaapproblemen met succes worden behandeld met melatonine.

Bij sommige mensen met een verstandelijke beperking die met melatonine worden behandeld, neemt na enkele weken succesvolle behandeling de effectiviteit van melatonine af. Het was tot nu toe niet bekend wat de oorzaak is van de afname van de werking van melatonine.

Om bij mensen met een verstandelijke beperking en slaap problemen de werkzaamheid van melatonine en de invloed op storend gedrag overdag te onderzoeken, en om een hypothese te vormen over de oorzaak van het afnemend effect van melatonine bij sommige gebruikers, voerden we de hieronder vermelde studies uit.

\section{STUDIES MET MELATONINE}

De resultaten van een meta-analyse naar de werkzaamheid van melatonine bij de behandeling van slaapproblemen bij personen met een verstandelijke handicap, worden gerapporteerd in hoofdstuk 2. In deze analyse werden 9 placebogecontroleerde gerandomiseerde studies, gepubliceerd tussen 1990 en 2008, opgenomen. Uit de analyses bleek dat de behandeling met melatonine leidde tot een aanzienlijke afname van de inslaaplatentie met een gemiddelde van 34 minuten, toename van de totale slaaptijd met een gemiddelde van 50 minuten en een daling van het aantal malen wakker worden per nacht.

De resultaten van een gerandomiseerd dubbelblind placebo-gecontroleerde studie naar de effectiviteit van melatonine bij slaapproblemen, worden gemeld in hoofdstuk 3. Dit onderzoek werd uitgevoerd bij 51 personen met een verstandelijke beperking, die onze polikliniek bezochten wegens meer dan een jaar bestaande chronische slaapproblemen. Deelnemers kregen ofwel melatonine $5 \mathrm{mg}(2,5 \mathrm{mg}<6 \mathrm{jr})$, dan wel een placebo. Gegevens over de verschillende slaap variabelen werden verzameld tijdens de basisweek en tijdens de 4 weken durende behandeling. Melatonine spiegels werden gemeten in speeksel aan het eind van de basis week en aan het einde van de vierde behandelweek.

De resultaten toonden aan dat, in vergelijking met placebo, melatonine het 
tijdstip van in slaap vallen gemiddeld met 34 minuten significant vervroegde, de gemiddelde slaaplatentie met 29 minuten verkortte, de gemiddelde totale slaaptijd met 48 minuten verlengde, het aantal malen 's nachts wakker worden verminderde en de DLMO (Dim Light Melatonin Onset: het tijdstip waarop 's avonds de stijging van de melatonine spiegel aanvangt) met gemiddeld 2 uur vervroegde. Het tijdstip van 's avonds licht uit doen, 's morgens wakker worden en het aantal nachten per week met 's nachts wakker worden, veranderde niet significant. Er werden slechts enkele milde of tijdelijke bijwerkingen en geen veranderingen in de frequentie van epileptische aanvallen gemeld.

Deze studie werd met dezelfde opzet herhaald bij 8 kinderen met het Angelman syndroom en chronische slapeloosheid (hoofdstuk 4). De resultaten toonden aan dat melatonine het tijdstip van in slaap vallen gemiddeld met 28 minuten significant vervroegde, de inslaaplatentie met gemiddeld 32 minuten verkortte, de gemiddelde totale slaaptijd met 56 minuten verlengde, het aantal malen 's nachts wakker worden van gemiddeld 3,1 tot 1,6 nachten per week deed afnemen en de endogene melatonine spiegels, gemeten in speeksel, verhoogde. Het was opmerkelijk dat bij 3 van de 4 kinderen die melatonine kregen, de melatonine spiegels in speeksel na 4 weken behandeling extreem hoog bleken te zijn en hun ouders de terugkeer of toename van het 's nachts wakker worden meldden. Na sterke verlaging van de dosering namen deze slaap problemen weer af.

In hoofdstuk 5 onderzochten we de gevolgen van een behandeling met melatonine op storend gedrag met behulp van gegevens uit de twee studies die werden gerapporteerd in hoofdstuk 2 en 3. De deelnemers waren 49 personen met een verstandelijke beperking en chronische slapeloosheid. De gemiddelde leeftijd was 18 jaar. Ze kregen ofwel $5 \mathrm{mg}$ melatonine $(<6$ jaar 2,5 mg) of een placebo gedurende 4 weken. Storend gedrag werd gemeten door invullen van de Storend Gedragsschaal voor Zwakzinnigen tijdens de basisweek en aan het einde van de vierde behandel week. Het moment van aanvang van de melatonine afgifte (DLMO) werd gemeten aan het eind van de basisweek en de vierde behandelweek. Een slaap dagboek werd gebruikt om informatie te verzamelen over slaap variabelen. De resultaten toonden aan dat de behandeling met melatonine de SGZ scores, de inslaap latentie en het aantal en de duur van het nachtelijk wakker worden, aanzienlijk verminderde, de totale slaaptijd verlengde en de DLMO vervroegde. Sterke correlaties werden gevonden tussen de veranderingen in de SGZ scores en de verandering in de DLMO en het aantal malen nachtelijk wakker worden. Deze resultaten geven aan dat een behandeling met melatonine bij personen met een verstandelijke beperking en chronische slapeloosheid het storend gedrag overdag vermindert, waarschijnlijk door een verbetering van de slaap, en/of door een verbetering van het circadiane melatonine ritme. 
Een aanvankelijk goede respons op een behandeling met melatonine kan bij sommige patiënten binnen een paar weken na het starten van de behandeling verdwijnen, terwijl de goede respons pas terugkeert na een aanzienlijke verlaging van de dosis. In onze pilot studie (hoofdstuk 6) hebben we de metabolisatie van melatonine gemeten bij twee vrouwelijke patiënten (leeftijd 61 en 6 jaar) en een mannelijke patiënt (leeftijd 3 jaar), met een matige verstandelijke beperking. Er was sprake van chronische slapeloosheid en een laat begin van de melatonine afgifte. Bij hen verslechterde de slaap een paar weken na een aanvankelijk goede respons op een behandeling met melatonine, wat zou kunnen wijzen op melatonine tolerantie. Na een wash-out periode van 3 weken kregen de patiënten 's morgens respectievelijk 1,0, 0,5 of 0,1 mg melatonine. Speeksel melatonine spiegels werden gemeten nét voor melatonine toediening, en 2 en 4 uur daarna. $\mathrm{Na}$ de melatonine clearance test werd de behandeling hervat met een aanzienlijk lagere dosis melatonine.

Bij alle patiënten bleven de melatonine spiegels 2 en 4 uur na toediening van melatonine $>50 \mathrm{pg} / \mathrm{ml}$. Na hervatting van de behandeling met melatonine verdwenen de slaapproblemen. Dezelfde procedure werd gevolgd bij 3 patiënten bij wie geen sprake was van een afnemend effect van melatonine na 6 maanden gebruik. Bij alle patiënten in de controle groep vertoonden de melatonine spiegels, afgenomen tussen 2 en 4 uur na toediening van melatonine, een gemiddelde afname van $76 \%$. Onze hypothese is dat het afnemend effect van melatonine wordt veroorzaakt door langzame metabolisatie van exogeen melatonine, waarschijnlijk als gevolg van een verminderde activiteit / inducibility van CYP1A2, mogelijk als gevolg van een mutatie van het CYP1A2-gen.

\section{SLOTCONCLUSIE}

Onze studies tonen aan dat melatonine bij mensen met een verstandelijke beperking en chronische slaapproblemen zowel de slaap verbetert (dat wil zeggen slaapproblemen vermindert) als het gedrag overdag verbetert (dat wil zeggen het overdag storend gedrag doet afnemen). Het fenomeen van de afnemende melatonine effectiviteit bij sommige patiënten kan worden veroorzaakt door langzame metabolisatie van melatonine, waarschijnlijk veroorzaakt door een mutatie in het CYP1A2 gen. 


\section{DANKWOORD}

[tekst] 


\section{CURRICULUM VITAE}

Wiebe Jan Braam (Wiebe Braam) werd op 26 december 1948 geboren in Oldehove (Groningen). Hij behaalde in 1966 zijn HBS-b diploma in Hoorn, deed zijn artsexamen in 1974 aan de Vrije Universiteit in Amsterdam en was hierna gedurende 6 maanden AGNIO gynaecologie. Hij vestigde zich vervolgens als huisarts in Castricum, om in 1978 in dienst te treden van het Provinciaal Ziekenhuis in Castricum.

Sinds 1995 is hij werkzaam als arts voor verstandelijk gehandicapten (AVG) bij 's Heeren Loo Zuid Veluwe, lokatie Wekerom (voorheen ‘de Hartenberg').

Tussen 1974 en 1999 was hij free lance medewerker van uitgeverij Spaarnestad, bij ondermeer het weekblad Libelle (de 'Libelle dokter') en de maandbladen Kinderen en Top Santé, was hij in 1984 mede oprichter van de Alzheimer Stichting Nederland en tot 1988 vice-voorzitter en werkte hij als medisch adviseur tussen 1978 - 1986 mee aan diverse televisie programma's. Sinds 1983 verschenen er van zijn hand een 26 tal boeken over diverse medische onderwerpen bij ondermeer uitgeverij Het Spectrum (serie '100 vragen over') en Inmerc (serie 'Spreekuur Thuis'). In 1992 deed hij, samen met Opzij- journaliste Martha van Buren, bij 92 vrouwen onderzoek naar de emotionele beleving van een miskraam. Dit leidde in 1993 tot het verschijnen van het boek 'Als je zwangerschap misloopt' (La Riviére \&

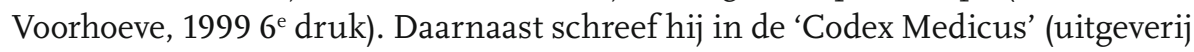
Elsevier) het hoofdstuk Medische zorg voor verstandelijk gehandicapten.

Wiebe Braam volgde in 1996 de voorloper van de huidige AVG opleiding bij de NSPH in Utrecht en is sinds 2000 ingeschreven in het specialistenregister AVG artsen.

In 1998 opende hij als eerste in ons land een polikliniek voor thuiswonende verstandelijk gehandicapten, in zowel de Hartenberg, als in het Ziekenhuis Gelderse Vallei te Ede.

Vanaf 2000 specialiseerde hij zich in slaapproblemen bij mensen met een verstandelijke beperking en onderzocht hij bij hen de rol van en de behandeling met melatonine. Dit leidde in 2004 tot toetreding tot het Gouverneur Kremers Centrum van de Universiteit en Academisch Ziekenhuis Maastricht en het oprichten van het Expertise Centrum voor Slaapproblemen bij mensen met een verstandelijke beperking (www.slaapstoornissen.nl / www.GKC-UM.nl). In deze periode werd dit proefschrift geschreven.

Tussen 2001 en 2007 was hij AVG consulent voor Estinea in Aalten en sinds 2004 is hij als AVG consulent werkzaam voor De Schutse in Kesteren en het Centrum voor Consultatie en Expertise (CCE). Eveneens in 2004 trad hij toe tot de redactie van het Tijdschrift voor Artsen voor Verstandelijk Gehandicapten 
(TAVG) en ontving hij de Hanna Oorthuys prijs, een 2-jaarlijkse prijs van de Nederlandse Vereniging van Artsen voor Verstandelijk Gehandicapten (NVAVG). Sinds 2008 is hij lid van de Van Gelderen Werkgroep (Werkgroep ter Bestudering van Somatische Oorzaken van Zwakzinnigheid). 


\section{PUBLICATIONS}

\section{INTERNATIONAL PEER-REVIEWED JOURNALS}

Braam W., Didden R., Smits M. G., \& Curfs L. (2008) Melatonin treatment in individuals with intellectual disability and chronic insomnia: a randomised placebo-controlled study. Journal of Intellectual Disability Research 52, 256-64.

Braam W., Didden R., Smits M. G., \& Curfs L. (2008) Melatonin for insomniac children with Angelman syndrome: a randomized placebo-controlled doubleblind study. Journal of Child Neurology 23, 649-54.

Maas A., Grossfeld P., Didden R., Korzilius H., Braam W., Smits M. G., \& Curfs L. (2008) Sleep problems in individuals with 11q terminal deletion disorder (Jacobsen Syndrome) Genetic Counseling 19, 225-35.

Maas A. H. P. M., Didden R., Korzilius H., Braam W., Smits M. G., \& Curfs L. M. G. (2009) Sleep in individuals with Cri du Chat syndrome: a comparative study. Journal of Intellectual Disability Research 53, 704-15.

Braam W., Smits M. G., Didden R., Korzilius H., van Geijlswijk I., Curfs L. M. G. (2009) Exogenous melatonin for sleep problems in individuals with intellectual disability: a meta-analysis. Developmental Medicine \& Child Neurology 51, 3409 .

Braam W., Didden R., Maas A. P. H. M., Korzilius H., Smits M. G., \& Curfs L. M. G. (2010) Melatonin decreases daytime challenging behaviour in persons with intellectual disability and chronic insomnia. Journal of Intellectual Disability Research 54, 52-9.

Braam W., van Geijlswijk I., Keijzer, H., Smits M.G., Didden R., Curfs L. M. G. (2010) Loss of response to melatonin treatment is associated with slow melatonin metabolism. Journal of Intellectual Disability Research 54, 547-55.

\section{PUBLISHED ABSTRACTS}

Van Tintelen P., Matthijs G., Braam W., Cassiman J. J., Duran M. \& Poll-The B. T. (1998) Homozygosity for the F119L mutation in the PMM2 gene in an adult with CDG syndrome type Ia. European Journal of Human Genetics 6, 62.

Braam W. \& Smits M. (2000) Melatonin treatment for chronic sleep problems in people with intellectual disability: a randomized placebo-controlled study. Journal of Intellectual Disability Research 44, 216.

Braam W. \& Smits M. (2004) Melatonin treatment for chronic sleep problems in people with intellectual disability: a randomized placebo-controlled study. Journal of Intellectual Disability Research 48, 351.

Maas A., Didden R., Smits M., Braam W. \& Curfs L. M. G. (2006) Scatter plot 
analysis of excessive daytime sleepiness and disruptive behaviours in eight individuals with Prader Willi syndrome. Journal of Applied Research in Intellectual Disabilities 19, 254.

Braam W., Maas A., Didden R., Smits M. \& Curfs L. M. G. (2006) Melatonin for chronic insomnia in Angelman syndrome: a randomized placebo-controlled trial. Journal of Applied Research in Intellectual Disabilities 19, 254.

Maas A., Didden R., Korzilius H., Braam W. J., Smits M. G. \& Curfs L. M. G. (2008) Sleep characteristics in individuals with Cri du Chat syndrome. Journal of Intellectual Disability Research 52, 661.

Maas A., Grossfeld P. D., Didden R., Korzilius H., Braam W. J., Smits M. G. \& Curfs L. M. G. (2008) Sleep problems in individuals with IIq terminal deletion disorder (Jacobsen syndrome). Journal of Intellectual Disability Research 52, 661

Maas A., Braam W. J., Collin P. J. L., Didden R., Smits M. G. \& Curfs L. M. G. (2008) Sleep clinic for individuals with intellectual disability. Intellectual Disability Research 52, 661.

Braam W., Smits M. G., Didden R. \& Curfs L. M. G. (2008) Melatonin is effective in treating sleep problems in Angelman syndrome but problems in metabolizing melatonin may be part of the Angelman phenotype. Journal of Intellectual Disability Research 52, 814.

\section{OTHER PUBLICATIONS}

Braam W., Smits M. G., Didden R., \& Curfs L. M. G. (2003) Diagnosis and treatment of sleep disturbances in people with intellectual disabilities: experiences in a regional expert centre. In: A. van Bemmel et al. (Eds.), Sleep-wake research in the Netherlands 14, 21-4. Leiden: Dutch Society for Sleep-wake Research.

Didden R., Braam W., Smits M. G., \& Curfs L. M. G. (2004) Treatment of sleep problems in individuals with Angelman syndrome: A study of six cases. In: G. Ruigt et al. (Eds.), Sleep-wake research in the Netherlands 15, 35-8. Leiden: Dutch Society for sleep-wake research.

Didden R., Smits M. G., Braam W., \& Curfs L. (2005) Scatter plot analysis of excessive daytime sleepiness in eight individuals with Prader-Willi syndrome: A case control study. In: G. Ruigt et al. (Eds.), Sleep-wake research in the Netherlands 16, 57-61. Leiden: Dutch Society for sleep-wake research.

Didden R., Braam W., De Weerd A., Smits M. G., \& Curfs L. (2006) Sleep and sleep problems in Angelman syndrome and Prader-Willi syndrome. In: Janet F. Engels (Ed.), Focus on Birth Defects Research (pp. 81-104) Hauppauge, NY: Nova Science Publishers.

Maas A., Braam W., Collin P., Smits M. G., Didden R., \& Curfs L. (2007) Referrals to the sleep clinic for individuals with intellectual disability. In: G. de Ruigt 
(Eds.), Sleep-wake research in the Netherlands 18, 93-6. Leiden: Dutch Society of Sleep-wake Research.

Didden R., Braam W., Maas A., Collin P., Smits M. G., \& Curfs L. (2007) Normal sleep duration, but increased time in bed in individuals with profound/severe intellectual disability who live in a residential facility. In: G. de Ruigt (Eds.), Sleep-wake research in the Netherlands 18, 45-7. Leiden: Dutch Society of Sleepwake Research.

\section{PUBLICATIONS IN DUTCH}

Braam W. (1985) Het failliet van de anticonceptie? Nederlands Tijdschrift voor Geneeskunde 129, 563-4.

Braam W. (1986) Het nut van de immunisatie tegen kinkhoest. Nederlands Tijdschrift voor Geneeskunde 130, 324.

Pronk E. \& Braam W. (1998) Het Prader-Willi-syndroom bij de jonge zuigeling. Nederlands Tijdschrift voor Geneeskunde 142, 155-6.

Braam W. (1999) Slaapproblemen bij verstandelijk gehandicapten. Tijdschrift voor Artsen voor Verstandelijk Gehandicapten 17, (3) 8-9.

Braam W. (1999) Aandachtspunten Down syndroom. Tijdschrift voor Artsen voor Verstandelijk Gehandicapten 17, (3) 7.

Braam W. (2000) Polikliniek voor verstandelijk gehandicapten. Medisch Contact 55, 1106-8.

Braam W. (2000) Polikliniek voor mensen met een verstandelijke beperking in een algemeen ziekenhuis. Tijdschrift voor Artsen voor Verstandelijk Gehandicapten 18, (2) 13-7.

Braam W, \& Smits M. G. (2001) Vergelijking van het effect van de orale toediening van melatonine versus placebo bij verstandelijk gehandicapten met langdurige slaapstoornissen. Tijdschrift voor Artsen voor Verstandelijk Gehandicapten 19, (3) 16-8.

Smits M. G., Van der Meer Y., \& Braam W. (2001) Farmacotherapie van slaapproblemen bij verstandelijk gehandicapten. In: Didden R., \& Curfs L. (red.), Slaap en slaapproblemen bij verstandelijk gehandicapten (pp. 105-119) Houten-Diegem: Bohn Stafleu Van Loghum.

Braam W. (2003) REM Sleep Behavior Disorder. Tijdschrift voor Artsen voor Verstandelijk Gehandicapten 21, (3) 15-7.

Braam W. (2005) Smith-Lemli-Opitz syndroom: onbekend maakt onbemind. Tijdschrift voor Artsen voor Verstandelijk Gehandicapten 23, (1) 9-11.

Braam W. (2005) Slaapproblemen bij verstandelijk gehandicapten. Tijdschrift voor Artsen voor Verstandelijk Gehandicapten 23, (2) 20-9.

Braam W. (2006) Het 22q13 deletie syndroom (Phelan-McDermid syndroom) 
Tijdschrift voor Artsen voor Verstandelijk Gehandicapten 24, (1) 4-6.

Braam W. (2006) Autisme en Down syndroom als duale diagnose. Tijdschrift voor Artsen voor Verstandelijk Gehandicapten 24, (1) 7-9.

Braam W. (2006) Down syndroom en hypothyreoïdie: aanpassing van normaalwaarden onvoldoende onderbouwd. Tijdschrift voor Artsen voor Verstandelijk Gehandicapten 24, (1) 14.

Braam W. (2006) Smith-Magenis syndroom. Tijdschriftvoor Artsen voor Verstandelijk Gehandicapten 24, (3) 14-17.

Braam W. (2007) Reactie op Devalkeneer L., Schieveld J., \& Bekers O. Het belang van CYP450 in de dagelijkse praktijk. Tijdschrift voor Artsen voor Verstandelijk Gehandicapten 25, 92.

Didden R., Maas A., Braam W., Collin P., Smits M. G., \& Curfs L. (2008) Slaap en slaapproblemen bij kinderen en jeugdigen met autisme spectrum stoornissen. In Didden R., \& Huskens B. (red.), Begeleiding van kinderen en jongeren met autisme. Van onderzoek naar praktijk (pp. 128-144) Houten: Bohn Stafleu Van Loghum.

Braam W. (2008) Risico op ontwikkelen van klinische hypothyreoïdie bij volwassenen met het syndroom van Down is kleiner dan verwacht. Tijdschrift voor Artsen voor Verstandelijk Gehandicapten 26, 43.

Braam W. (2008) Off label voorschrijven van geneesmiddelen. Tijdschrift voor Artsen voor Verstandelijk Gehandicapten 26, 84.

Braam W., \& Evenhuis H (2009) Medische zorg voor verstandelijk gehandicapten. In: Gans R.O.B., Van Schil P.E.Y., Vandenbroucke J.P., \& Van Weel C. (red.), Codex Medicus (pp. 647-656) Doetinchem: Elsevier.

Braam W. (2010) MCDD (Multiple Complex Developmental Disorder): een hypediagnose? Tijdschrift voor Artsen voor Verstandelijk Gehandicapten 28, 8-10. 


